\title{
A Model For Simulating Rotational Data For Wind Turbine Applications
}

D. C. Powell

J. R. Connell

April 1986

Prepared for the U.S. Department of Energy under Contract DE-AC06-76RLO 1830

Pacific Northwest Laboratory

Operated for the U.S. Department of Energy by Battelle Memorial Institute 


\title{
DISCLAIMER
}

This report was prepared as an account of work sponsored by an agency of the United States Government. Neither the United States Government nor any agency thereof, nor any of their employees, makes any warranty, express or implied, or assumes any legal liability or responsibility for the accuracy, completeness, or usefulness of any information, apparatus, product, or process disclosed, or represents that its use would not infringe privately owned rights. Reference herein to any specific commercial product, process, or service by trade name, trademark, manufacturer, or otherwise, does not necessarily constitute or imply its endorsement, recommendation, or favoring by the United States Government or any agency thereof. The views and opinions of authors expressed herein do not necessarily state or reflect those of the United States Government or any agency thereof.

\author{
PACIFIC NORTHWEST LABORATORY \\ operated by \\ BATTELLE \\ for the \\ UNITED STATES DEPARTMENT OF ENERGY \\ under Contract DE-AC06-76RLO 1830
}

\begin{tabular}{|c|c|}
\hline \multicolumn{2}{|c|}{ Printed in the United States of America } \\
\hline \multicolumn{2}{|c|}{ Available from } \\
\hline \multicolumn{2}{|c|}{ National Technical Information Service } \\
\hline \multicolumn{2}{|c|}{ United States Department of Commerce } \\
\hline \multicolumn{2}{|c|}{5285 Port Royal Road } \\
\hline \multicolumn{2}{|c|}{ Springfield, Virginia 22161} \\
\hline \multicolumn{2}{|c|}{$\begin{array}{l}\text { NTIS Price Codes } \\
\text { Microfiche } A 01\end{array}$} \\
\hline & \\
\hline \multicolumn{2}{|c|}{ Printed Copy } \\
\hline & Price \\
\hline Pages & Codes \\
\hline $001-025$ & $\mathrm{~A} 02$ \\
\hline $026-050$ & $\mathrm{~A} 03$ \\
\hline $051-075$ & $\mathrm{~A} 04$ \\
\hline $076-100$ & A05 \\
\hline $101-125$ & A06 \\
\hline $126-150$ & $\mathrm{~A} 07$ \\
\hline $151-175$ & $\mathrm{~A} 08$ \\
\hline $176-200$ & A09 \\
\hline $201-225$ & A010 \\
\hline $226-250$ & A011 \\
\hline $251-275$ & A012 \\
\hline $276-300$ & A013 \\
\hline
\end{tabular}


A MODEL FOR SIMULATING

ROTATIONAL DATA FOR WIND

TURBINE APPLICATIOINS

D. C. Powell

J. R. Connell

Apri1 1986

Prepared for the U.S. Department of Energy under Contract DE-AC06-76RLO 1830

Pacific Northwest Laboratory

Richland, Washington 99352 


\section{SUMMARY}

This document describes a wind simulation model to be used in relation to wind turbine operations. The model is a computer code written in FORTRAN 77. The model simulates turbulence and mean wind effects as they are experienced at a rotating point on the blade of either a horizontal-axis wind turbine (HAWT) or a vertical-axis wind turbine (VAWT). The model is fast, requiring 15 to 120 seconds of V.AX execution time to produce a simulation and related statistics.

The model allows the user to set a number of wind parameters so that he may evaluate the uncertainty of model results as well as their typical values. When this capability is combined with short execution time, the user can quickly produce a number of simulations based on reasonable variation of input parameters and can use these simulations to obtain a range of wind turbine responses to the turbulence. This ability is important because some of the wind parameters that cannot be precisely evaluated should be prescribed over a range of values.

- The model has its limitations: it does not model any machine-induced modifications to the turbulence, it does not model any kind of meteorological event, and it simulates only the neutrally stable atmospheric boundary layer.

This document is essentially a user's guide. Its features include theoretical derivations, samples of output, comparisons of measured and modeled results, a listing of the FORTRAN code, a glossary for the code, and the input and output of a sample run. 


\section{ACKNOWLEDGMENT}

The authors gratefully acknowlege the helpful reviews by Paul Veers, A. H. Miller, and George P. Tennyson, as well as the considerable task of typing and editing performed by Rosemary E1lis and Laurel Grove, respectively.

This work was funded by the U.S. Department of Energy under Contract DE-AC06-76RLO 1830. The Pacific Northwest Laboratory is operated for the U.S. Department of Energy by Battelle Memorial Institute. 


\section{CONTENTS}

SUMMARY

1.0 INTRODUCT ION

2.0 THE BASIC SPECTRAL THEORY.

2.1 FOR THE HAWT

2.2 FOR THE VAWT

2.3 TURBULENCE SIMULATION

2.3.1 Simulation of Mean Wind Effects and Adding to

Turbulence . . . . . . .

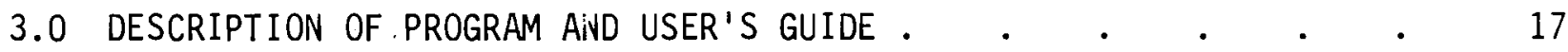

3.1 PARAMETERS TO BE READ IN .

3.1 .1 First Record . . . . . . . . . . . . 17

3.1 .2 Second Record . . . . . . . . . . . . $\quad . \quad$. 18

3.1.3 Third Record . . . . . . . . . . . . 21

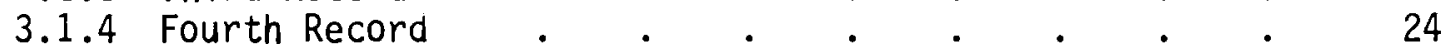

3.1 .5 Fifth Record . . . . . . . . . . . . . 25

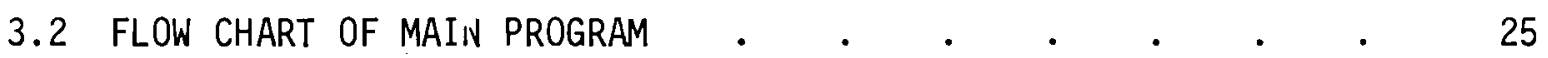

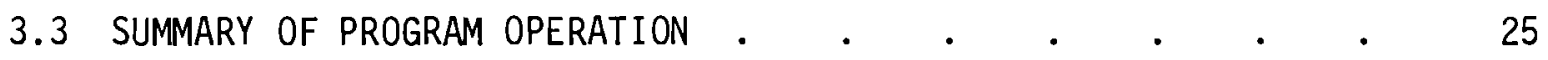

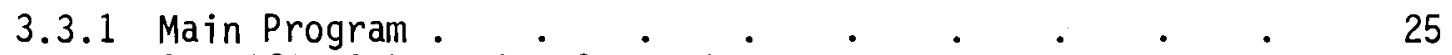

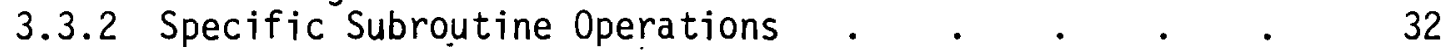

3.4 ON BRACKETING THE AINSWERS BY ENVELOPING INPUT PARAMETERS • 35

4.0 MODELING OF SPECTRAL ANALYSIS OBTAINED BY ANALYSIS OF FIELD

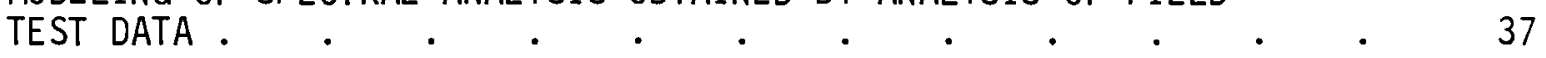

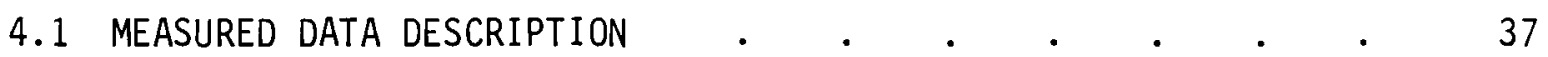

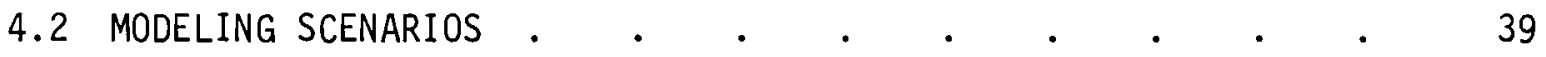

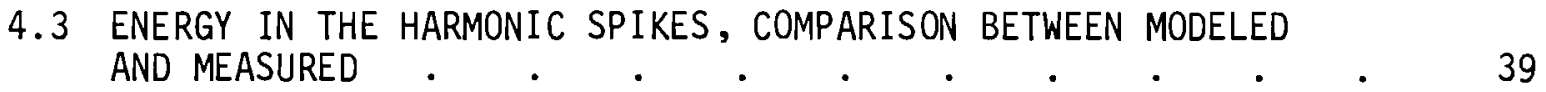

4.3.1 First Harmonic . . . . . . . . . . . 40

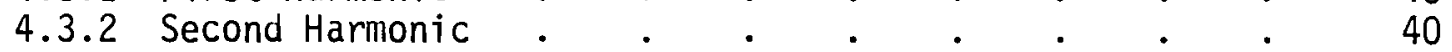

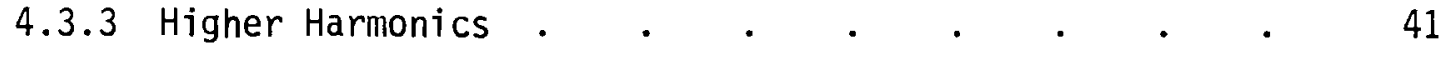

4.4 SPECTRAL PLOTS, MODELED VS. MEASURED . . . . . . . 43

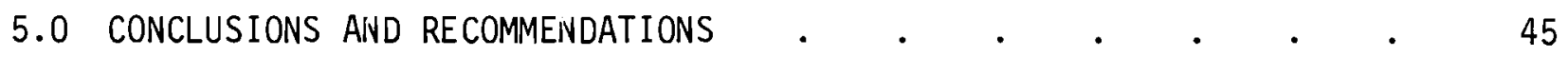

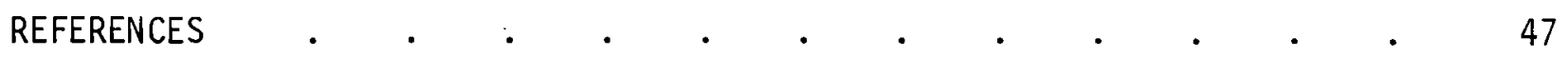

APPENDIX A - LISTINGS OF THE PROGRAM CODE, A GLOSSARY, AND A TEST CASE. A-1

APPENDIX B - COMPARISON OF VON KARMAN SPECTRA WITH CORRESPONDING

ROTATIONAL SPECTRA WHEN ROTATIONAL RATE AND ROTATION

RADIUS OF THE LATTER APPROACH ZERO . . . . . . B B 1

APPENDIX C - SOME BASIC TURBULENCE DEFINITIONS AND LENGTH SCALE CONSIDERATI ONS 
-

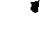


FIGURES

1 Geometry of $r$ in Equation (1) . . . . . . . . 4

2 Radius Definition for VAWT Rotational Movement $\quad$. $\quad$ • $\quad 7$

3 Turbulence Components at Points and in Two Arbitrary

4 Direction Cosine Illustrated in Two Dimensions $\quad . \quad$. $\quad . \quad \cdot \quad 9$

5 HAWT Geometry for Mean Wind Effects . . . . . . . 15

6 Flow Chart Illustrating Operation of the Main Program . . 26

$7 \quad$ Tangential and Radial Component Data, Test $1327 \quad$. . . 38

8 Spectra of Tangential Component of Rotational Wind - Mean Wind Effect Plus Turbulence . . . . . . . . 41

9 Spectra of Radial Component of Rotational Wind - Mean Wind

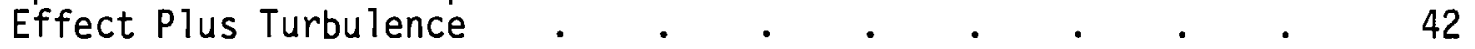

10 Harmonic Spike Energy, Tangential Component, Modeled and

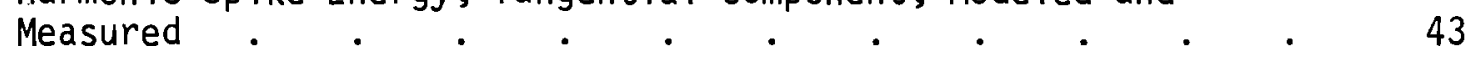

11 Harmonic Spike Energy, Radial Component, Modeled and Measured . . . . . . . . . . . . . 44

B.1 Rotational Spectra with Rotational Rate and Radii Approaching Zero, Compared to von Karman Spectra and von Karman Variant Spectra

B.2 Rotational Spectra with Rotational Rate and Radii Approaching Zero, Compared to von Karman Spectra and von Karman Variant

Spectra . . . . . . . . . . . . . B

D.1 Rotational HAWT $u$ - and VAWT u-Spectra . . . . . . D-2

D.2 Rotational Spectra $S(n)$ and $n S(n)$ for the Four VAWT

D.3 Simulated Turbulence Data .

D.4 Turbulence Variances for the First Five Harmonics . . . . D-6 


\section{$\underline{T A B L E S}$}

1 Conditions for the Four Test Periods, June 5, 1984 . . . 38

2 Average Ratio of Modeled/Measured Energy in Harmonic

Spikes, Averaging over Al1 Tests, and over Harmonics 2 to 6 . 39

3 Average Ratio of Modeled/Measured Energy in Harmonic Spikes, by Harmonic, Averaging over Ali Tests . . . . 40

D.1 Variances of the Five Simulations . . . . . . . D-4 


\subsection{INTRODUCTION}

In the past few years, a theoretical method has been developed for modeling turbulence as it would be experienced at a point rotating in a circle in a plane perpendicular to the mean wind direction. Thus turbulence as experienced just ahead of a point on the rotating blade of a horizontal-axis wind turbine (HAWT) is simulated. The theory (called the PNL theory) was developed by Connel1 (1982). Other applications are described by George (1984), George and Connell (1984), and Powell et al. (1985).

Prior to the development of the PNL theory, a so-called disk-averaging theory was invoked, e.g., by Frost et al. (1978). The underlying assumption of that theory was that turbulence features of smaller dimension than the rotational disk did not contribute significantly to the effects of turbulence on wind turbine operation; thus frequencies of fluctuation faster than the rotation rate of the blade could be ignored. Mathematically, this is accomplished by appropriate low-pass filtering of single-point turbulence data. Larger scale turbulence was treated as a time-varying wind that was the same throughout the disk.

But Connell's work theoretically and experimentally showed that turbulence as experienced at a rotating point on a wind turbine blade contributes significantly to the flap-wise bending moment fluctuations on the blade and the drive train at higher frequencies. The physical effect of the rotational motion is that energy is transferred from low and middle frequencies to that high frequency domain that includes the rotational frequency of the blade and harmonics of the rotational frequency. These frequencies are sometimes called $1 \mathrm{P}, 2 \mathrm{P}$, and so on.

In this report, the previous spectral work is expanded to simulate rotational wind speed time series, with the mean wind effect either included or excluded. Also the theoretical work is extended to apply to a vertical-axis wind turbine (VAWT), such as a Darrieus wind turbine. Four different turbulence components are modeled. These are defined in Section 2. An additional objective of this report is to make the simulation technique more broadly usable, by providing a user's manual describing the computer program, which is written in FORTRAN 77 for a VAX 11/780 computer. 
Section 2 presents the mathematical derivations of the HAWT and VAWT rotational turbulence and explains their physical significance. Section 3 is the user's guide proper, discussing the program from an operational point of view. Section 4 compares modeled and measured results. Section 5 presents our conclusions and recommendations.

There are four appendices. Appendix A provides a listing of the code, a glossary of important variables, and the input and output of a test case. Appendix $B$ discusses the rotational spectra produced by the model as conditions approach the Eulerian, $i . e$. , as the rate and the radius of rotation approach zero. Appendix C presents theoretical definitions of autocorrelations, of spatial correlations, and of length scales. Appendix $D$ is a sample of model results from input parameters different from those used in the experiment modeled in Section 4. 


\subsection{THE BASIC SPECTRAL THEORY}

The basic spectral theory consists of derivations of autocorrelation functions (acf's) for turbulence as experienced at a rotating point. The point rotates either in a vertical plane, as on a HAWT blade, or in a horizontal plane, as on a VAWT blade.

\subsection{FOR THE HAWT}

The autocorrelation function u-component $\left(R_{11}\right)$ turbulence at a point rotating in a vertical plane perpendicular to the mean wind direction in the wind turbine layer has been given by Conne11 (1982). The equation is

$$
R_{11}(r)=\frac{2 \sigma^{2}}{\Gamma(1 / 3)}\left(\frac{r}{2 L}\right)^{1 / 3}\left\{K_{1 / 3}\left(\frac{r}{L}\right)-\frac{r}{2 L}\left[1-\frac{x^{2}}{r^{2}}\right] K_{2 / 3}\left(\frac{r}{L}\right)\right\}
$$

where:

$\Gamma$ is the gamma function

$\sigma^{2}$ is the turbulence variance

$r$ is the separation distance

$L$ is a length characteristic of the turbulence

$\mathrm{K}_{1 / 3}$ is the modified Bessel function of the second kind, of fractional order $1 / 3\left(K_{2 / 3}\right.$ is the same function, of fractional order $\left.2 / 3\right)$

$x$ is the alongwind component of the separation distance.

To physically understand the $r$, one must visualize the two ends of the segment defining $r$ as follows (see Figure 1): One end is fixed to an arbitrary point on the blade and thus describes a circular path in the disk of rotation, perpendicular to the mean wind direction, as the blade rotates. The other end is downstream of its original position ( $P_{0}$ on Figure 1 ) on the blade at a distance $x$, or $U t$ where $U$ is mean wind speed and $t$ is travel time. Mathematically, this is expressed

$$
r^{2}=\left[2 \rho \sin \frac{\Omega t}{2}\right]^{2}+(U t)^{2}
$$




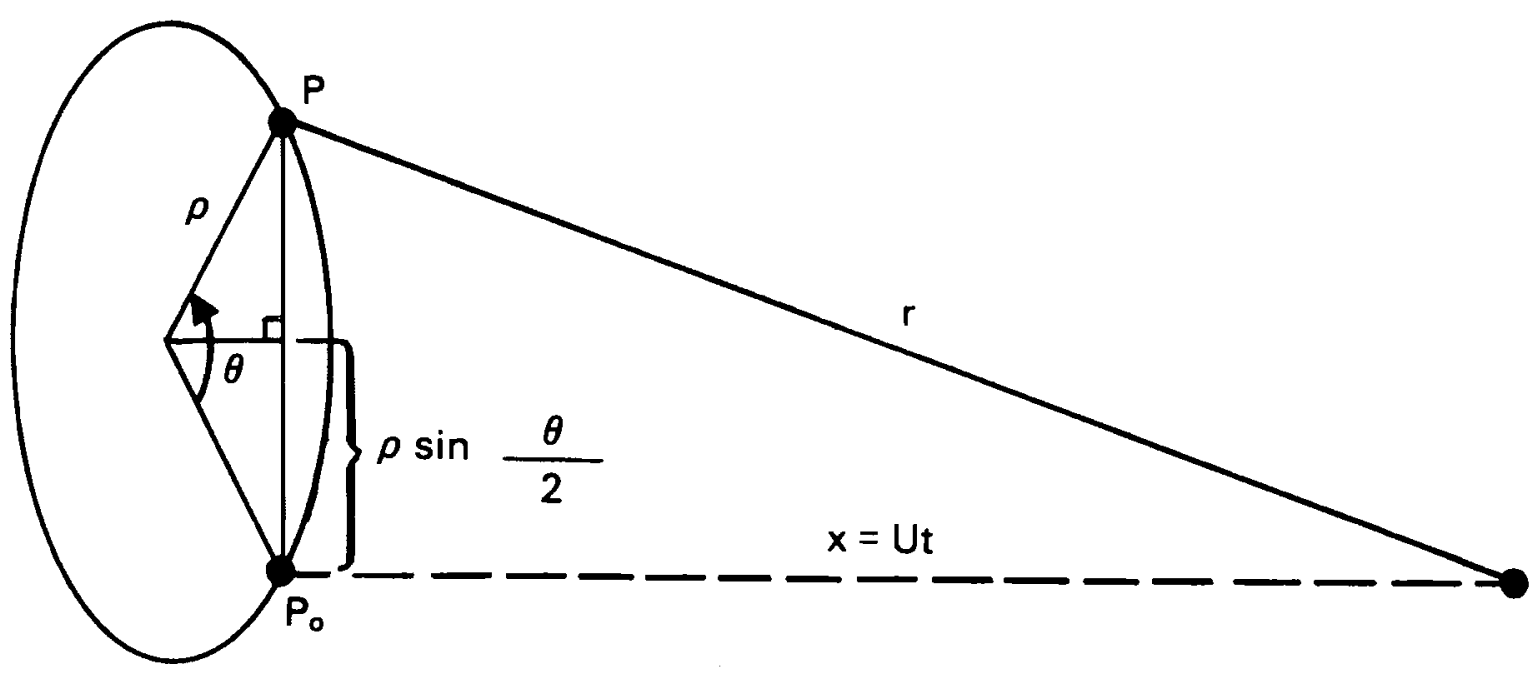

$P_{0}$ is position of $P$ at initial time

$\Omega \mathrm{t}=\theta+2 \mathrm{n} \pi$ where $\mathrm{n}$ is number of revolutions in time $\mathrm{t}$

FIGURE 1. Geometry of $r$ in Equation (1)

where $\rho$ is the radius of rotation of the one end and $\Omega$ is the rotation rate. These two terms express the rotational and translation effects, respectively. The second term dominates the first as $t$ becomes 1 arge.

By setting $x$ equal to $r$ in Equation (1), we model Eulerian motion. The $K_{2 / 3}$ term vanishes. The $L$ in the correlation is defined by the fact that when this Eulerian acf is integrated over time (substituting Ut for $R$ ) and then multiplied by the mean wind speed, the result is a length scale L/1.34.

The expression for $r$ in Equation (2) must be introduced into Equation (1). But first, we divide both sides of Equation (2) by $(2 L)^{2}$. This yields

$$
\left(\frac{r}{2 L}\right)^{2}=\left[\frac{\rho}{L} \sin \frac{\Omega t}{2}\right]^{2}+\left(\frac{U t}{2 L}\right)^{2},
$$

which is substituted into (1).

We notice in Equation (3) that the same length scale is used as a denominator for both the alongwind length, Ut, and the crosswind length, $\rho$. 
Accordingly, we now effectively redefine the $L$ on the left by introducing two new scales on the right, to correspond to the essential physics. The result is

$$
\left(\frac{r}{2 L}\right)^{2}=\left[\left(\frac{\rho}{L_{y}}\right) \sin \frac{\Omega t}{2}\right]^{2}+\left(\frac{U t}{2 L_{x}}\right)^{2}
$$

where $L_{y}$ is some lateral scale of turbulence, and $L_{x}$ is the corresponding longitudinal scale. They could be the lateral and longitudinal integral length scales of turbulence, or possibly $3 / 4$ of each, respectively. Here, $L$ must be some weighted average of $L_{x}$ and $L_{y}$.

The essential physics of interaction between machine and atmosphere imposes two non-turbulence length scales. One, $\rho$, is the radius of the wind turbine, and the other is the length $\mathrm{U} / \Omega$, the length of a column of air advected through the plane of the rotor during one rotor revolution.

The ratios of corresponding variables are expressed by the following dimensionless parameters:

$$
\alpha=\rho / L_{y}
$$

and

$$
\beta=U /\left(\Omega L_{X}\right)
$$

Also, a dimensionless time was defined:

$$
\tau=\Omega t / 2
$$

We note that

$$
x / L_{x}=2 \beta \tau
$$

We define a dimensionless autocorrelation function

$$
P(\tau)=R_{11} / \sigma^{2}
$$


Substitution of Equations (4), (5), (6), and (7) into (1), and then into Equation (9) yields

$$
P(\tau)=2 / \Gamma(1 / 3)\left(\alpha^{2} \sin ^{2}(\tau)+\beta^{2} \tau^{2}\right)^{1 / 6}(D-E)
$$

where

$$
D=K_{1 / 3}\left[2\left(\alpha^{2} \sin ^{2}(\tau)+\beta^{2} \tau^{2}\right)^{1 / 2}\right]
$$

and

$$
E=\frac{\left(\alpha^{2} \sin ^{2}(\tau)\right)}{\left(\alpha^{2} \sin ^{2}(\tau)+\beta^{2} \tau^{2}\right)^{1 / 2}} K_{2 / 3}\left[2\left(\alpha^{2} \sin ^{2}(\tau)+\beta^{2} \tau^{2}\right)^{1 / 2}\right] .
$$

$P(\tau)$ is a correlation in the dimensionless time variable $\tau$ in terms of the dimensionless parameters $\alpha$ and $B$. Because of this construction, changing the uncertain value of $L_{y}$ is equivalent to changing the certain value of $\rho$; and changing the uncertain value of $L_{x}$ is equivalent to changing the value of $U / \Omega$.

This correlation function is then Fourier-transformed into a power spectrum that is converted to dimensional form. We have not found any theoretical guarantee that the spectrum so calculated will be positive at every value.

\subsection{FOR THE VAWT}

The correlation distance $r$ involved in VAWT rotational motion has an expression somewhat different from that given by Connell (1982) for the $r$ involved in HAWT rotational motion. The reason is seen in the different geometry illustrated in Figure 2 , where rotation is in the horizontal $(x, y)$ plane. The circle represents the maximum horizontal projection of a VAWT. Applying some algebra and trigonometry, we find that

$$
r^{2}=(U t)^{2}+4 \rho^{2}\left(1+\frac{U T}{\rho}\right) \sin ^{2}\left(\frac{\theta}{2}\right)
$$




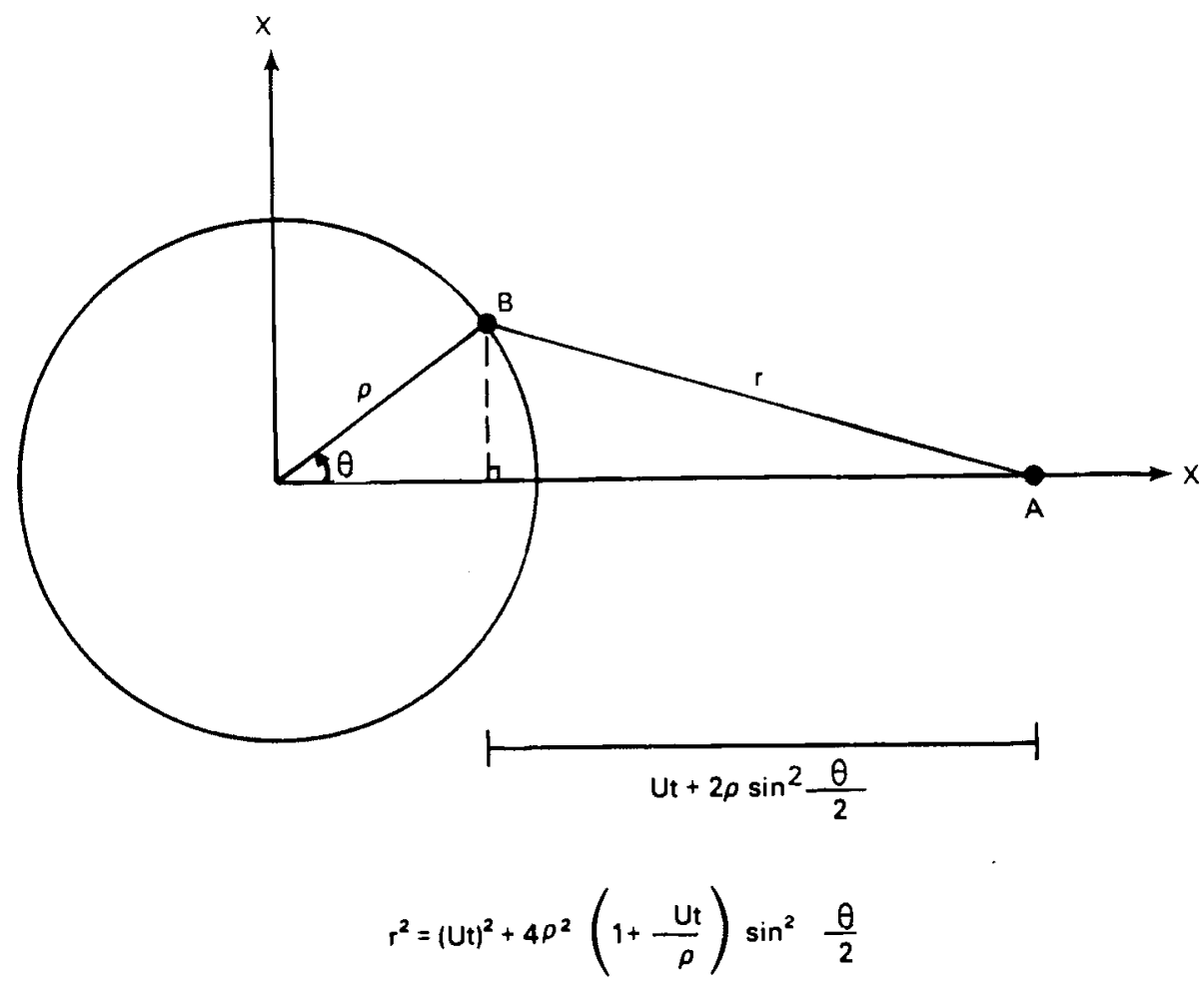

FIGURE 2. Radius Definition for VAWT Rotational Movement

The autocorrelations of turbulence at the moving point may be derived using the theory of isotropic turbulence for the cross correlation of turbulence at two points, in this case, the two ends of the radius, $r$. Consider the most general case, where we are interested in the cross correlation of turbulence components at any two points in any two specified directions. We will call these two turbulence functions $\left(u_{a}\right)_{A}$ and $\left(u_{b}\right)_{B}$, which are the turbulence component in direction a at point $A$ and the turbulence component in direction $b$ at point $B$. This concept is illustrated in Figure 3.

The vectors $U_{a}$ and $U_{b}$ are the instantaneous turbulence vectors. The directions $a$ and $b$ in the figure are shown specialized in the four diagrams so that both are the directions of

1. the u-component,

2. the $v$-component,

3. the component in the plane of the disk and tangential to the VAWT circumference, or

4. the component in the radial direction. 


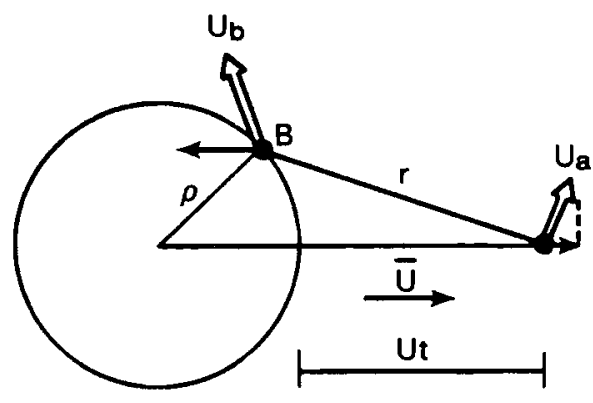

a

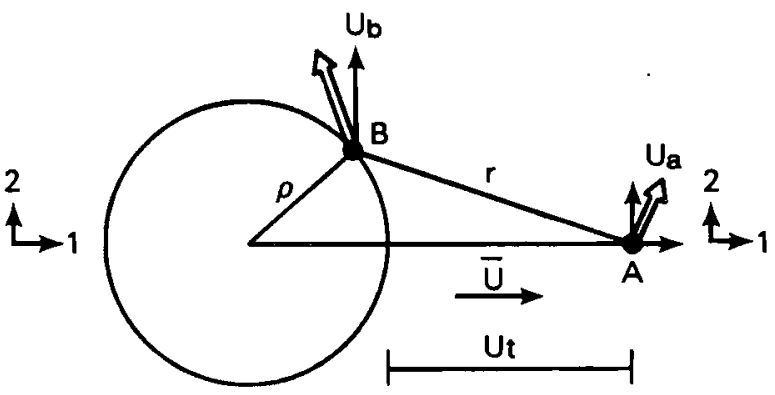

b

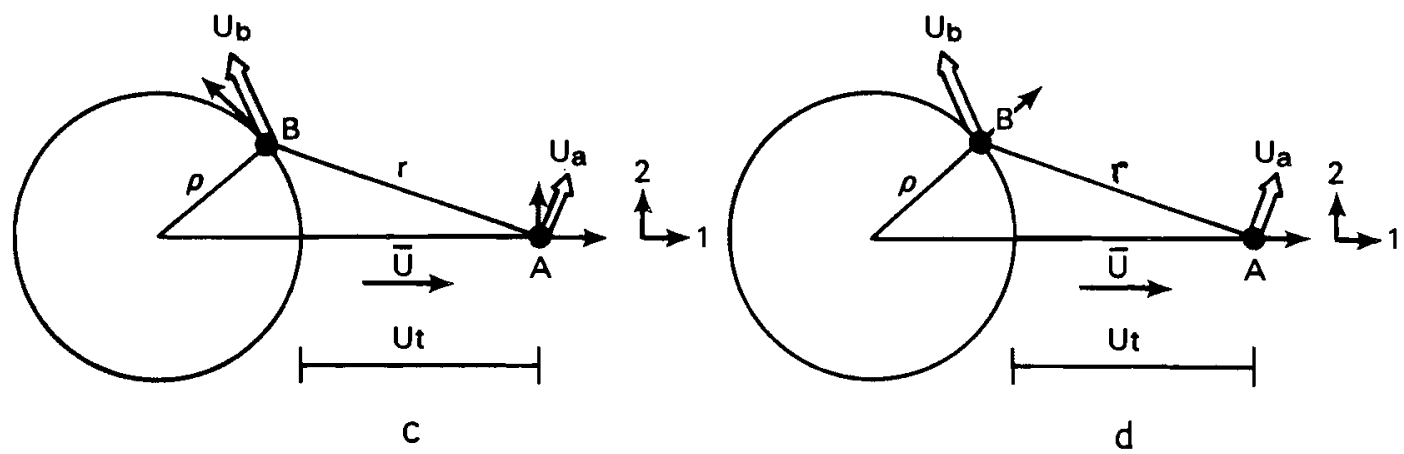

FIGURE 3. Turbutence Components at Points and in Two Arbitrary Directions a. u-Component; b. v-Component; $\mathrm{c}$. Tangential Component; d. Radial Component

Restricting attention to the two horizontal dimensions, the correlation of turbulence in direction a at point $A$ with that in direction $b$ at point $B$ is the sum of components multiplied by direction cosines according to the equation

$$
Q_{a b}(A B)=Q_{11} e_{a 1} e_{b 1}+Q_{12}\left(e_{a 1} e_{b 2}+e_{a 2} e_{b 1}\right)+Q_{22} e_{a 2} e_{b 2}
$$

where

$Q_{11}=$ the correlation of $u$-component turbulence at points $A$ and $B$

$Q_{12}=$ the correlation of $u$ at $A$ with $v$ at $B$, which is the same at the correlation of $v$ at $A$ with $u$ at $B$ in homogeneous, isotropic turbulence

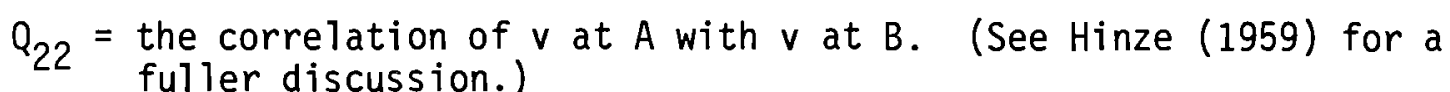


These are all dimensional correlations, the dimension being velocity-squared. The direction cosines, as illustrated by Figure 4, are

$$
\begin{aligned}
& e_{a 1}=\cos \theta_{a 1} \\
& e_{a 2}=\cos \theta_{a 2}=\sin \theta_{a 1} \\
& e_{b 1}=\cos \theta_{b 1} \\
& e_{b 2}=\cos \theta_{b 2}=\sin \theta_{b 1} .
\end{aligned}
$$

Hereafter in this discussion we will use only the angles with subscript 1 , and so we will drop the subscript.
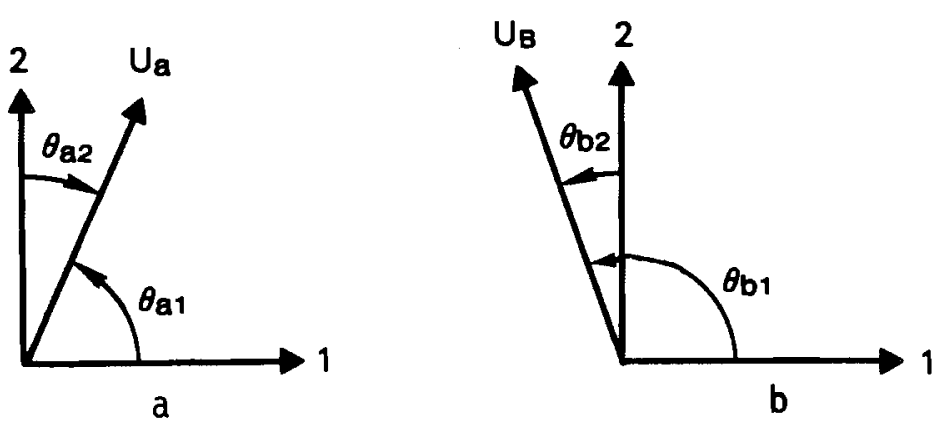

FIGURE 4. Direction Cosine Illustrated in Two Dimensions a. Direction a; b. Direction b

In all cases, the point $A$ is placed on the diameter that is perpendicular to the mean wind direction and on the downwind side of the turbine. Therefore, the following statements hold.

When $\left(u_{a}\right) A$ and $\left(u_{b}\right) B$ are both the u-component, $\theta_{a}$ and $\theta_{b}$ are both zero and

$$
Q_{a b}(A B)=Q_{11}
$$

Define this as $Q_{u u}(A B)$. Likewise, when $u_{a}(A)$ and $\left(u_{b}\right) B$ are both the $v$-component, $\theta_{a}$ and $\theta_{b}$ are both 90 degrees and

$$
Q_{a b}(A B)=Q_{22}
$$

Define this as $Q_{v v}(A B)$. 
When $u_{a}(A)$ and $u_{b}(B)$ are the tangential component, $\cos \theta_{a}$ is zero, $\sin \theta_{a}$ is one, and we have

$$
Q_{a b}(A B)=Q_{12} \cos \theta_{b}+Q_{22} \sin \theta_{b}
$$

Define this as $Q_{t t}(A B)$.

When $u_{a}(A)$ and $u_{b}(B)$ are the radial component, $\cos \theta_{a}$ is one and $\sin \theta_{a}$ is zero, and we have

$$
Q_{a b}(A B)=Q_{11} \cos \theta_{b}+Q_{12} \sin \theta_{b}
$$

Define this as $Q_{n n}(A B)$.

The functions $Q_{11}, Q_{12}$, and $Q_{22}$ are given by Hinze (1959) as functions of the dimensionless correlations $f(r)$, the two-point longitudinal correlation of isotropic turbulence, and $g(r)$, the two-point lateral correlation of isotropic turbulence.

Von Karman (1948) has derived expressions of these in terms of the radius, $r$, the longitudinal and lateral components of $r, x$ and $y$, and an unspecified length scale, $L$, characteristic of the turbulence. These expressions are

$$
f(r)=C K_{1 / 3}(r / L)
$$

and

$$
g(r)=C\left[K_{1 / 3}(r / L)-(r / 2 L) K_{2 / 3}(r / L)\right]
$$

where

$$
C=\frac{2}{\Gamma_{1 / 3}}\left(\frac{r}{2 L}\right)^{1 / 3}
$$

Letting $\sigma^{2}$ represent the isotropic turbulence variance, the expressions for $Q_{11}, Q_{12}$, and $Q_{22}$ are 


$$
\begin{aligned}
& Q_{11} / \sigma^{2}=(x / r)^{2}[f(r)-g(r)]+g(r), \\
& Q_{12} / \sigma^{2}=(x y / r)^{2}[f(r)-g(r)], \\
& Q_{22} / \sigma^{2}=(y / r)^{2}[f(r)-g(r)]+g(r) .
\end{aligned}
$$

The final expressions for these correlations are given in dimensionless variables similar to those used in (10). However, $\alpha$ must be defined because rotation is now in the horizontal plane; in the horizontal plane, the radial direction may be either longitudinal or lateral with respect to the mean wind. Therefore, if a single value has to be assigned to an effective length scale, this value would be somewhere between those of $L_{x}$ and $L_{y}$. We call it $L_{h}$ and define

$$
\alpha_{h}=\rho / L_{h}
$$

Then the final dimensionless correlations in terms of $\alpha, \beta$, and $\tau$ are

$$
\begin{gathered}
Q_{u u}(A B)(\tau)=c\left[k_{1 / 3}(2 Z)-z\left(1-\frac{\beta^{2} \tau^{2}}{z^{2}}\right) k_{2 / 3}(2 Z)\right], \\
Q_{v v}(A B)(\tau)=c\left[k_{1 / 3}(2 Z)-z\left(1-\frac{\alpha_{h}^{2}}{4 z^{2}} \sin ^{2}(2 \tau)\right) k_{2 / 3}(2 Z)\right], \\
Q_{t t}(A B)(\tau)=c\left[\frac{\alpha_{h} \beta \tau}{2 Z} \sin (2 \tau) K_{2 / 3}(2 Z)\right] \cos \theta_{b} \\
+c\left[k_{1 / 3}(2 Z)-z\left(1-\frac{\alpha_{h}^{2}}{4 z^{2}} \sin ^{2}(2 \tau)\right) k_{2 / 3}(2 Z)\right] \sin \theta_{b},
\end{gathered}
$$




$$
\begin{aligned}
Q_{n n}(A B)(\tau)= & c\left[K_{1 / 3}(2 Z)-z\left(1-\frac{\beta^{2} \tau^{2}}{Z^{2}}\right) K_{2 / 3}(2 Z)\right] \cos \theta_{b} \\
& +c\left[K_{1 / 3}(2 Z)-z\left(1-\frac{\alpha_{h}^{2}}{4 Z^{2}} \sin ^{2}(2 \tau)\right) K_{2 / 3}(2 Z)\right] \sin \theta_{b},
\end{aligned}
$$

where

$$
Z=r / 2 L
$$

and

$$
z^{2}=(\beta \tau)^{2}+\alpha_{h}^{2}\left(1+\frac{2 \beta \tau}{\alpha}\right) \sin ^{2}(\tau) .
$$

\subsection{TURBULENCE SIMULATION}

Under the principle of simulation used, the power spectrum derived from one of the above correlation functions supplies half of the degrees of freedom (that is, the amplitude information) of the simulated data, while the other half is supplied by the assumption of a random phase structure from one harmonic to the next in the simulated data.

Let $Q$ stand for any of the correlations derived just above. Theoretically, the spectrum of the same correlations is given as the Fourier transformation of $Q$. That is,

$$
S(N)=4 \sigma^{2} \int_{0}^{\infty} Q(\tau) \cos (2 \pi N \tau) d \tau
$$

where $N$ is dimensionless frequency. This can be transformed to a spectrum of dimensional frequency $n$ by using the transformation

$$
S(n)=2 S(N) / \Omega
$$

where $n=\Omega N / 2$. $N$ is related to $n$ as $t$ is to $\tau$ (see Equation (7)). 
The actual procedure consists of computing $S(N)$ by submitting $Q(\tau)$ to a fast Fourier routine. This routine requires that $2^{m}$, where $m$ is an integer, members of $Q(\tau)$ be submitted. The $S(N)$ that is transformed to $S(n)$ has values at $2^{m}$ frequencies such that

$$
S_{j}=S(n), \quad n=j / T
$$

where $T$ is the length of the data series to be simulated, given by

$$
T=2^{m+1} \Delta \tau
$$

Let $M=2^{m}$. Then the simulated data series is given by

$$
u(k \Delta t)=\sum_{j=1-M / 2}^{M / 2} c_{j} \exp (i 2 \pi j k / M), k=1, M,
$$

where the $c_{j}$ are complex Fourier coefficients such that

$$
S_{j}=2 T c^{*}{ }_{j} c_{j} \quad\left(c^{*}{ }_{j} \text { is the complex conjugate of } c(j)\right)
$$

and such that the phase angle

$$
\text { phase }_{j}=\operatorname{Arctan}\left(\text { Imaginary } c_{j} / \text { Real } c_{j}\right. \text { ) }
$$

is evenly distributed between zero and $2 \pi$ for $j=1,2, \ldots, M / 2$.

\subsubsection{Simulation of Mean Wind Effects and Adding to Turbulence}

The mean wind effects are very different for HAWT and VAWT, both analytically and in magnitude. In either case, it is sufficiently accurate to assign the entire variational effect to the rotational frequency of the blade. In fact, for the VAWT, the entire mean wind effect is theoretically at the rotational frequency. 


\subsubsection{HAWT Mean Wind Effects}

In the neutrally stable atmospheric boundary layer, the relation between the wind at two heights $z_{1}$ and $z_{2}$ is

$$
U\left(z_{2}\right)=U\left(z_{1}\right) \ln \left(z_{2} / z_{0}\right) / \ln \left(z_{1} / z_{0}\right)
$$

where $z_{0}$ is the surface roughness length (discussed in Section 3.1.2). In Figure $5, z_{1}$ is the HAWT hub height; $U\left(z_{1}\right)$ is the hub height wind speed (called $U$ in the description so far); $z_{2}$ is the current blade position height, and $U\left(z_{2}\right)$ is the mean wind speed at that height. The mean wind effect then is $U\left(z_{2}\right)$, which is a function of time at the varying heights $z_{2}$, where $z_{2}$ is.given by

$$
z_{2}=z_{1}+\rho \sin (\Omega t)
$$

where ( $\Omega t$ ) is the angle $\theta$ in Figure 5 .

Thus, $U\left(z_{2}\right)$ is a period function whose period is the inverse of the rotational frequency. It approaches but does not become a sinusoid because the logarithm of $z_{2}$ is used. The spectral content of $U\left(z_{2}\right)$ at the overtone frequencies is slight (Powell et al. 1985).

\subsubsection{VAWT Mean Wind Effects}

The mean wind effects for the four VAWT simulations are caused by the blade moving in and out of the mean wind without height change. For the $u$ - and $v$-components, the problem is trivial. If we let $U(t)$ be the mean wind effect (mwe), we can write:

$$
\begin{array}{ll}
\text { VAWT u-simulation: } & U(t)=U(z)-\text { a constant } \\
\text { VAWT v-simulation: } & U(t)=0 .
\end{array}
$$

For the tangential and radial simulations, the mwe is

$$
\begin{aligned}
U(\text { tangential }) & =U \sin [\pi(\Omega t+1)]+2 \pi \Omega \rho \\
U(\text { radial }) & =U \cos [\pi(\Omega t+1)] .
\end{aligned}
$$




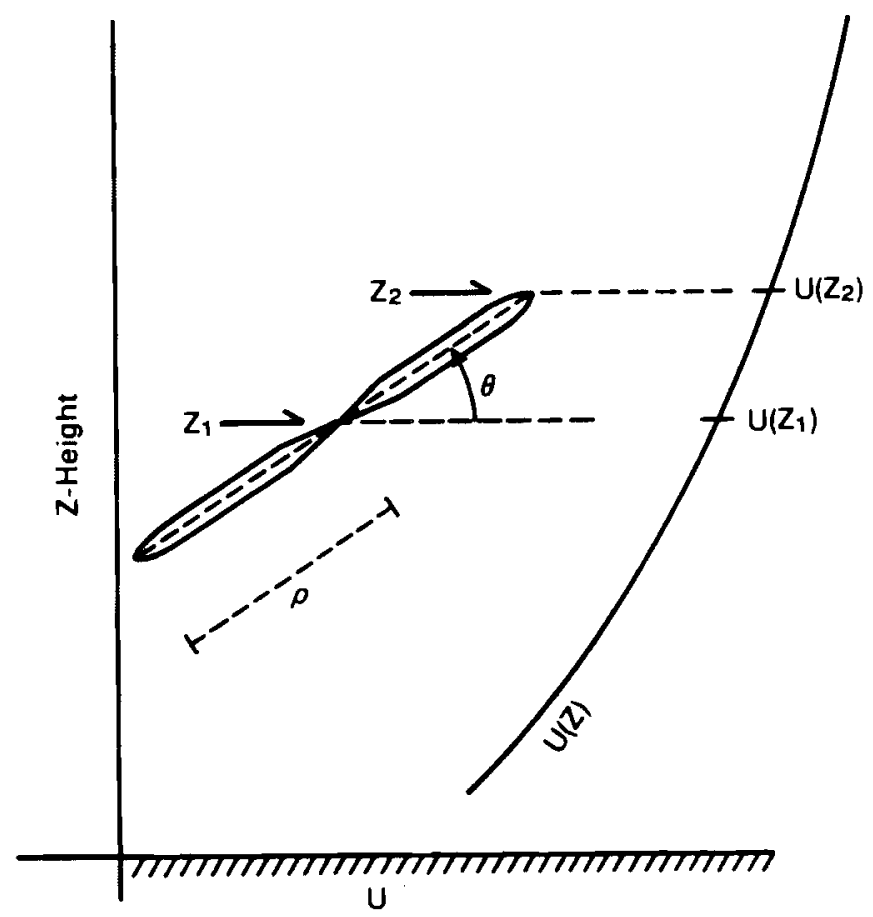

FIGURE 5. HAWT Geometry for Mean Wind Effects

The offset 1 makes the equations agree with Figure 3 , parts $c$ and $d$. The mwe energy contribution is

$$
\operatorname{Energy}(\text { mwe }, 1 P)=1 / 2 U^{2}
$$

and occurs at the rotational frequency, as the notation indicates. 


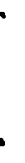




\subsection{DESCRIPTION OF PROGRAM AND USER'S GUIDE}

The computer program is executed by submitting a prepared command file. This command file specifies numerous variables and options set by the user. The variables include both wind turbine and meteorological parameters. The read-in parameters are defined and discussed in the first section. The following section summarizes the operation of the program. The main program is treated first, and then the subroutines. Appendix A lists the code and provides a more complete glossary of program variables.

\subsection{PARAMETERS TO BE READ IN}

The parameters to be read in are organized in five groups, referred to as records. Each parameter has several optional values, described below. Units of the input physical parameters are mks.

\subsubsection{First Record}

KAWT: The option KAWT directs which of the following simulations will be performed:

$$
\begin{aligned}
\text { KAWT }= & \text { 1: } \\
& \text { HAWT } u \\
& \text { 3: VAWT } u \\
& \text { 4: VAWT } v \\
& \text { 5AWT tangential (VAWT } t \text { ) }
\end{aligned}
$$

MWIivD: The program has the option of simulating either the total wind component, including the mean wind effect, or turbulence only, as determined by the value of MWIND.

$$
\begin{aligned}
\text { MWIND }= & 0: \text { simulate turbulence only } \\
& 1: \text { simulate turbulence and mean wind effect. }
\end{aligned}
$$

DELAY: This is the phase delay, in degrees, imposed on the mean wind effect (mwe), modeled at the rotational frequency $1 P$. If DELAY is zero, the program is written so that the $1 P$ harmonics of mwe and turbulence will be in phase. For any other value of DELAY, the mwe is delayed by that angle. Thus, the mwe DELAY would be incorporated as follows 


$$
U(t, \text { mwe })=\phi(\omega \times t-\pi \times \operatorname{DELAY} / 180 .)
$$

where $\phi$ is either a sine or a cosine function.

One possible treatment for DELAY is to treat it as a random variable of even distribution. In this case, several runs could be made so that the statistical nature of the interrelation of mean flow and turbulence could be sampled. Another plausible scenario would be to read DELAY in as zero. This is a worst-case scenario for the HAWT U-component and the VAWT tangential component simulations, making the mwe and turbulence $1 \mathrm{P}$ effects occur in phase. A lesser variance is produced for the radial simulations when DELAY equals zero, since the radial turbulence is 90 degrees out of phase with the tangential turbulence, and therefore 90 degrees out of phase with the mean wind effect.

\subsubsection{Second Record}

The second record consists of physical parameters and related options.

RADIUS: This specifies the radius of rotation to be simulated.

ENO: This is the rate of rotation, in $\mathrm{Hz}$, to be simulated.

$Z$ : This is hub height.

$U:$ This is the mean wind speed at height $Z$. $U(Z)$ will necessarily take on a value between the machine's cut-in and cut-out wind speeds.

Z0: Z0 is a length parameter invented exclusively for meteorological reasons. This is the surface roughness length. Surface roughness consists physically of such things as grasses, bushes, trees, buildings, and terrain features. The rougher the surface, the larger the value of $Z 0$. It corresponds to no single factor that can be measured in nature. Since it cannot be measured, a value must be selected from a table of surface roughness values, such as those given by Chan et al. (1983) and by Panofsky and Dutton (1984). (The first is an engineering report, the second a meteorological book.) For a typical rural setting, gently rolling land with crops and a few trees, setting a $Z 0$ value of $0.1 \mathrm{~m}$ is appropriate. The value of $Z 0$ affects only the turbulence variance, not the shape of the spectrum. 
KSE: This option determines whether the computer or the user provides values for SIGU and SIGV, the turbulence rms of the $u$ - and v-components, respectively.

$K S G=0:$ The program calculates SIGU and SIGV.

1: The program accepts values of SIGU and SIGV as the next numbers read in.

There are uncertainties and inconsistencies to be recognized whether SIGU and SIGV are calculated or read in. The uncertainties arise from the fact that not all the physics necessary to model the low frequency part of the $u$ and $v$ turbulence spectra are known. Therefore, when these parameters are estimated using existing models, measured and modeled values may differ significantly. Since the rms is the square root of the frequency integral of the spectrum, these uncertainties are part of the calculated rms. In addition and for the same reason, a measured value may not be typical for the site at which it was measured.

The inconsistency comes from the fact that the von Karman theory on which this model is based assumes that SIGU equals SIGV. Actually, the von Karman theory is based on the theory of isotropic turbulence, which assumes that all variances of turbulence-directional components are equal. In the atmosphere, this is not true. It is more reasonable to assume that SIGV is about 0.8 SIGU. But if such values are used in the program, the high frequency portions of the spectra, which are well-known, will be out of the proper relationship to each other. This higher frequency range of the spectrum is where the harmonic spikes occur.

If the program is allowed to calculate SIGU and SIGV, it takes a conservative approach by setting them equal to each other. Thus, SIGV is set at the higher value appropriate for SIGU.

If measured values are supplied by the user, the values should be based on Eulerian data samples at least 10 minutes long and sampled at a discretization rate of no less than 5 samples per second. Otherwise the calculated variance will be too low. It can be corrected, but the correction depends on the current height and mean wind speed and requires good understanding of meteorological dimensionless turbulence spectra. 
KEL: This option can have the following values:

$$
\begin{aligned}
\text { KEL }= & 0: \\
=1: & \text { Program calculates EL1 and EL2. } \\
& \text { read in. }
\end{aligned}
$$

The parameters EL1 and EL2 are the integral scales of u-component turbulence in the longitudinal and lateral directions, $L_{x}$ and $L_{y}$, respectively. Numerically, they are of more uncertain evaluation than the rms values. These integral scales are more fully defined and described in Appendix $C$.

The character of the rotational spectra may be adjusted by manipulating values of EL1 and EL2 (Powell et a1. 1985). In general, increasing $L_{y}$ decreases the portion of the energy transferred to the spikes and decreases the peakedness. Increasing $L_{x}$ increases the peakedness without significantly affecting the amount of energy transferred to the peaks. Therefore, increasing both length scales proportionally lowers the amount of energy transferred into the spikes without significantly changing the peakedness.

This completes the information on the second record. A simple procedure for determining values for this record is as follows:

Set RADIUS, ENO, and $Z$ according to the machine specifications.

Set $U$ at the assumed mean wind speed.

Set $Z 0$ at 0.1 if terrain and building feature are of "average rural roughness." Make comparisons by setting $Z 0$ at 0.3 and at 1.0 if greater roughness is estimated; make comparisons by setting 20 at 0.03 and 0.01 if less roughness is estimated. Obtaining a table of surface roughness values will help in estimating 20 . Because individual runs with this model are very cheap, it is economical to try several alternatives to achieve the greatest accuracy.

For HAWT analysis, set KSG and KEL at zero.

For VAWT analysis, set KSG at zero and KEL at 1. Then set EL1 and EL2 at about $3.3 \mathrm{Z}$.

Remember that all units are mks. 


\subsubsection{Third Record}

The parameters of the third read-in record are more manipulable. Before choosing values, the user must decide how many data he wants to simulate and at what discretization interval. The discretization interval is most easily specified indirectly, by specifying the number of samples per revolution. The following suggestions are made:

KNDOPT: This is an option that allows the user to specify the discretization interval either in angular units or in seconds.

$$
\begin{gathered}
\text { KNDOPT = 0: This is the easiest option, because the program rather } \\
\text { than the user makes the calculations. }
\end{gathered}
$$

KNDOPT must be set at zero if MWIND does not equal zero. That is, if the nwe is to be simulated, the model requires an integral number of samples about the rotational circle, specified by the integer NANGLE.

$$
\begin{aligned}
& \text { KNDOPT }=1: \text { Discretization interval (DT) is read in directly. If } \\
& \text { this option is used, DT should be no greater than } \\
& 1.0 /(12 . \star \text { ENO }) .
\end{aligned}
$$

NANGLE: This is the number of sectors the sampling (discretization) divides the rotational circle into. Note that NANGLE is an integer. The minimum allowable value of NANGLE is twice the number of harmonics the analyst wishes to model, which would be at least four or five. Therefore, NANGLE must be at least eight or ten. Actually, a value of twelve or greater is recommended. If the value is twelve, sampling positions 30 degrees apart are simulated. The discretization interval in seconds (DT) is calculated from NANGLE and ENO. That is, DT equals 1/(NANGLE $x$ ENO). NANGLE is used directly in the calculation of the autocorrelation function only if KAWT is four or five, i.e., if the simulation is of either the VAWT tangential component or the VAWT radial component. NANGLE is used only if KNDOPT equals zero.

DT: DT is the discretization, or sampling, interval in seconds. A read-in value of DT is used only if KNDOPT equals one. If KNDOPT equals zero, NANGLE is used. 
MMT: This is the number of simulated data. It must be $2^{N}$, where $N$ is an integer. This is because the FFT method cannot handle any number of data other than $2^{N}$. A problem arises because the number of rotational cycles simulated is more likely to be fractional than integral. Thus, when the spectrum of these data is computed, the energy that physically belongs to certain frequencies is diffused upward and downward among all frequencies. However, if enough rotational cycles are simulated, the fraction of energy diffused out of the $1 P$ rotational band by this mathematical artifice will be small. Twenty cycles seem to be sufficient for this purpose. Therefore, we recommend that the product (MMT $\times$ DT $\times$ ENO), or, equivalently, the quotient MMT/NANGLE, should at least equal 20. Thus, MMT must be greater than 20/(DT $\times$ ENO) or greater than $20 \times$ NANGLE. The program requires the user to perform these calculations.

There are other considerations in setting MMT. Usually the spectrum $S(n)$ should be calculated to a minimum frequency on the order of $0.01 \mathrm{~Hz}$ to adequately model the low frequency part of the spectrum. To do so requires that MMT be no less than the order of $(100 / D T)$.

A minimum value of 1024 is recommended for MMT (these considerations may indicate the need for a higher minimum). The speed of the model means that the greater economy resulting from selecting smaller values is not important. In addition, the product MMT $x$ ILIAS, the next parameter, must not exceed 16384 .

ILIAS: This parameter removes the high-frequency part of the spectrum calculated by Fourier transform of the autocorrelation function (acf). The low frequency portion of the spectrum remaining equals 1/ILIAS. Thus:

ILIAS $=1:$ none of the spectrum is removed. The high-frequency end will be severely aliased.

$=2:$ the upper half of the spectrum is removed, leaving the lower frequency half.

$=4:$ three-fourths of the spectrum is removed.

A value of 4 is recommended for ILIAS. The program will accordingly use a discretization interval DTA one-fourth of the original and will allow calculation of an acf four times as long as the maximum allowance specification. After the 
spectral transform of this acf has been calculated, three-fourths of it will be discarded and the relatively unaliased remainder will be used for data simulation.

KWINDOW: This is an option allowing the use of the Hamming window (Blackman and Tukey 1958) to taper the end of the autocorrelation function. The tapered autocorrelation function is given by:

$$
\begin{aligned}
R(t) \text { tapered } & =0.5 R(t)+0.5 R(t) \cos (\pi t / T), t \leq T, \\
& =0, t>T .
\end{aligned}
$$

$T$ is the time length of the function at the point where it converges according to the convergence criterion $\mathrm{CHK}$, the next parameter read in. If this criterion is not met, $T$ is the maximum time allowed for the acf. The limit on the number of members of $R(t)$ is (MMT $x$ ILIAS/2). Therefore, the limit on $T$ is (DT $\times$ MMT $\times$ ILIAS/2). The algorithm uses the value of CHK such that the acf is deemed convergent when the the sum of the absolute values of the last three computed values of the function does not exceed $3 \times$ CHK. KWINDOW values are as follows:

$$
\begin{aligned}
& \text { KWINDOW }=0: \text { Hanning window is not used. } \\
&=1: \text { Hanning window is used whether acf was terminated by } \\
& \text { the convergence criterion or not. Otherwise the } \\
& \text { spectral transform may have a "beard" (a rapid fre- } \\
& \text { quency oscillation in the spectrum). }
\end{aligned}
$$

CHK: This is the convergence criterion discussed above. A reasonable value range for $\mathrm{CHK}$ is 0.001 to 0.01 .

NP: This is the number of degrees of freedom used in the impulse response function when the simulated data are calculated by the convolution of Gaussian white noise with an impulse response function. NP may not exceed MMT/2. It may very well be about one-tenth that amount. As will be explained in Section 3.1.5, the method of calculation using Gaussian white noise is one of two options for calculating the final simulated data. Since the other option, based on harmonic analysis, is the preferred one, we have had little experience setting NP. When the other option is used, NP is ignored. 
This completes the information on the third record. A reasonable set of values would be:

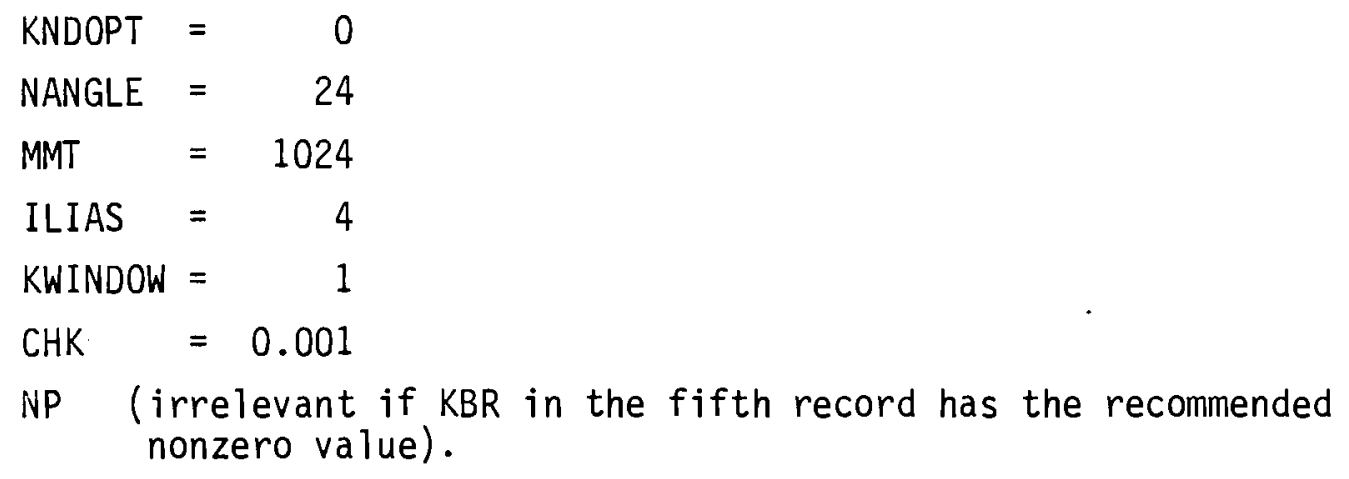

Such a simulation requires about 20 to 45 seconds on the VAX 11/780, if an executable image of the code already exists.

\subsubsection{Fourth Record}

All of the options on this record govern writing to output files that are suitable for plotting by some other program. When they are set at any value other than zero, the specified task is done. Normally k8 and K14 are not used.

K8: Write the entire calculated impulse response function to disk.

K9: Write the following $S(n)$ spectra to disk:

* the FFT transform of the autocorrelation function

* the spectrum calculated from the simulated data.

K11: Write the $S(n)$ from cosine integration of the autocorrelation function to disk.

K12: Write the simulated data to disk.

K13: Write both the original and the altered von Karman $S(n)$ spectra to disk. (These alternatives will be explained below.)

K14: Write the complex Fourier coefficients of the transform of simulated data to disk.

K15: Calculate the logarithmically banded $\mathrm{nS}(n)$ spectrum of simulated data and write it to disk, preceded by the unbanded $n S(n)$ values for the lowest three frequenies. (Banding is a smoothing procedure.) 


\subsubsection{Fifth Record}

The last read-in record consists of further options.

KSERIAL: This is a five-character alphameric array used for naming a run.

KBR: This option governs the analytical method by which the simulated data are computed.

$$
\begin{aligned}
\text { KBR } & =0: \begin{array}{l}
\text { Use convolution integral of Gaussian white noise and } \\
\text { impulse response function. }
\end{array} \\
& =1:
\end{aligned}
$$

KXIFPR, KVKPR: These are printing options for the unbanded estimates of the spectrum, as calculated by transformation of the autocorrelation function and for the von Karman spectrum, respectively. These spectra are not those of 80 frequencies from $0.1 \mathrm{P}$ to $8 \mathrm{P}$. Rather, these are the $2^{\mathrm{N}}$ harmonic estimates, where $\mathrm{N}$ may be 10 or 11 . Therefore, the printouts can be quite large. Usually there is no need of them, as is explained below. Any nonzero value for these options results in printing.

\subsection{FLOW CHART OF MAIN PROGRAM}

Figure 6 is a flow chart of the main program. Subroutines are identified by names written in capital letters, in boxes having probes extending to other boxes. The abbreviation WDO stands for "written to disk by option." The option is usually one of the $K^{*}$ variables, such as $\mathrm{Kg}$. If the variable does not equal zero, the writing occurs.

\subsection{SUMMARY OF PROGRAM OPERATION}

Operation of the main program is summarized first, followed by the operations of specific routines.

\subsubsection{Main Program}

The user initiates the program by entering the parameters and variables as described in Section 3.1. The program then calculates autocorrelation functions, spectra and harmonic spike variances, and produces simulated data. 


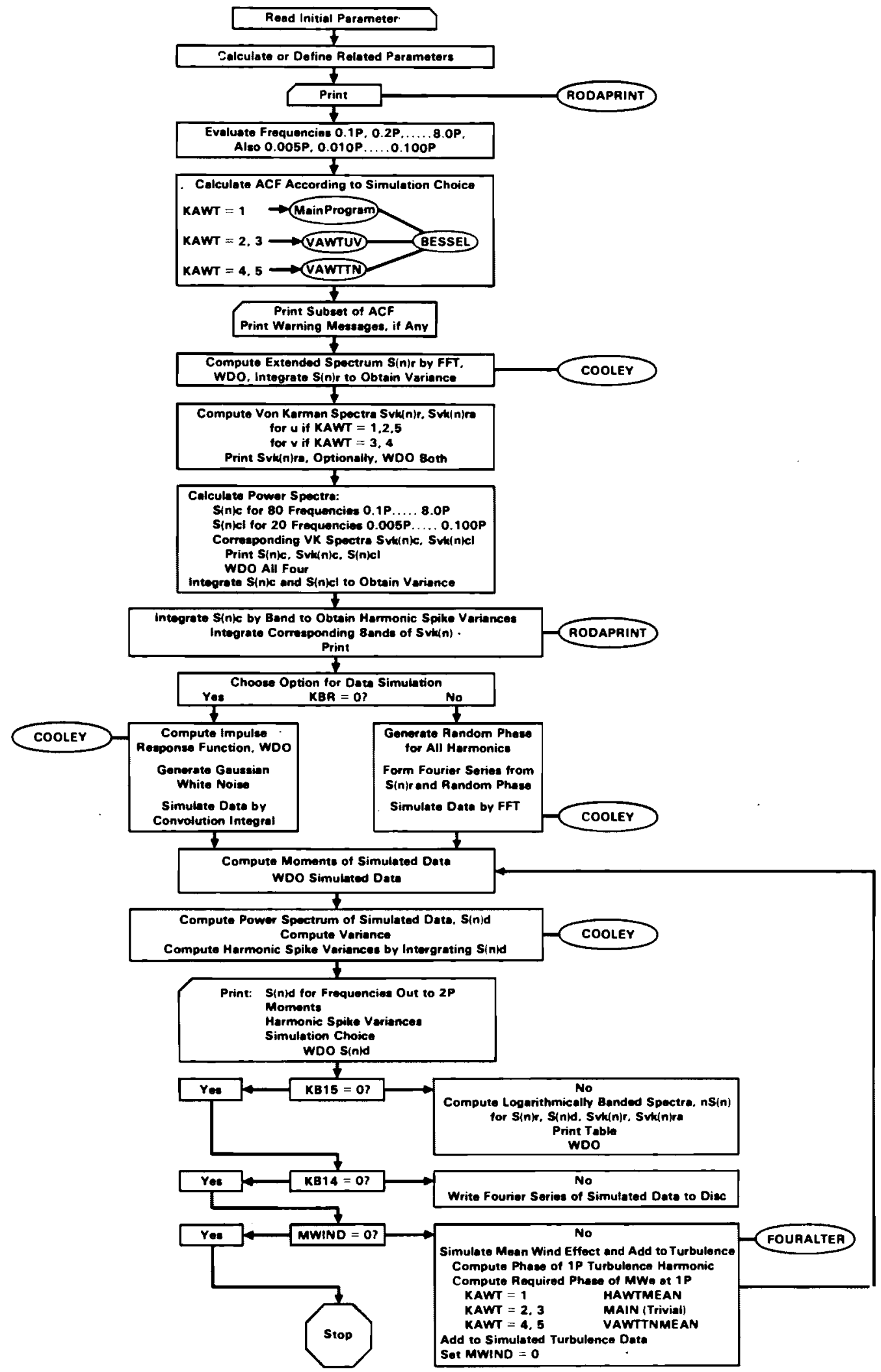

FIGURE 6. Flow Chart Illustrating Operation of the Main Program. $S(n)$ refers to the spectrum of the simulated data, it is numerically equivalent to $S(n)_{r}$. 


\subsubsection{Entering Parameters and Variables}

First, the necessary parameter values are read in or determined internally. Then the two limit frequencies for certain of the calculated spectra are determined. The lowest frequency, EN1, is the inverse of the total time period of the simulated data. The highest frequency, EN2, is one-half the reciprocal of the sampling interval, DT.

At this point, other variables are identified by adding the letters A, ND, or AND to variable names already defined. The meanings are best illustrated by examples. Consider the variable DT, the discretization interval. The most direct way to create a spectrum reasonably free of aliasing is to create one with an extended high frequency range that is not needed and which is later disregarded. This is done by using a reduced discretization interval to compute the autocorrelation function of the rotational data. This reduced discretization interval is called DTA. It is computed by dividing DT by the alias reduction factor, ALIAS (the floating point version of ILIAS). Because the autocorrelation function is first computed in terms of dimensionless variables, we also need dimensionless equivalents of DT and DTA. These are DTND and DTAND, obtained by multiplying the corresponding dimensional variable by (PI $\times$ ENO). Other modified variables exist in some or a 11 of these forms for MMT, EN1, EN2, and NANGLE. Some of these additional values are defined for printing only. Others have an analytical role.

Once the initial variables are defined, Subroutine RODAPRINT is called to print out the initial variables.

\subsubsection{Calculation of Autocorrelation Functions and of Several}

The next section of the program calculates the autocorrelation function of the simulated data according to the specifications just read in and those just calculated. It calls on Subroutine BESSEL to calculate the modified Bessel functions of the second kind, $K(1 / 3)$ and $K(2 / 3)$. Then the logic in the main program uses the Besse 1 function values to determine the particular acf that corresponds to the value of KAWT read in, that is, HAWT $u$, VAWT $u$, etc. The discretization interval of the acf is DTAND. 
If KAWT equals one (HAWT u-simulation), all of the acf calculation is done in the main program except the part done by Subroutine BESSEL. If KAWT is greater than 1 , setting up one of the VAWT simulations, the entire acf calculation is performed in subroutines. Specifically,

if KAWT equals two or three (VAWT $u$ or $v$ simulation), Subroutine VAWTUV is used;

if KAWT equals four or five (VAWT tangential or radial simulation), Subroutine VAWTTN is used.

Subroutines VAWTUV and VAWTTiN call Subroutine BESSEL at the appropriate point. The Hanning window adjustment is done in each of the VAWT subroutines as well as in the main program.

The next section of the program calculates several spectral functions. They may be easily confused with each other unless they are defined at the outset. These spectra are defined and described as follows:

$$
S(n)_{f} \text {, in }(m / s)^{2} / H z
$$

This is the full spectrum calculated by submitting the acf to the fast Fourier transforms, FFT. These are performed by the Cooley-Tukey subroutine, called Subroutine COOLEY. The lowest value of $n$ is EN1. The highest value is EN2A, or EN2 $x$ ALIAS. The number of frequencies is MMT $\times$ ILIAS $/ 2$.

$$
S(n)_{r}, \text { in }(m / s)^{2} / H z
$$

This is the reduced, relatively unaliased spectrum. It can be defined as

$$
\begin{aligned}
S(n)_{r} & =S(n)_{f}, \text { if } n \text { is not greater than the original EN2. } \\
& =0 \text {, if } n \text { is greater than the original EN2. }
\end{aligned}
$$

The lowest frequency is EN1; the highest frequency is EN2. The number of frequencies is MMT/2. $S(n)_{f}$ is never used after $S(n)_{r}$ is determined. $S(n)_{r}$ is the spectrum used as the basis for later data simulation.

$$
S(n)_{c} \text {, in }(m / s)^{2} / H z .
$$


This spectrum is computed by direct cosine integration of the acf for frequencies $0.1 \mathrm{P}, 0.2 \mathrm{P}, \ldots .8 .0 \mathrm{P}$ or EN2, whichever is 1ower. The maximum number of frequencies is 80 .

$$
S(n)_{c 1} \text {, in }(m / s)^{2} / H z
$$

A detailed low frequency description analogous to $S(n)_{C}$, at 20 frequencies, is $0.005 \mathrm{P}, 0.010 \mathrm{P} . . . ., 0.100 \mathrm{P}$.

The following corresponding von Karman spectra are computed.

$\operatorname{Svk}(n)_{r}$, in $(m / s)^{2} / H z$ - original von Karman spectrum analog of $S(n)_{r}$, $\operatorname{Svk}(n)_{r a}$, in $(m / s)^{2} / H z$ - altered von Karman spectrum analog of $S(n)_{r}$, $\operatorname{Svk}(n)_{c a}$, in $(m / s)^{2} / H z$ - altered von Karman spectrum analog of $S(n)_{c}$.

The term "ra" stands for the altered u- or v-spectra that were found to be the limit spectra of the rotational spectra, as rotational rate and radius (or rate alone) approach zero. This finding was not expected. More details and the analytical forms of the original and altered spectra are given in Appendix $B$. Both original and altered versions of the spectra are computed at this point and can be written to disk.

The von Karman spectra are computed according to which component simulation is being performed. The u-spectra are computed if the simulation is of HAWT $u$, VAWT $u$ or VAWT $t$. The v-spectra are computed if the simulation is VAWT $v$ or VAWT $r$. Most of these spectral functions can also be written to disk.

The spectra $S(n)_{c}$ and von Karman $S_{v k}(n)_{c a}$ are printed out, along with the variance computed by integrating $S(n)_{c}$. At the bottom of the page, just above the variance, is a print-out of $S(n) \mathrm{Cl}$ that was calculated for 20 divisions of the lowest frequency band, that is, from $0.005 \mathrm{P}$ to $0.100 \mathrm{P}$. The reas on for computing $S(n)_{C}$ is that both its numerical print-out and its plot make for very easy visual assessment of the rotational effect. $S(n)_{c}$ is a handy spectrum in this respect. The von Karman analogs, $\operatorname{Svk}(n)_{c}$ and $\operatorname{Svk}(n)_{C a}$, are printed and plotted for comparison of the rotational and corresponding Eulerian spectra. 


\subsubsection{Calculation of Harmonic Spike Variances}

The next section of the program computes variances for the first six harmonic spikes of the rotational spectrum. This is the amount of energy per unit mass in each spike. The amount of energy in the von. Karman spectrum in each of these frequency bands is also computed for comparison. These results are printed out. The spectra used in these computations are $S(n)_{C}, S(n)_{r}$, and $\operatorname{Svk}(n)_{\mathrm{ca}}$.

The reader should note at this point that since the $S(n)_{r}$ spectrum is used for data simulation, the $S(n)_{C}$ and its von Karman analogs $\operatorname{Svk}(n)_{c}$ and $\operatorname{Svk}(n)_{c a}$ are no longer necessary for the central purpose of the program. However, the $S(n)_{c}$ and $\operatorname{Svk}(n)_{c a}$ spectra were the basis of earlier reported material (Powell et al. 1985) before the simulation capability was added to the code. For this reason, and because these spectra could conceivably be used to generate simulated data by the Gaussian white noise method, they have been retained.

\subsubsection{Data Simulation}

The remainder of the program performs the wind-speed time-series simulation by one of two alternative methods, according to the value given for the option KBR. The first method, used when KBR equals zero, calculates the simulated data by a convolution integration of Gaussian white noise with an impulse response function. The impulse response function is calculated from the spectrum $S(n)_{r}$ and can be written to disk. The result depends on an additional arbitrary input by the user, namely the number of degrees of freedom (members or NP), to be used in the calculated impulse response function. Increasing the number of members gets more of the spectral characteristics into the simulated data, at a cost of greater running expense. Experience is needed to determine what is an optimal number of members to use.

The computations we made by this method used about 50 members in the impulse response function. The spectrum of the simulated data differed somewhat from the original spectrum, and more than $20 \%$ of the original variance was lost. In contrast, when the second simulation alternative is used, the spectrum of the simulated data is identical with the original rotational spectrum, $S(n)_{r}$. Therefore, the two variances are also identical. There is no choice 
to be made corresponding to what number of members of an impulse response function to use. For these reasons, we recommend the second alternative.

The second alternative, chosen when KBR equals one, uses the spectral estimates to calculate the amplitudes of the Fourier harmonics of the simulated data and to add the phase as an uncorrelated random variable from harmonic to harmonic. The random phase is provided by calling a routine that generates an evenly distributed random variable over the range 0 to 1 and scaling this over the range 0 to $2 \pi$.

Following either kind of simulation, several statistical calculations are made based on the simulated data. The variance, skewness and kurtosis of the simulated data are computed. Then the simulated data may be written to disk. Next, the power spectrum of the simulated data is computed. This is identical to the original power spectrum if the second simulation alternative was used or if the mwe has not yet been added in (see Figure 6 ). The computation of variance in the first half-P and in the harmonic spikes is repeated, this time using the spectrum of the simulated data. The spectrum and the Fourier coefficents it was computed from may be written to disk. The last computation, also optional, is a conversion of the $S(n)$ spectrum of the simulated data at evenly spaced frequencies to an $n S(n)$ spectrum at logarithmically spaced frequencies. There are ten bands per frequency decade. The $n S(n)$ estimates for the lowest frequencies are left unbanded. This is because banding has no advantages when the ratio between successive frequencies of the unbanded spectrum is greater than the frequency ratio within the specified band width. The $n S(n)$ version of the von Karman spectrum is also computed if the original version was written to disk.

The program terminates here if MWIND is zero, i.e., if no mwe simulation is to be made. Otherwise, the following operations are performed:

First, Subroutine FOURALTER is called to find the phase angle of the IP harmonic in the simulated data D1. The ANGLE is identified by 


$$
\begin{aligned}
\text { ANGLE } & =\operatorname{Arctan}(B, A) \text {, in degrees, where the equation of the mwe is } \\
U[\text { mwe }](t) & =A \cos (\omega \times t)+B \sin (\omega \times t)
\end{aligned}
$$

or

$$
U[\text { mwe }](t)=C \cos (\omega \times t-\pi \times \text { ANGLE/180. }),
$$

where

$$
C=\sqrt{A^{2}+B^{2}}
$$

and $\omega$ is the rotational rate in radians per second.

The calculated variables OFFSET and IFFSET are a combination designed to bring $U[m w e](t)$ into phase with the $1 P$ turbulence harmonic when DELAY is zero, and when the mwe equations are written as they are in Subroutines HAWTMEAN and VAWTTNMEAN. The program calls up the appropriate subroutine to calculate one cycle of mwe for the particular HAWT or VAWT component simulation being calculated. This does not occur for either the VAWT u- or VAWT v-component simulations.

The one cycle of mwe is returned to the main program. It is extended through as many cycles as are needed to cover the turbulence. It is then added to the turbulence.

With this done, the program goes back to the moment-calculating routine and recalculates all the statistics of the simulated data. These include the moments, spectrum and harmonic spike integrations of the spectrum of the simulated data including mwe.

\subsubsection{Specific Subroutine Operations}

A selection of the following subroutines is called by each run. Figure 6 illustrates where the subroutines fit in the operation of the whole program.

\subsubsection{Subroutine BESSEL}

Subroutine BESSEL computes a summation for each of the Bessel functions until both addends are reduced below a certain tolerance. At this point, the 
computed sums become the two Bessel function values, and control returns to the main program. The argument going into the summation begins near zero. When the argument exceeds eight, the sums diverge. Therefore, if the argument reaches eight, control is returned to the main program, and a warning message is printed out. Fortunately, this potential problem does not seem to exist in actual computations.

Of the four arguments in the call list, three are essential. The fourth applies only in the so-called D-line output used for checking the subroutine. The three essential arguments are the single input argument for the two Bessel functions and the two output values.

\subsubsection{Subroutines VAWTUV and VAWTTN}

These subroutines are alternate routes for the main program, depending on the value of KAWT, that is, on what kind of simulation is being executed. If the simulation is any of the VAWT simulations, the part of the main program that computes the acf for the HAWT simulation is bypassed and one of these subroutines is called. Subroutine VAWTUV is used for a VAWT u- or v-component simulation and Subroutine VAWTTN is used for a VAWT tangential or radial component simulation. Both of these subroutines have the same call to Subroutine BESSEL and the same windowing option as the main program has for the HAWT simulation. The call lists are somewhat long. Most of the variables therein are defined in the glossary in Appendix A. Ordinarily, the user need not be concerned with them.

\subsubsection{Subroutine COOLEY}

This FFT subroutine was authored by Winkelman and Smith before 1970. It accepts two real data series as the real and imaginary parts of a complex series and performs the FFT of the complex series. Certain additional logic is necessary to sort out the values for the two power spectra and the cross spectra when two sets of original data are entered, filling both the real and the imaginary parts of the complex series seen by the subroutine. In the present operations, we filled only the real slots. 
The subroutine is called three times to effect the transform. There are two input variables. The first is the complex data series. The second is an indicator that differs on each of the three submissions:

1. the negative of the number of members in the complex data vector

2. the positive of the same number

3. zero.

The output Fourier transform values occupy the same slots the original data occupied.

\subsubsection{Subroutine LOGBAND}

This subroutine reads in a number of evenly banded $S(n)$ spectra over the same frequency range and converts them to $\mathrm{nS}(n)$ spectra logarithmically banded. This operation is performed on $S(n)_{r}$, and on the von Karman spectra $S v k(n)_{r}$ and $\operatorname{Svk}(n)_{r a}$, if they have been calculated and written to disk. The call list for the subroutine consists of

BPSD number of logarithmically-spaced frequency bands per spectral decade. The recommended value of BPSD is 10.

K13 the option governing whether the von Karman spectra are written to disk.

MWF a flag telling the subroutine whether or not to read a third record of $S(n)$ values. This third spectrum is of simulated data including mwe.

After the subroutine reads the $S(n)$ input spectra, it constructs the bounds of the logarithmically spaced bands. The highest frequency band has the Nyquist frequency (0.5/DT) for $i$ ts upper bound. Upper bounds of the successively lower frequency bands are all related by the same ratio, which is

$$
\text { RATIO }=10.0^{(1.0 / B P S D)} \text {. }
$$

That is, if the upper bound of the highest band is FQQ, the Nyquist frequency, the lower bound of this band is FQQ/RATIO, and the central frequency is the geometric mean of those two. The second highest band has FQQ/RATIO for its upper frequency bound and FQQ/RATIO ${ }^{2}$ for its lower bound. This formation of frequency bands continues until the frequency band width becomes less than the 
fundamental frequency, thus leaving some of the lowest frequency values of $S(n)$ unbanded. Once the band limits are established, the $n S(n)$ values are computed by straightforward arithmetic. The subroutine prints out a table of the banded estimates and, below these, the unbanded $n S(n)$ values are also printed out.

This feature was used to generate the spectra shown in Appendix B. Genuine rotational spectra would be distorted by this type of banding. Therefore, operation of Subroutine LOGBAND is not essential.

\subsubsection{Subroutine FOURALTER}

Given a frequency ENO, Subroutine FOURALTER computes the $A$ and the $B$ of the $1 P$ wave:

$$
S(1 P) \text { turbulence }=A \cos (2 \pi \times E N O \times t)+B \sin (2 \pi \times E N O \times t) .
$$

These are printed out, and the phase angle

$$
\operatorname{ANGLE}=\operatorname{Arctan}(B, A)
$$

is computed and returned to the main program so that the mean wind effect, which is a wave with frequency $1 P$, can be adjusted to the proper phase relation with the IP wave of the turbulence.

\subsubsection{Subroutines HAWTMEAN and VAWTTNMEAN}

These subroutines calculate one cycle of simulated mean wind effect. Then this cycle is transferred to the main program and added repeatedly to the turbulence until enough cycles, including partial cycles, have been added to cover the turbulence record. Subroutine HAWTMEAN simulates the mwe for HAWT rotation; Subroutine VAWTTNMEAN simulates the mwe for either the tangential or the radial component of VAWT rotation.

\subsection{ON BRACKETING THE ANSWERS BY ENVELOPING INPUT PARAMETERS}

As indicated above, turbulence rms and length scales are uncertain. The turbulence rms during unstable conditions may well be 50 percent greater than 
the program-calculated value, which applies for neutral conditions. Similarly, the effective surface roughness length may well be anywhere from $2 / 3$ to $3 / 2$ that reasonably assumed. Surface roughness length affects model calculations only through the rms. The results described in the next section suggest that both length scales specified by the model may be about 3.5 times the height. However, turbulence length scales do not scale exactly with height. Therefore, a wider range should be considered. The user may wish to submit a series of runs, varying parameter values within these ranges and plotting all results in order to get an envelope.

A reasonable envelope for rms would be 0.8 to 1.5 times the programcalculated values for SIGU. This allows for uncertainty about both atmospheric stability and surface roughness. However, if the stable atmosphere is to be modeled, the rms may well be half the program-calculated values. An envelope of values for rms can be used without running the model again because all simulated wind values are directly proportional to rms and all spectral values are directly proportional to the square of the rms. Other reasonable envelopes would be:

$$
\begin{aligned}
& L_{x}: 3 Z \text { to } 6 Z . \\
& L_{y}: 0.4 L_{x} \text { to } 1.0 L_{x} \text {. }
\end{aligned}
$$

For HAWT simulations, a smaller choice of $L_{y}(u)$ is appropriate. For VAWT simulations, $L_{y}$ should approximate $L_{x}$ more closely. Calculating an envelope of values for $L_{x}$ and $L_{y}$ requires running the model for each individual pair of specified values. 


\subsection{MODELING OF SPECTRAL ANALYSIS OBTAINED BY ANALYSIS OF FIELD DATA}

The comparison in this section is based on spectral analysis. We use two descriptors. One is the spectrum itself. The spectrum of rotational turbulence data produces a series of spikes at the rotational frequency and at a number of its harmonics, or overtones (see figures in Appendix D). The other descriptor is the energy in the harmonic spikes of the rotational spectrum. The energy is computed by integrating over the frequency range of each harmonic spike. Since the latter descriptor is more important in application, it is presented first.

\subsection{MEASURED DATA DESCRIPTION}

On June 5, 1984, data were taken by two hotf $j 1 \mathrm{~m}$ devices mounted on the boom of a vertical-axis rotating boom apparatus located within the Hanford 300 area. The boom, driven by an electric motor, rotated in a horizontal plane in response to the wind. The final hot film analysis data consisted of the components of the wind tangential and radial to the circle of rotation (see Figure 2), recorded at a sampling rate of $25 / \mathrm{sec}$. The rotating boom was mounted at a height of $7.2 \mathrm{~m}$ above the ground and the hot films were located at a radius of $4.17 \mathrm{~m}$ from the vertical axis of rotation. The mean wind speeds were taken from analysis of data from a Gill anemometer mounted at the same height nearby.

Data were collected for four test periods. Table 1 summarizes the conditions for these test periods, including starting times, mean wind speed and rotational rate of the blade. Starting times are used to identify the test periods.

The final analyses were performed by taking a segment of 8192 rotational data (representing 328 seconds) from each test period and subdividing it into four equal sections. Each section was analyzed separately before the four results were averaged together to arrive at the final characterization for each test case. A sample of the rotating boom hotfilm-measured wind speed is given in Figure 7. 
TABLE 1. Conditions for the Four Test Periods, June 5, 1984. All measurements were taken $7.2 \mathrm{~m}$ above ground level, and with a 4.17 m radius of rotation

$\begin{array}{ccc}\begin{array}{c}\text { Starting } \\ \text { time } \\ \text { (hours, minutes) }\end{array} & \begin{array}{c}\text { Mean wind } \\ \text { speed } \\ (\mathrm{m} / \mathrm{s})\end{array} & \begin{array}{c}\text { Rotation } \\ \text { rate } \\ (\mathrm{Hz})\end{array} \\ 1327 & 7.3 & 0.582 \\ 1432 & 6.7 & 0.591 \\ 1502 & 8.2 & 0.590 \\ 1521 & 6.6 & 0.776\end{array}$

a

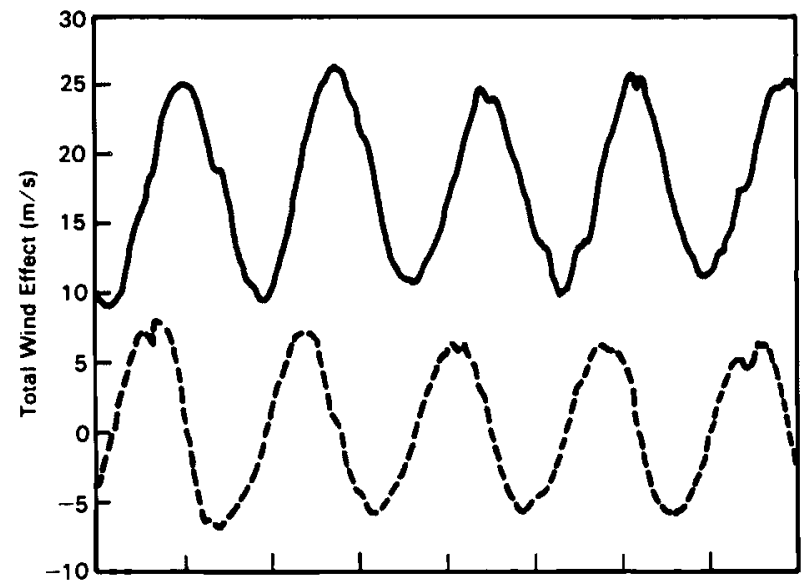

b

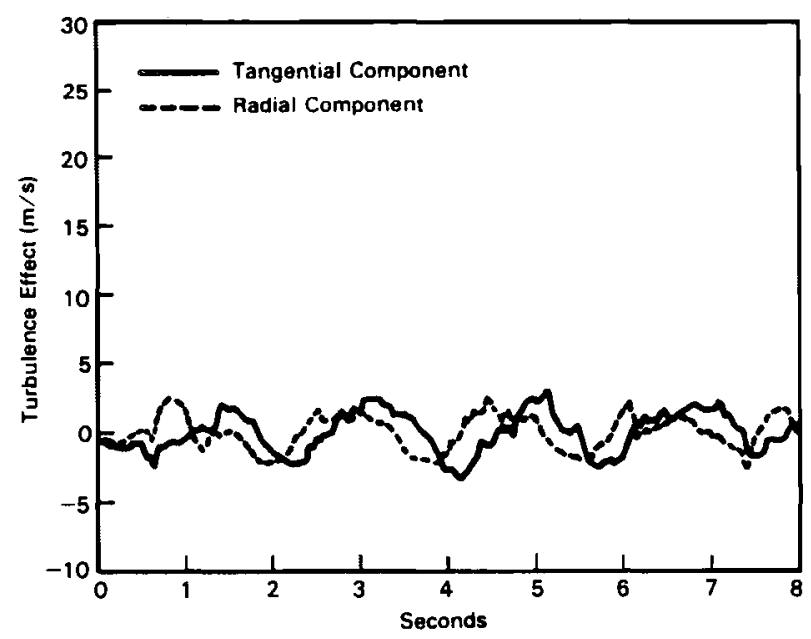

FIGURE 7. Tangential and Radial Component Data, Test 1327. a. Total wind effect, in $\mathrm{m} / \mathrm{s}$; b. Turbulence effect, in $\mathrm{m} / \mathrm{s}$ 
Figure $7 \mathrm{a}$ shows the total of mean wind and turbulence, while Figure $7 \mathrm{~b}$ shows the turbulence only. Evidently the mean wind effect dominates the turbulence at the frequency that corresponds to the rotation rate of the blade. It is perhaps this evidence that of ten leads to the conclusion that turbulence is not important for VAWTs. However, our results show that at higher frequencies of wind fluctuation the turbulence dominates.

\subsection{MODELING SCENARIOS}

Two modeling scenarios were applied. They were the "MWIND=0" and "MWIND=1" models. In the first case, turbulence alone was handled in the model and the mean wind effect was simulated by adding $0.5 \mathrm{U}^{2}$ at the first harmonic. In the second case, the mean wind effect went directly into the model.

In all cases, the discretization interval was determined by specifying NANGLE. The value specified was calculated by determining the number of samples per rotational cycle from the values of the discretization interval used in measurement and the rotational frequency. Thus a value of 42 was used for NANGLE for Tests 1327, 1432, and 1502, while a value of 33 was used for Test 1521. Both length scales, EL1 and EL2, were set at $3.5 \mathrm{Z}$, or $25 \mathrm{~m}$.

\subsection{ENERGY IN THE HARMOINIC SPIKES, COMPARISON BETWEEN MODELED AND MEASURED}

Ratios were computed between energy in the harmonic spikes as calculated by the model and as calculated from data analysis. The results, averaged over the second through sixth harmonics (leaving out the mean wind effect, which is in the first harmonic), are given in Table 2. Table 3 breaks these down by harmonic.

TABLE 2. Average Ratio of Modeled/Measured Energy in Harmonic Spikes, Averaging over Al1 Tests, and over Harmonics 2 to 6. Turbulence and mean wind effects are modeled together.

$\begin{array}{ccc}\text { MWIND }=0 & \begin{array}{c}\text { Tangential } \\ \text { Simulation }\end{array} & \begin{array}{c}\text { Radial } \\ \text { Simulation }\end{array} \\ \text { MWIND }=1 & 1.06 & 0.91 \\ 1.17 & 0.96\end{array}$


TABLE 3. Average Ratio of Modeled/Measured Energy in Harmonic Spikes, by Harmonic, Averaging over All Tests. Mean wind and turbulence effects are modeled together.

\begin{tabular}{|c|c|c|c|c|c|c|}
\hline Harmonic & 1 & 2 & 3 & 4 & 5 & 6 \\
\hline \multicolumn{7}{|l|}{ MWIND $=0$} \\
\hline Tangential & 0.82 & 1.61 & 1.00 & 1.06 & 0.80 & 0.83 \\
\hline Radial & 1.02 & 0.50 & 0.99 & 1.17 & 1.10 & 0.78 \\
\hline \multicolumn{7}{|l|}{ MWIND= 1} \\
\hline Tangential & 0.86 & 2.03 & 1.07 & 1.09 & 0.80 & 0.83 \\
\hline Radial & 1.02 & 0.53 & 1.06 & 1.18 & 1.18 & 0.83 \\
\hline
\end{tabular}

Comparisons should be made for different harmonics separately. We recall that the first harmonic result, combining mwe and turbulence, is primarily a mwe result because the mwe is more than an order of magnitude greater than the turbulence. The higher harmonic results are primarily turbulence and, thus, depend on the length scale and variance choices used in the modeling scenario.

\subsubsection{First Harmonic (rotational frequency)}

The entire purpose of creating the "MWIND $=1$ " model was to obtain a better simulation of the first harmonic and of the data by providing for phase adjustment between the mwe $1 \mathrm{P}$ harmonic and the turbulence $1 \mathrm{P}$ harmonic. In the "MWIND $=1$ " model, the two harmonics in the tangential analysis are modeled as being in phase. The same modeling renders the two harmonics 90 degrees out of phase in the radial analysis. The results show a small improvement in the tangential analysis at the first harmonic. The energy ratios for the "MWIND $=1$ " models and "MWIND $=0$ " models are 0.86 and 0.82 , respectively. This difference is not great enough to require that this phase relationship be more accurately modeled (assuming the in-phase modeling for the tangential component is correct). The two results for the radial component also do not differ significantly. Both are just over 1.0 , showing that the model slightly overestimates the $1 P$ energy in the radial component.

\subsubsection{Second Harmonic}

There are significant differences here between modeled and measured results. In both scenarios, the model overestimates $2 \mathrm{P}$ energy in the tangential 
simulation and underestimates it in the radial simulation. Each error is by a factor of two. We hope this difference can be explained as more examples of wind measurements are analyzed.

\subsubsection{Higher Harmonics}

At the higher harmonics, the model estimates are all reasonably good. However, as is seen in Figures 8 and 9 , the rotational character in the spectra of either model calculation or data analysis is not as strong as for the lower harmonics. Therefore, in these scenarios, the fit of measured and modeled results at these harmonics depends more on fortunate choice of length scale than on anything else, since the program was allowed to calculate the turbulence variance.

a

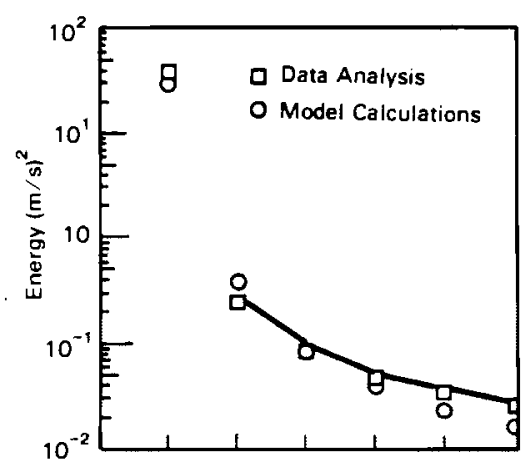

C

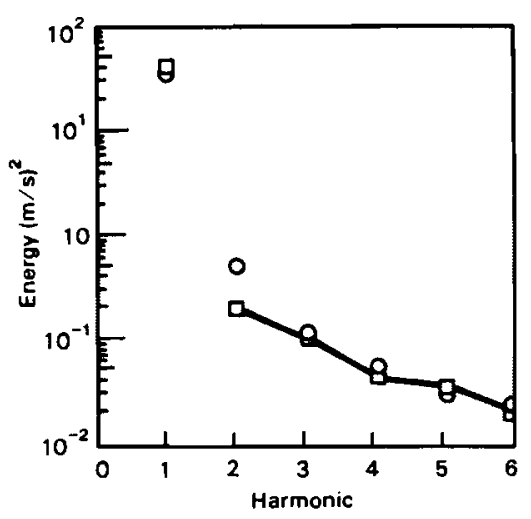

b

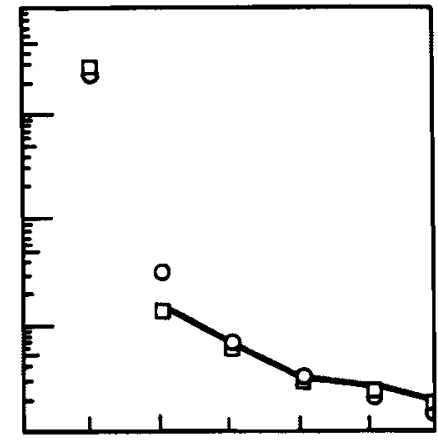

d

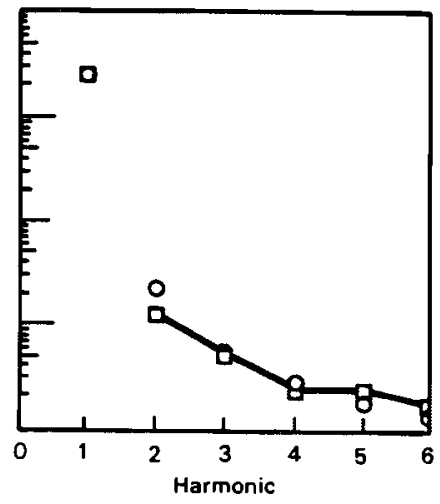

FIGURE 8. Spectra of Tangential Component of Rotational Wind - Mean Wind Effect Plus Turbulence. a. Test 1327;

b. Test 1432 ; c. Test 1502 ; d. Test 1521 
a

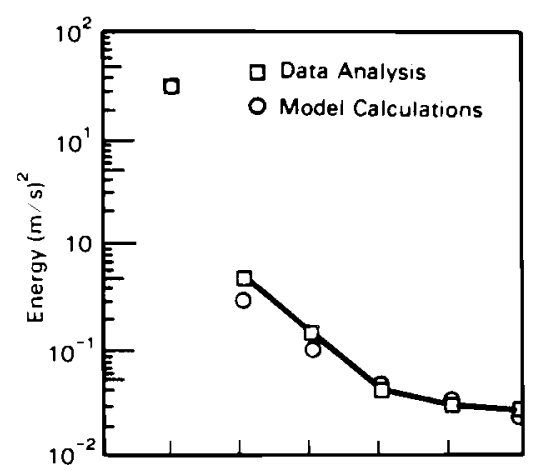

C

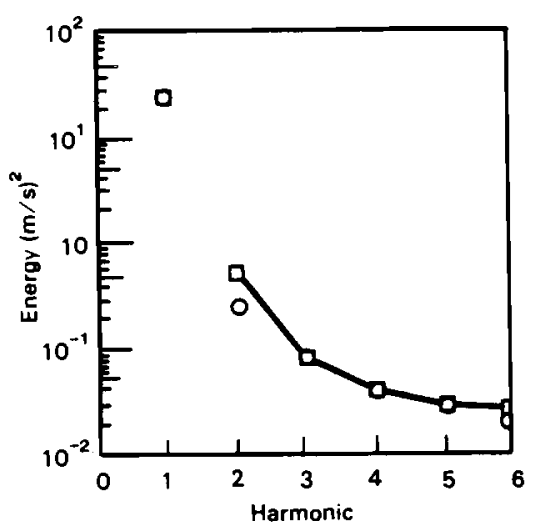

b.

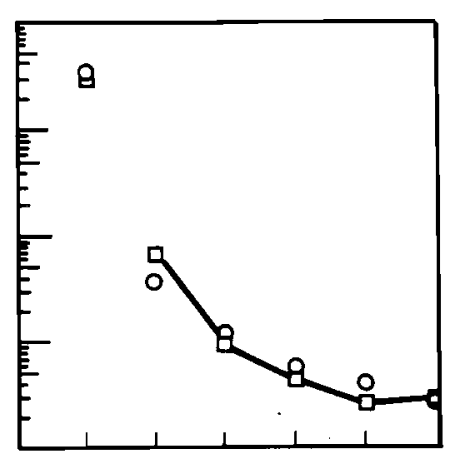

d

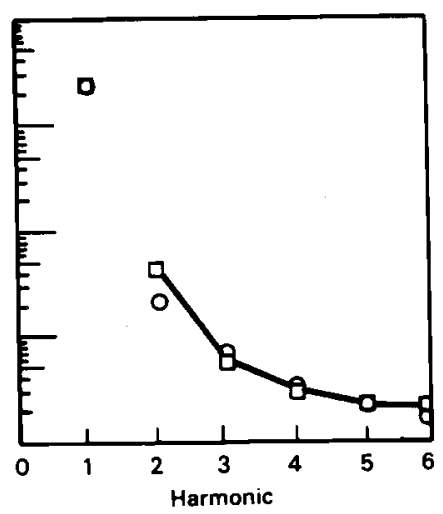

FIGURE 9. Spectra of Radial Component of Rotational Wind

- Mean Wind Effect Plus Turbulence. a. Test 1327;

b. Test 1432 ; c. Test 1502; d. Test 1521

The overall result obtained by Powell et a1. (1985) in their HAWT analysis is better than the VAWT analysis results obtained here, particularly at the second narmonic. The reason is thought to be the longer radius used in the HAWT simulations.

We now turn to comparisons between modeled and measured results for the same component in the same test. The comparisons are shown in Figure 10 for the tangential component and in Figure 11 for the radial component. Most of the pertinent observations that can be made from these graphs have already been made under Table 3, the contents of which are the ratios of modeled to measured results averaged over the four tests, displayed for each harmonic. The results appear to be reasonably consistent among the four test cases in both the tangential and the radial analyses. 
a

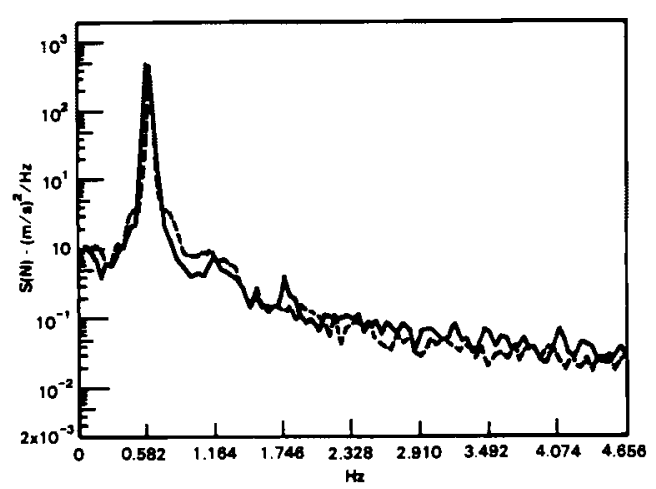

c

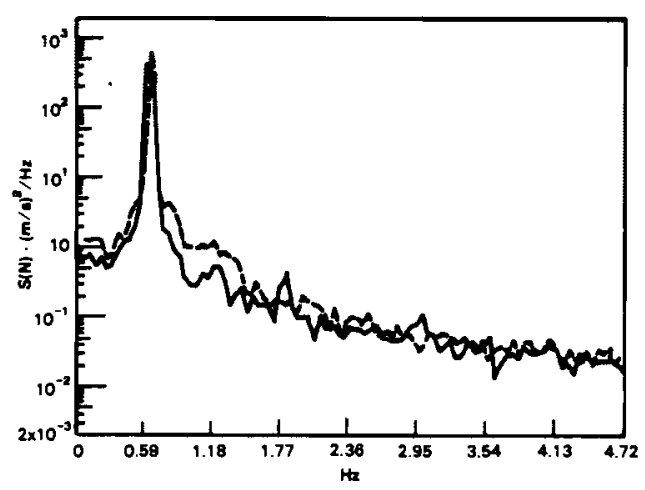

b

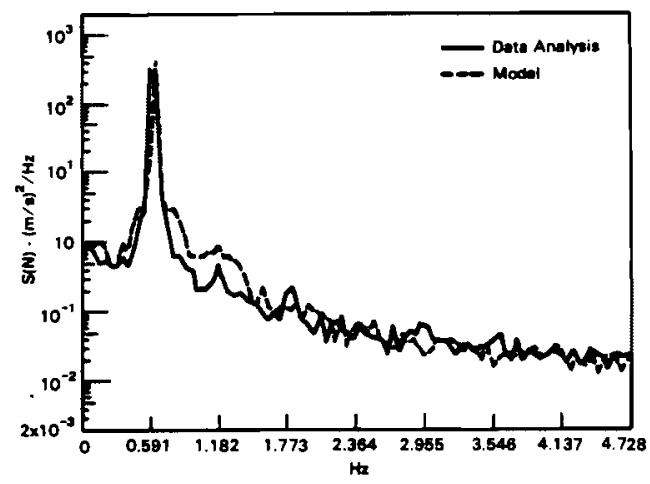

d

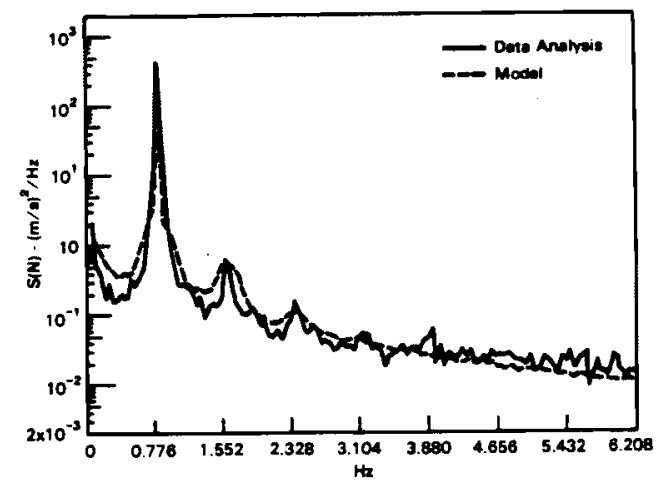

FIGURE 10. Harmonic Spike Energy, Tangential Component, Modeled and Measured. a. Test 1327; b. 1432;

c. Test 1502 ; d. Test 1521

\subsection{SPECTRAL PLOTS, MODELED VS. MEASURED}

The match of $S(n)$ spectra for the tangential and radial components for the four tests are shown in Figures 8 and 9 , respectively. These graphs do not add a great deal to the result because neither type of spectrum, whether from the model or from data analysis, shows much of the narrow spike character beyond the second harmonic, except for some of the spectra for the radial analyses in the third harmonic. Note that the modeled and measured results differ in this respect.

The short radius of rotation, coupled with a low rotation rate, accounts for the lack of characterization at higher harmonics. Appendix D provides samples of modeled analysis using a greater radius of rotation. It is also possible that the rotational character would have been more evident if the data had been averaged into a longer discretization interval and the parameter NANGLE correspondingly reduced in the model. 
a

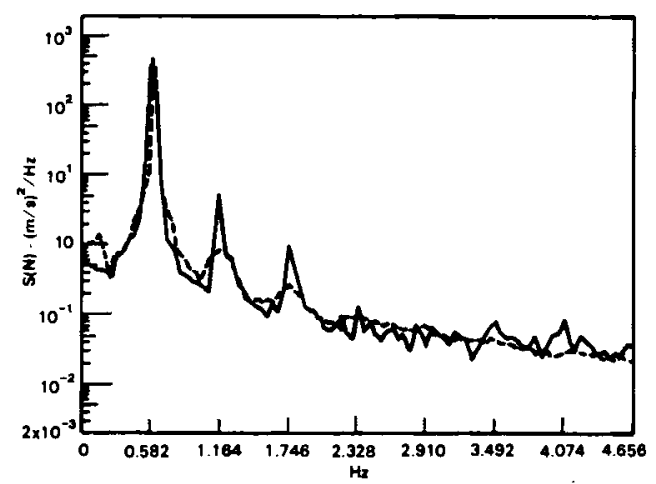

C

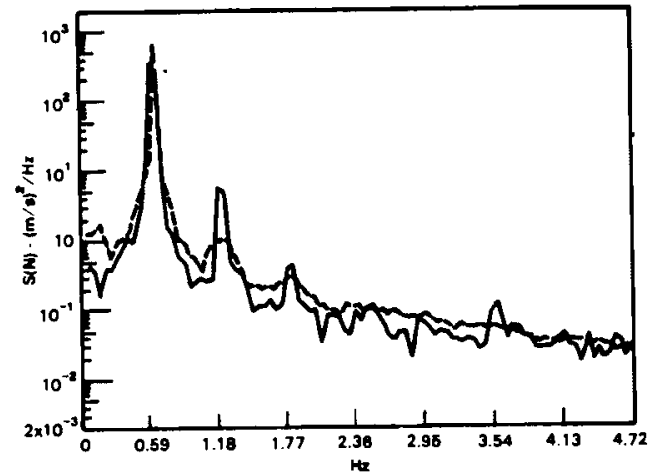

$b$

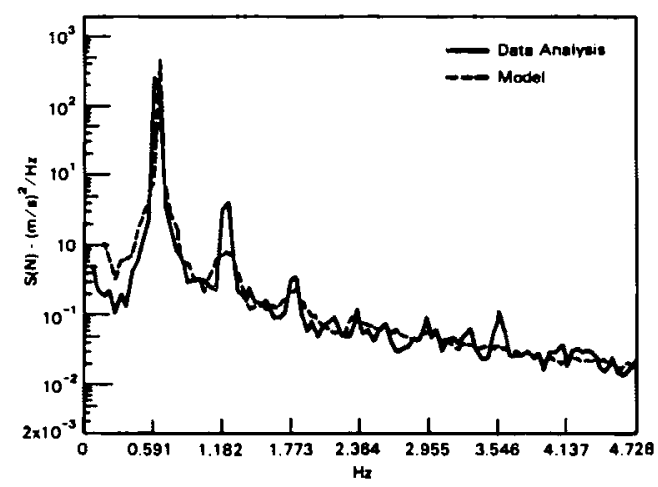

d

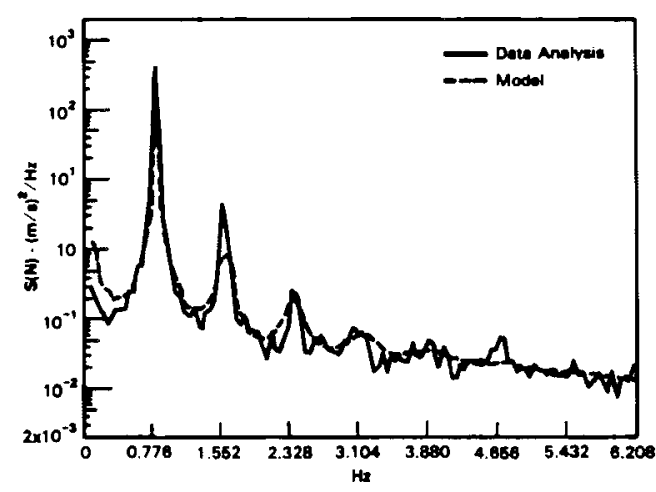

FIGURE 11. Harmonic Spike Energy, Radial Component, Modeled and Measured. a. Test 1327;

b. Test 1432; c. Test 1502; d. Test 1521

The difference, mentioned earlier, between modeled and measured results for the second harmonic in the radial analysis is clearly shown in the spectra. We believe that there would be more harmonic spike character in both measured and modeled results if a longer radius had been used in measurement and simulated in modeling. 


\subsection{CONCLUSIONS AND RECOMMENDATIONS}

We conclude that the model offered here is a useful and very economical means of simulating turbulence along a rotational path in the neutrally stable atmospheric boundary layer, i.e., the wind turbine layer, providing that the following limitations are recognized:

1. Meteorological events are not simulated.

2. Modifications of turbulence by the rotating machine are not included.

3. There is some theoretical uncertainty regarding choice of turbulence length scales.

Because execution time is very short for this model, less than 120 seconds on the VAX 11/780, the model is economically rerun using multiple choices of input parameters, so an envelope can be constructed that should include actual conditions. A boundary layer turbulence model must not be presumed to be more precise than this, unless modeling is limited to so-called isotropic scales. These are small scales and do not include most scales significant to wind turbine operations. Key parameters such as turbulence rms and length scales should be enveloped rather than assumed, since they cannot be precisely evaluated.

For future work, it is suggested that the experience gained in constructing this model be used to improve the state of the art of simulating correlated turbulence inputs at two positions on the same blade. 



\section{REFERENCES}

Blackman, R. B., and J. W. Tukey. 1958. The Measurement of Power Spectra. Dover Pub. Inc., New York, New York.

Chan, S. M., D. Curtice, and S.-K. Chang. 1983. Methods of Wind Turbine Dynamic Analysis. AP-3259, Research Project 1977-1. Systems Control, Inc., Palo Alto, California.

Conne11, J. R. 1982. "The Spectrum of Wind Speed Fluctuations Encountered by a Rotating Blade of a Wind Energy Conversion System." Solar Energy $29: 363-375$.

Frost, W., B. H. Long, and R. E. Turner. 1978. Engineering Handbook on the Atmospheric Environmental Guidelines for Use in Wind Turbine Generator Development. NASA Technical Paper 1359, Marshall Space Flight Center, HuntsviTTe, Al abama.

George, R. L. 1984. Simulation of Winds as Seen by a Rotating Vertical Axis Wind Turbine Blade. PNL-4914, Pacific Northwest Laboratory, Richland, Washington.

George, R. L., and J. R. Conne11. 1984. Rotationally Sampled Wind Characteristics and Correlations with MOD-OA Wind Turbine Responses. PNL-5238, Pacific Northwest Laboratory, Richland, Washington.

Hinze, J. 0. 1959. Turbulence. McGraw-Hi11, New York, New York.

Panofsky, H. A., and J. A. Dutton. 1984. Atmospheric Turbulence. John Wiley \& Sons, New York, New York.

Powell, D. C., J. R. Connell, and R. L. George. 1985. Verification of Theoretically Computed Spectra for a Point Rotating in a Vertical Plane. PNL-5440, Pacific Northwest Laboratory, Richland, Washington.

von Karman, T. 1948. "Progress in the Statistical Theory of Turbulence." In Proceedings of the National Academy of Science, 34:530-539. 
.

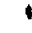




\section{APPENDIX A}

LISTINGS OF THE PROGRAM CODE, A GLOSSARY, AND A TEST CASE 

This appendix has three parts. The first is the listing of the program and all its subroutines. The second part is a glossary of code terms. The third part is the input and output of a test case.

\section{A.1 CODE LISTING}

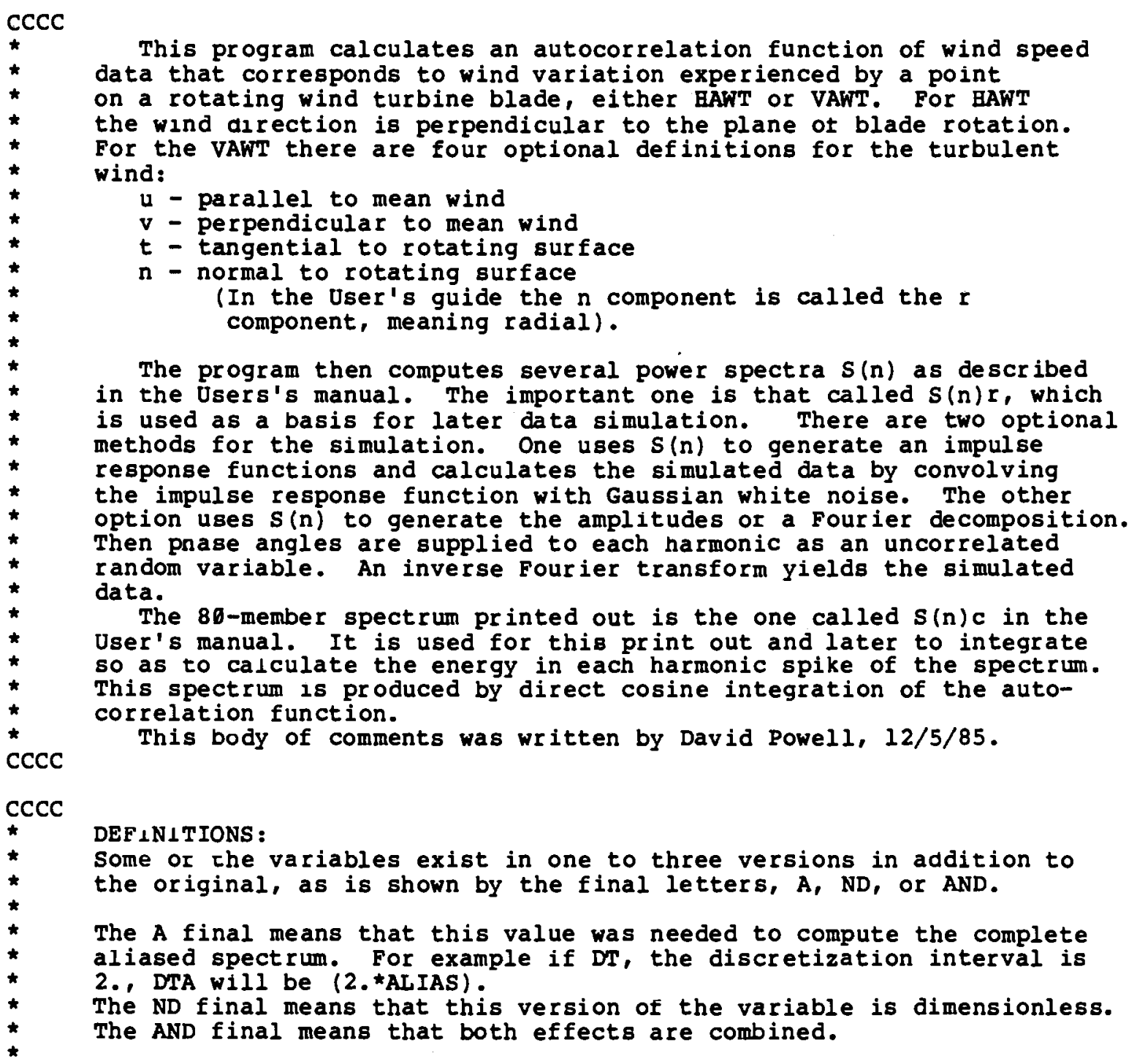


DELAY - offset angle between mean wind etfect and IP harmonic of simulated turbulence (degrees)

ALFA is the radius of blade radius to turbulence length scale.

ANGLE - Phase angle of $1 P$ harmonic in simulated data. zero value indicates a cosine wave (degrees).

ANGLEA - The angle the tangent or normal to the circle at the initial position makes with the mean wind direction (degrees). It is now defined in subroutine VAWTTN.

BETA is the ratio of ALFA to tip speed ratio OMEGA*RADIUS/U.

CAR is the highest final value that will be accepted in an autocorrelation function without windowing (Banning).

CMMT - number data to be simulated. CMMTA

DT - the data discretization interval in seconds. DTA, DTND, DTAND

Dl() - Iinal simulatea cata.

DIM() - one cycle of mean wind simulation.

ELl is the turbulence length scale in beta, (Lu)x.

EL2 is the turbulence length scale in alfa, (Iu)y.

ENL() - frequencies $n$ in Bz. These are linearly spaced and limited in number to 80 . ENLND ()

ENLI() - Frequencies for 20 divisions of the first band of ENL(). ENLIND ()

ENP () - Cyclic frequency in terms ot blade rotation rate (so many $P$ ).

ENO is the blade rotation rate in cycles per second.

ENl - lowest frequency for which spectral computation is possible reciprocal of data length - Eundamental frequency - Hz ENIND

EN2 - Nyquist frequency - highest frequency for which spectral computation is possible - Ez. EN2A, EN2ND, EN2AND

Gl() - white noise

HTI() - two-sided impulse reponse function

IFFSET - Number of positions mean wind wave is to be shifted before adding to simulated turbulence.

ILIAS is the reciprocal of the fraction of the spectrum that is regarded as $f$ it to retain because aliasing can be ignoed. For example: ILIAS = 1 - Retain all of the spectrum.

$=2$ - Retain the lower frequency half.

- 4 - Retain the lower frequency quarter. Recommended values are 2 or 4 .

KAWI - Option: 1 - DO HAWT u analysis and simulation

2 - DO VAWT $u$

3 - DO VAWT V

4 - DO VAWT $t$

5 - DO VAWT $n$

KBR - option: B - Do Gaussian white noise simulation.

1 - Do random phase simulation. This preferred.

RMAX is the maximum number of arguements that may be computed

for the autocorrelation function.

KSG is an option

B: Calculate sigu from neutral boundary layer theory.

1: Use SIGU as read in.

KWINDOW - additional option to turn off windowing.

$=0$, windowing is bypassed regardless of characterof acf.

K8....K15 are options to write to LU $8 \ldots \ldots .15$

K8 - Write impulse response function to disc.

K9 - Write $S(n)$ spectrum to disc

a) FFT of origianal acf

b) $S(n)$ of simulated data

Kll - Write $S(n)$ from cosine integration of acf to file (needed?) 


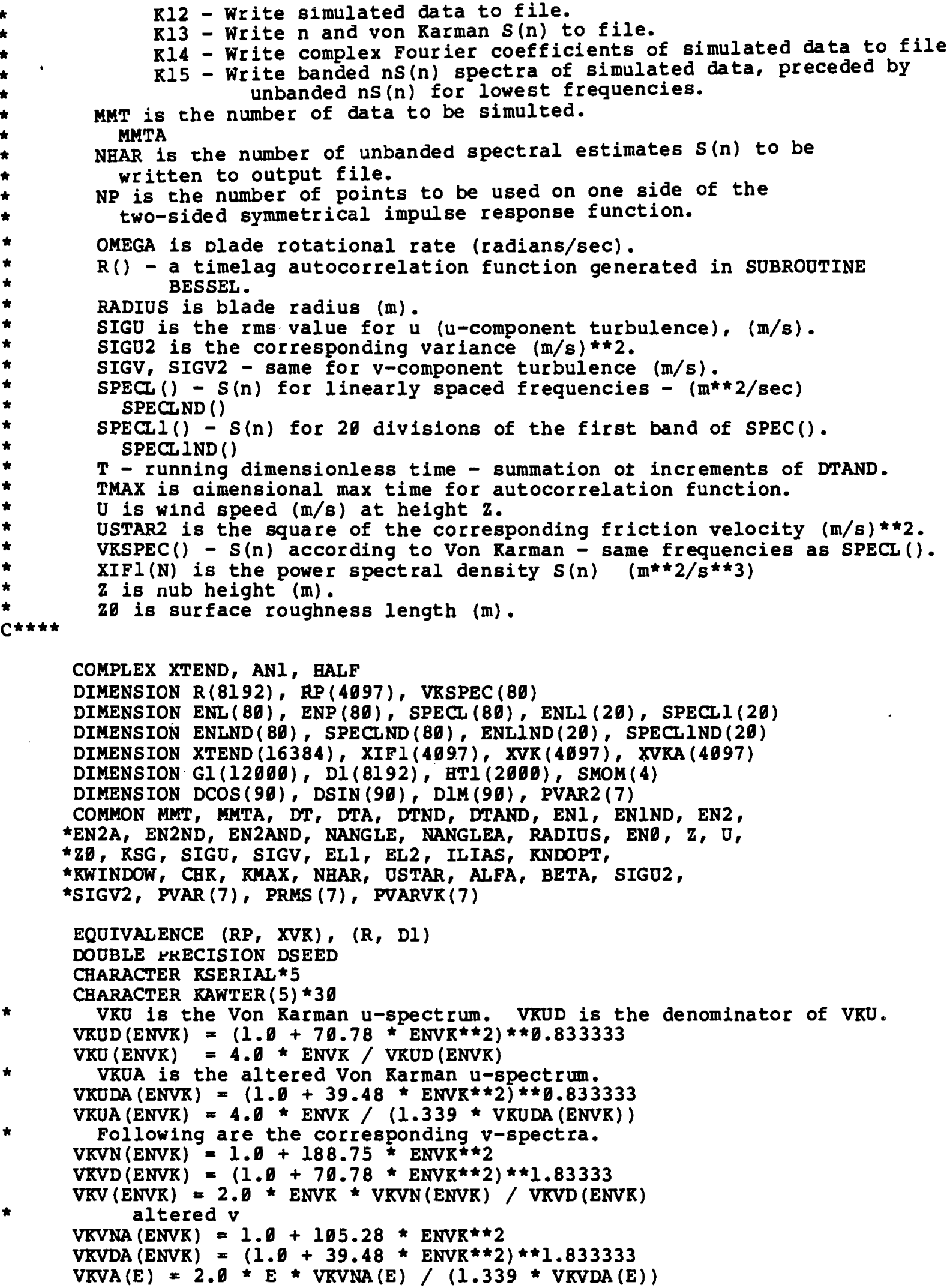


DATA KAW'IER/'BAWT SIMULATION', 'VAWT U SIMULATION',

*'VAWT V SIMULATION', 'VAWT TANGENTIAL SIMULATION',

* 'VAWT NORMAL SIMULATION'/

$P I=3.141592654$

TWUPI $=2.0 \star P I$

BALF $=(0.5,0.0)$

MWINDFLAG $=0$

$\operatorname{READ}(5, \star)$

$\operatorname{READ}(5, *)$ RAWT, MWIND, DELAY

$\operatorname{READ}(5, *)$

READ $(5, \star)$ RADIOS, ENO, Z, U, Z0, RSG, SIGU, SIGV, KEL, ELl, EL2

$\operatorname{READ}(5, *)$

READ $(5, \star)$ RNDOPT, NANGLE, DT, MMT, ILIAS, KWINDOW, CHR, NP

$\operatorname{READ}(5, *)$

$\operatorname{READ}(5, *) \mathrm{K} 8, \mathrm{~K} 9, \mathrm{~K} 11, \mathrm{~K} 12, \mathrm{~K} 13, \mathrm{~K} 14, \mathrm{~K} 15$

$\operatorname{READ}(5, *)$

READ (5, ) RSERIAL, KBR, KXIFPR, KVKPR

IF (MWIND.EQ.0.OR. KNDOPT. EQ.Ө) GO TO 101

WRITE $(7,1001)$

1001 FORMAT(1H, 'KNDOPT MUST EQUAL AND NANGLE MUST BE SPECIFIED

* WHEN MN $\perp$ ND.EQ.I')

STOP

101 CONTINUE

IF (RNDOPT.EQ. $\theta$ ) DT $=1.0 /($ FLOAT (NANGLE) * EN $\theta$ )

IF (RNDOPT. NE. $\theta$ ) NANGLE $=0.01+1.0 /$ (DT* EN $\theta$ )

PIENG = PI * ENO

MHTA $=$ MMT * ILIAS

KMAX = MMTA / 2

NHAR $=$ MMT $/ 2$

ALIAS = ILIAS

DTA $=$ DT / ALIAS

DTND $=$ DT * PIENE

DTAND = DTND / ALIAS

NANGLEA = NANGLE * ILIAS

IF (NANGLEA. GT. MMTA) NANGLEA = MMTA

IF (R15.NE. O) $\mathrm{K} 9=1$

CMMT $=$ MMT

CHMTA $=$ MHTA

The fundamental and Nyquist frequencies of the spectrum $S(n)$ before removal of high frequency (highly aliased) part.

ENI $=1.0 /$ (CMMT * DT)

EN1ND = EN1 $/$ (PIENB)

EN2 $=0.5 / \mathrm{DT}$

EN2A $=$ EN2 $*$ ALIAS

EN2 ND $=$ EN2 $/$ (PIENO)

EN2AND $=$ EN2ND * ALIAS

$F F=1.0 /$ (CMMT * DT)

IF (RSG.GT.B) GO TO 165

SIGU $=0.96 *$ D/ALOG $(2 / 2 \theta)$

SIGV $=$ SIGO

105 SIGU2 = SIGU * SIGU

SIGV2 $=$ SIGV * SIGV

USTI $=0.4$ U $/ \operatorname{ALOG}(\mathrm{z} / \mathrm{ZB})$

UST2 $=$ SIGU / 2.4

USTAR2 = UST1 * UST2

USTAR = SQRT (USTAR2)

IF (REL.GT. $\theta$ ) GO TO 11

ELI $=4.2 * Z$

EL2 $=0.4 *$ ELI

11 ALFA $=$ RADIOS $/$ EL2

OMEGA $=$ TWOPI $\star$ EN

BETA $=U /($ ELI * OMEGA $)$ 


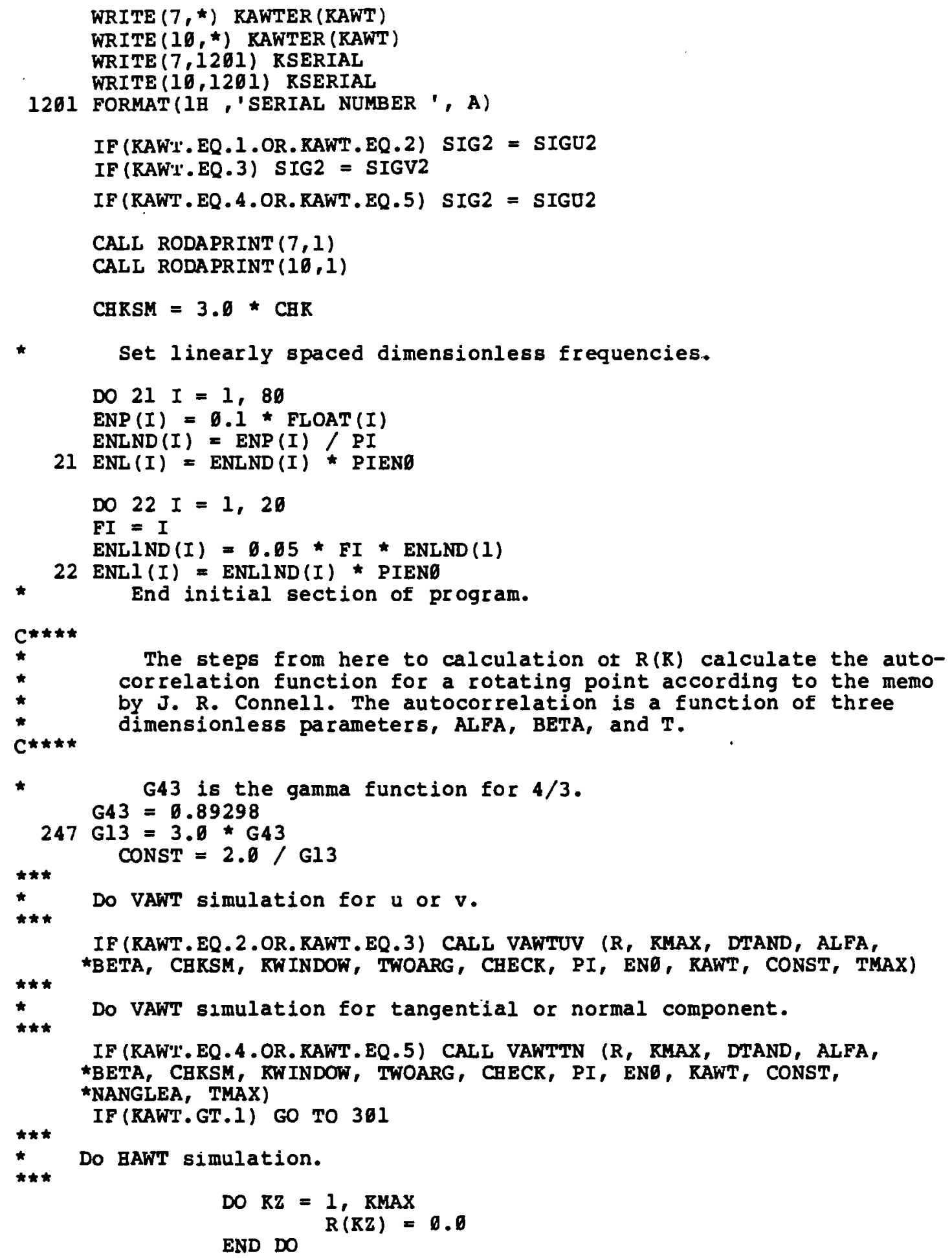


$T=0.0$

DO $25 \mathrm{~K}=1$, RMAX

* T is the dimensionless time arguement for the autocorrelation function.

$T=T+$ DTAND

ARGA $=($ ALFA $\star \operatorname{SIN}(T)) \star \star 2$.

ARGB $=($ BETA $\star T) * 2$

ARG = SQRT (ARGA + ARGB)

TWOARG $=2.0 *$ ARG

$\mathrm{BR} 13=0.0$

$\operatorname{BR} 23=0.0$ 


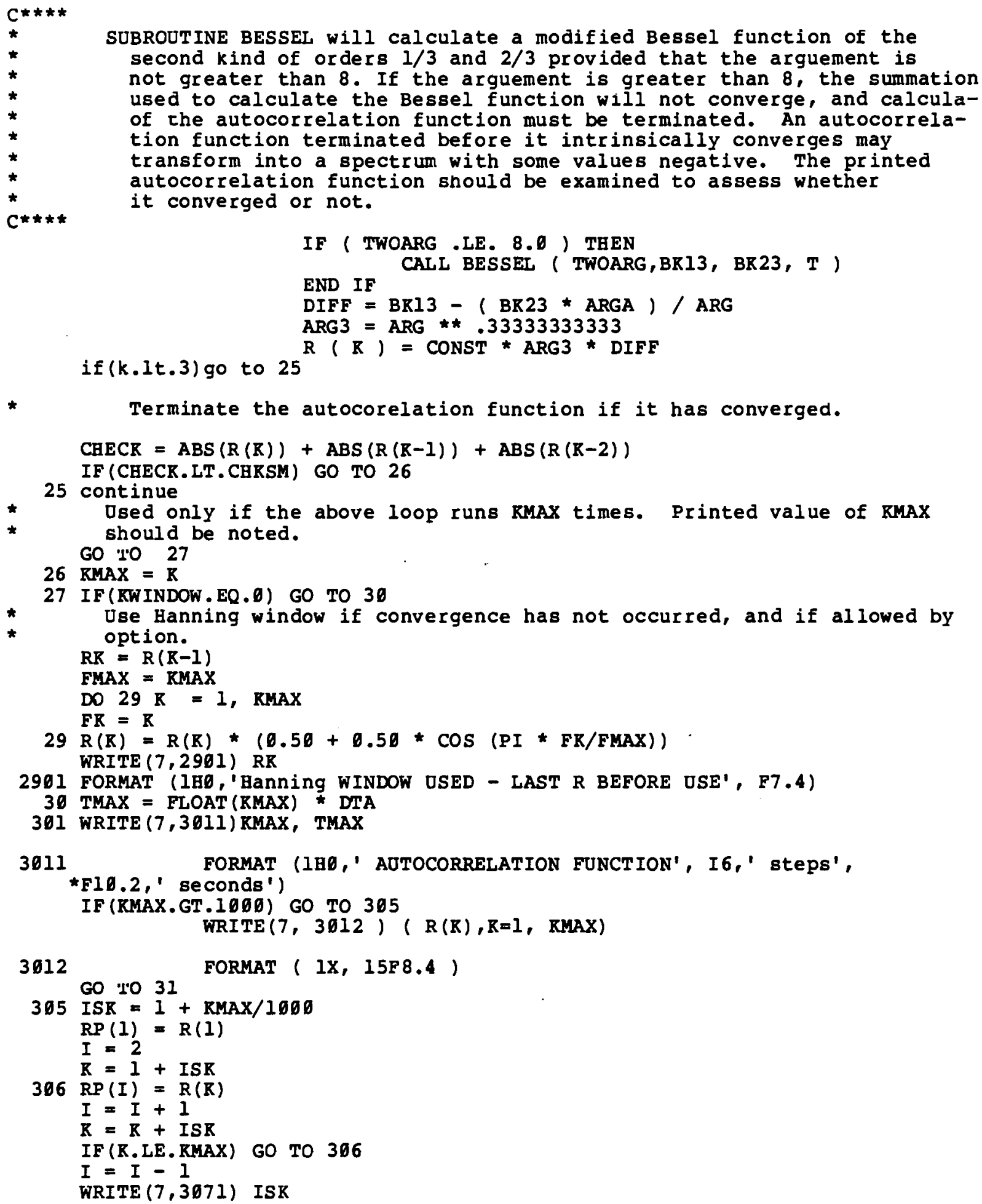


3071 FORMAT (1日, 'After first value skip interval is', I3)

WRITE (7,3012) (RP (R), $R=1, I)$

* Determine which warning should be printed out becuse of manner of

* termination ot acf.

31 IF (KWINDOW.NE. $\oslash$ ) GO TO 315

IFLAG $=\varnothing$

IF (TWUARG.GT.8.0) IFLAG $=1$

IF (CHECK. GT.CHKSM) IFLAG = IFLAG + 2

IF (IFLAG.EQ.0) GO TO 315

GO TO $(311,312,313)$ IFLAG

311 WRITE $(7,3111)$

3111 FORMAT (1H, 'WARNING - BESSEL FUNCTION DID NOT CONVERGE') GO TO 315

312 WRITE $(7,3121)$ CHECK

3121 FORMAT (1H,'WARNING - ACF DID NOT CONVERGE, CHECK = ',E11.3) GO TO 315

313 WRITE $(7,3111)$

WRITE $(7,3121)$ CHECK

End correlation calculating section of program 


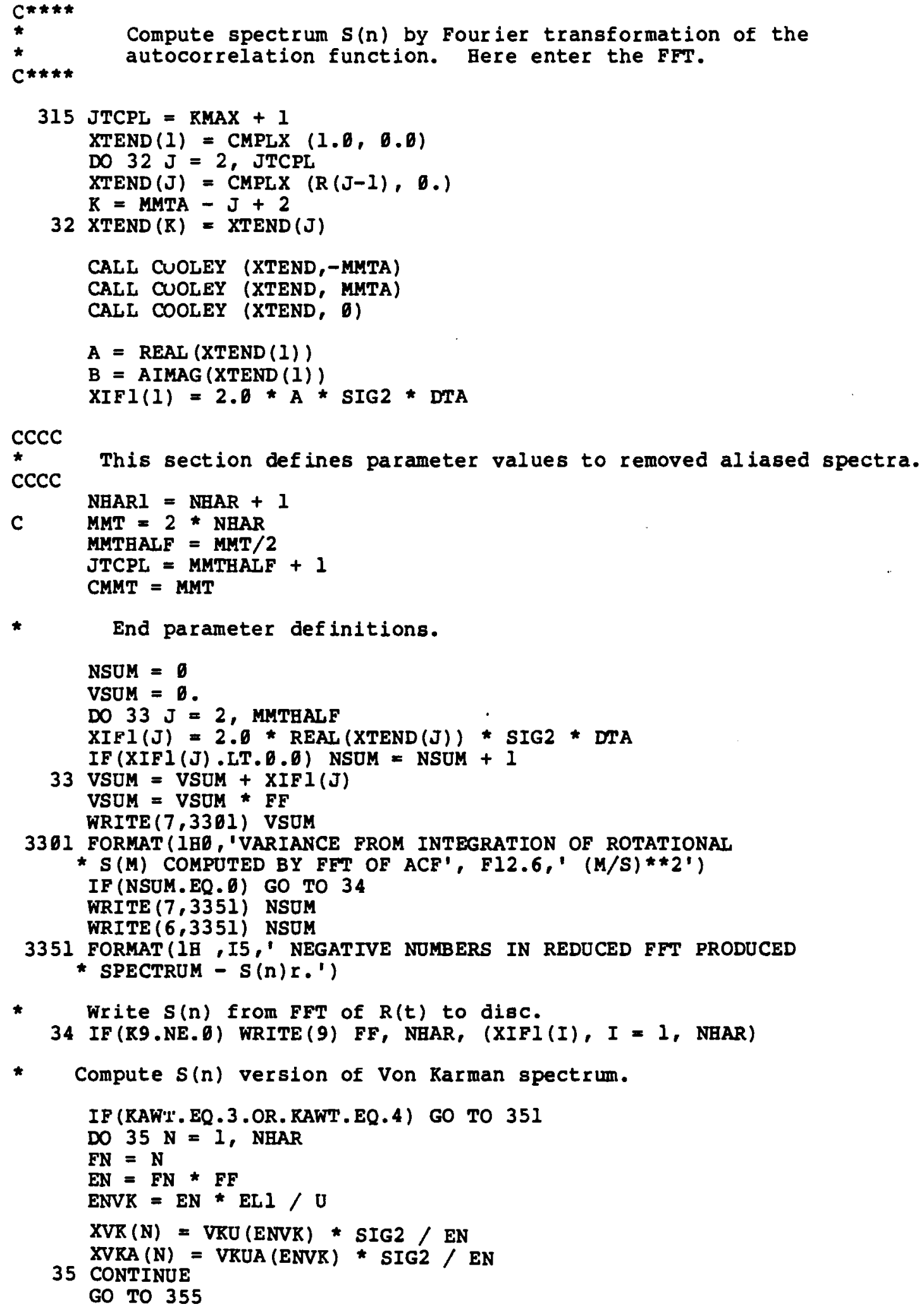

* Compute $S(n)$ version of Von Karman spectrum.

IF (KAW'. EQ.3.OR. RAWT.EQ.4) GO TO 351

DO $35 \mathrm{~N}=1$, NHAR

$\mathrm{FN}=\mathrm{N}$

$E N=F N \star F F$

ENVK $=$ EN * ELI $/ \mathrm{U}$

$\mathrm{XVR}(\mathrm{N})=\mathrm{VRU}(\mathrm{ENVR}) * \mathrm{SIG} 2 / \mathrm{EN}$

XVRA (N) = VRUA (ENVR) * SIG2 / EN

35 CONTINUE

GO TO 355 
351 DO $352 \mathrm{~N}=1$, NHAR

FN $=\mathbf{N}$

$\mathrm{EN}=\mathrm{FN} * \mathbf{F F}$

ENVR $=$ EN * ELl $/ U$

$\operatorname{XVR}(N)=\operatorname{VRV}(E N V R) * \operatorname{SIG} 2 / E N$

$\operatorname{XVKA}(N)=\operatorname{VKVA}(E N V K)$ sIG2 / EN

352 CONTINUE

355 IF (RVKPR. EQ.0) GO TO 38

WRITE $(7,3701)(X V R A(N), N=1$, NHAR)

3701 FORMAT (IHI, 'VON KARMAN S(N) SPECTRUM', $\star /(1 \mathrm{~B}, 5 \mathrm{~F} 12.6, \mathrm{~F} 15.6,4 \mathrm{~F} 12.6))$

* Write von Karman spectra and frequencies to disc.

38 CONTINUE

IF (RI3.EO.0) GO TO 39

WRITE (13) NHAR, (XVR(N), N = 1, NHAR),

*(XVRA $(N), N=1, \quad$ NHAR)

$C^{\star \star \star \star \star ~}$
$\star$
$\star$
$\star$
$\star$
$C \star \star \star \star$

REWIND 13

Compute spectum $S(n)$ by Fourier transformation of the autocorrelation

function at evely spaced * Compute the upper limit wave number base

and the frequency difference in the frequency vector ENL, which is

0.1 * ENด.

$39 \mathrm{NEF}=0.001+5.0 /(\mathrm{DT} * \mathrm{EN} \theta)$

IF (NEF.GT.80) NEF $=80$

DO $N=1, N E F$

$A=0.5$

$T=0.0$

$D O R=1, \operatorname{RMAX}$

$T=T+D T A N D$

$A=A+R(R) \star C O S(T W O P I * \operatorname{ENLND}(N) \star T)$

END DO

Dimensional equivalent of DT is DT/PIENB.

END DO $\operatorname{SPECL}(\mathrm{N})=4.0$ SIG2 *A $A$ DTA

Compute spectral density within lowest frequency band.

DO $42 \mathrm{~N}=1,20$

$A=0.5$

$T=0.0$

DO $41 \mathrm{~K}=1, \mathrm{RHAX}$

$T=T+$ DTAND

$41 A=A+R(R) * \operatorname{COS}($ TWOPI $* \operatorname{ENLIND}(\mathrm{N}) * T)$

$42 \operatorname{SPECLI}(\mathrm{N})=4.0 * \operatorname{SIG} 2 \star A * \operatorname{DTA}$

*

Calculate length scale by integrating acf.

$A=0.5$

DO $43 \mathrm{~K}=1$, RMAX

$43 A=A+R(R)$

SCALEL $=A$ * DTA * 0

Write $S(n)$ spectrum from cosine integration or acf to file.

IF (K11.NE. O) WRITE (11) NEF, (SPECLI(N), N = 1, 20),

$\star(\operatorname{SPECL}(N), N=1, N E F),(\operatorname{ENLl}(N), N=1,2 \theta),(\operatorname{ENL}(N), N=1, N E F)$ 


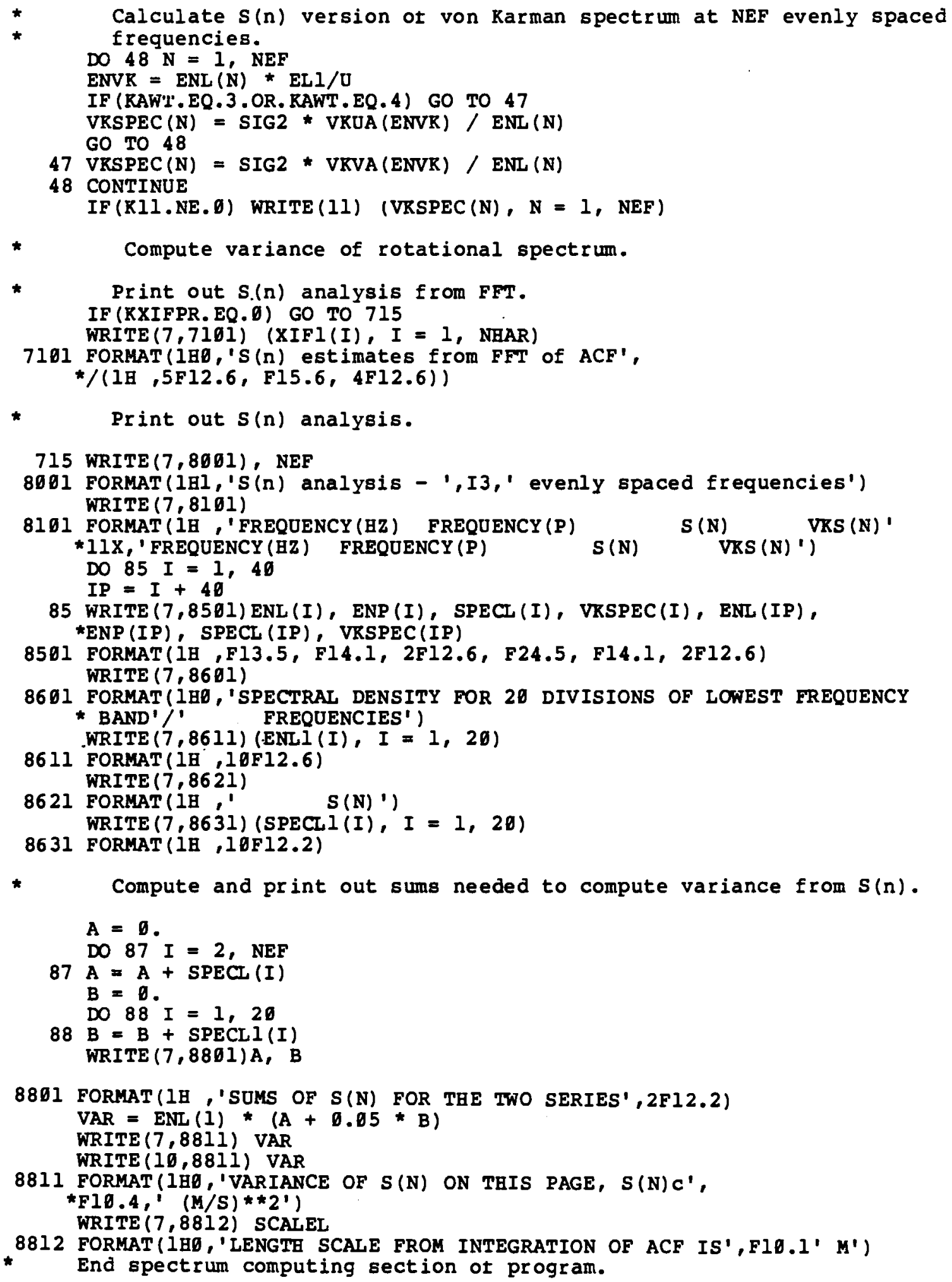




\begin{abstract}
Compute variance (energy) in the $1 P, 2 P, \ldots \ldots 6 P$ bands, where for example, the variance in the $1 P$ band is found by integrating from the 6 th through the l5th evenly spaced $S(n)$ harmonics. This is done for both the rotational spectrum SPECL(N) and the von Rarman spectrum VRSPEC(N). The first lop ending on Lable $\mathbf{8 8 2}$ performs this integration at frequencies below the IP band.
\end{abstract}

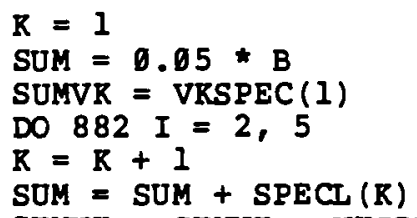

882 SOMVK $=$ SUMVR + VRSPEC $(R)$

$\operatorname{PVAR}(1)=S O M * 0.1 *$ ENØ

PRMS (l) = SQRT (PVAR (1))

PVARVR (1) = SUMVR *0.1 * ENO

DO $885 \mathrm{~J}=2,7$

SUM $=0$.

SUMVR $=0$.

DO $883 I=1,10$

$R=R+1$

IF (K.GT. NHARI) GO TO 884

SUM $=$ SUM + SPECL $(R)$

883 SUMVR $=$ SUMVR + VRSPEC $(R)$

$\operatorname{PVAR}(J)=S O M * 0.1$ * ENO

$884 \operatorname{PRMS}(J)=\operatorname{SQRT}(\operatorname{PVAR}(J))$

885 PVARVK $(J)=$ SUMVR * 0.1 EN

CALL RODAPRINT $(7,2)$

CALL RODAPRINT $(10,2)$

WRITE $(16,8851)$, ENO

WRITE $(16,8851)$ PVAR

WRITE $(16,8851)$ PVARVR

8851 FORMAT (1B ,F10.4, F15.4, 5F10.4)

C BEGIN DATA SIMULATING SECTION OF PROGRAH.

C Compute impulse reponse function using FFT.

896 IF (RBR. NE. $\theta$ ) GO TO 50

$\mathrm{XTEND}(1)=(0.0,1.0)$

DO $90 \mathrm{~J}=2$, JTCPL

$A=\operatorname{SQRT}(0.5 * \mathrm{XIFl}(\mathrm{J}) / \mathrm{DT})$

$B=0$.

XTEND $(J)=\operatorname{CMPLX}(A, B)$

$R=$ MMT $-J+2$

90 XTEND (R) = XTEND (J)

CALL COOLEY (XTEND,-MHT)

CALL CUOLEY (XTEND, MHT)

CALL CUOLEY (XTEND,

DO $9 I \mathrm{~J}=1$, MMTHALF

91 XIFl (J) = REAL (XTEND (J)) / CHMT

*

Write impulse response function to disc.

IF (R8.NE.0) WRITE (8) MMTHALF, (XIFI(I), I = 1, MMTHALF)

WRITE $(7,9211)$ (XIFI(I), I = 1, 100)

9211 FORMAT (li , 5F6.3, F9.3, 4F6.3, F10.3, 4F6.3, F9.3, 4F6.3) WRITE $(7,9221)$ NP

9221 FORMAT( $1 \mathrm{H} 0$, I6,' POINTS USED TO CREATE SIMULATED DATA')

CCCC

* This portion executes a convolution of impulse response function H'l 


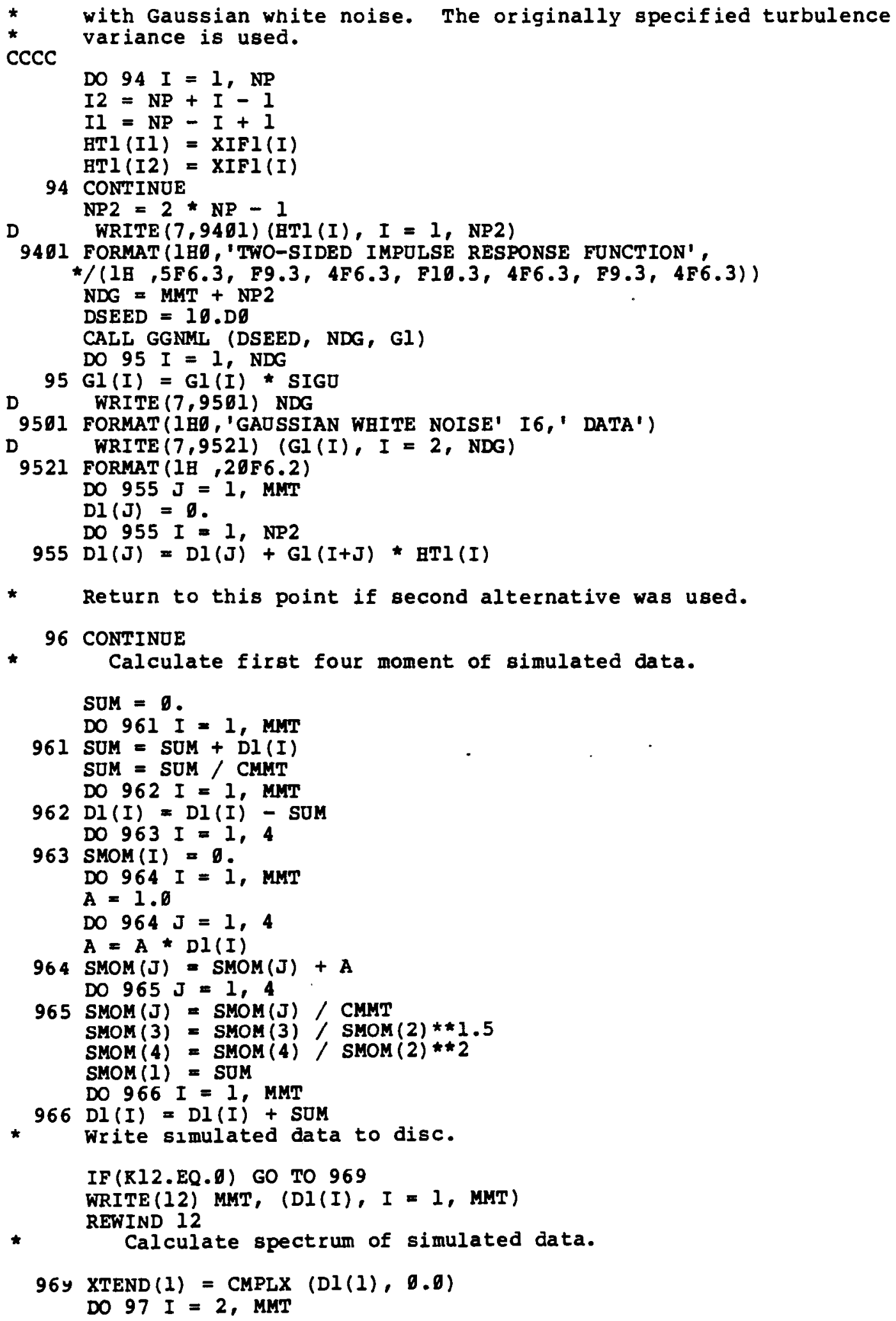


$97 \operatorname{XTEND}(I)=\operatorname{CMPLX}(D I(I), 0 . B)$

CALL COOLEY (XTEND, - MMT)

CALL CUOLEY (XTEND, MMT)

CALL CUOLEY (XTEND,

FAC $=2.0 * D T /$ CMMT

XIFI(1) = REAL (XTEND(1)) * FAC

XIFl(JTCPL) = REAL (XTEND (JTCPL)) * REAL (XTEND (JTCPL)) * FAC

9701 FORMAT(IH,'MHT, MMTEALF, JTCPL, ENø, FF, FAC AT 9701',

*3I 6, 2F10.4, E12.4)

VSUM $=0$.

DO $971 \mathrm{~J}=2$, MMTHALF

$\mathrm{IJ}=$ MMT $-\mathrm{J}+2$

ANI $=$ BALF $*(\operatorname{XTEND}(J)+$ CONJG $(X T E N D(I J)))$

$\operatorname{XIYl}(\mathrm{J})=\operatorname{ANI}$ * CONJG(ANI) * FAC

971 VSUM $=$ VSOM $+\operatorname{XIFI(J)}$

VSUM $=$ VSOM $* F F$

$\operatorname{PVAR2}(1)=0$.

$L D O=0.5 * E N \theta / F F$

DO $972 I=1$, LDO

972 PVAR2 (I) $=$ PVAR2 (I) + XIFI (I)

PVAR2 (1) $=$ PVAR2 (1) * FF

DO $974 \mathrm{~K}=1,6$

$I I=L D O+I$

$F R=R$

$R I=R+I$

$L D O=(F R+0.5) * E N \emptyset / F F$

$\operatorname{PVAR2}(R I)=0$.

DO $973 \mathrm{I}=\mathrm{Il}$, LDO

$973 \operatorname{PVAR2}(\mathrm{KI})=\operatorname{PVAR2}(\mathrm{RI})+\mathrm{XIFI}(\mathrm{I})$

97 PVAR2 (RI) = PVAR2(RI) * FF

WRITE $(7,9751)$ PVAR2

WRITE $(10,9751)$ PVAR2

$97 \supset 1$ FORMAT (IHQ, 'VARIANCES FOR FIRST HALF-P AND FOR 6P FROM

* SPECTRUM OF SIMULATED DATA, $S(n) r^{\prime}, / 1 \mathrm{H}$, F10.4, F15.4,

*5F10.4)

WRITE $(17,8851)$ ENB

WRITE $(17,8851)$ PVAR2

LPRXIFI $=5.0+2.0 *$ EN $6 / F F$

IF (LPRXIFI.GT.JTCPL) LPRXIFI = JTCPL

WRITE $(7,9801)(X I F 1(I), I=1$, LPRXIFI)

9801 FORMAT(IHI, 'SPECTRAL ESTIMATES FROM SIMULATED DATA', */(1日, IGFI2.4))

WRITE $(7,98 I 1)$ VSOM

WRITE $(10,9811)$ VSUM

9811 FORMAT (IBD, 'VARIANCE OF $S(N)$ I FROM SIMOLATED DATA',FI0.4) WRITE $(7,9812)$ SMOM(1), SMOM(2)

9812 FORMAT (1B,'SMOM(1), SMOM(2)', 2F10.4) WRITE $(7,9821)$ SMOM (3), SMOM(4)

WRITE $(16,9821)$ SMOM (3), SMOM (4)

9821 FORMAT (1B , 'SREWNESS AND KURTOSIS', 2F10.4)

IF (KBR. EQ. . ) $\operatorname{WRITE}(7,9831)$

9831 FORMAT(IBE,'FULL RANDOMIZING SIMULAITON - IMPOLSE RESPONSE * FUNCTION')

IF (KBR.NE. . ) WRITE $(7,9841)$

9841 FORMAT (1HE, 'HALF-RANDOMIZING SIMULATION - PEASE RANDOMIZED')

* Write $S(n)$ from simulated data to disc.

IF (K9.NE. Đ) WRITE(9) (XIFI(I), I = 1, NBAR)

REWIND 9

* Write ns(n) from simulated data to disc. 


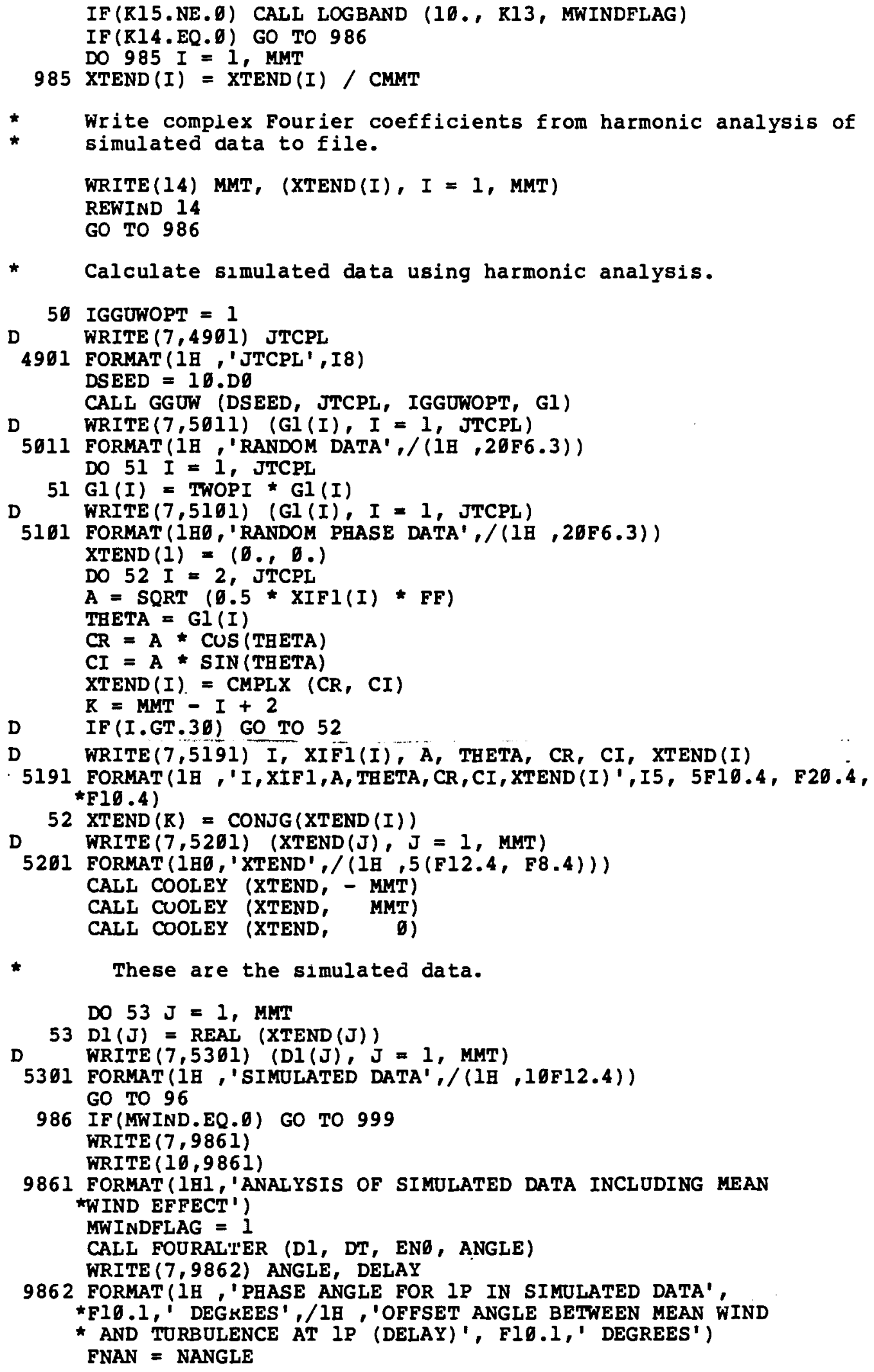




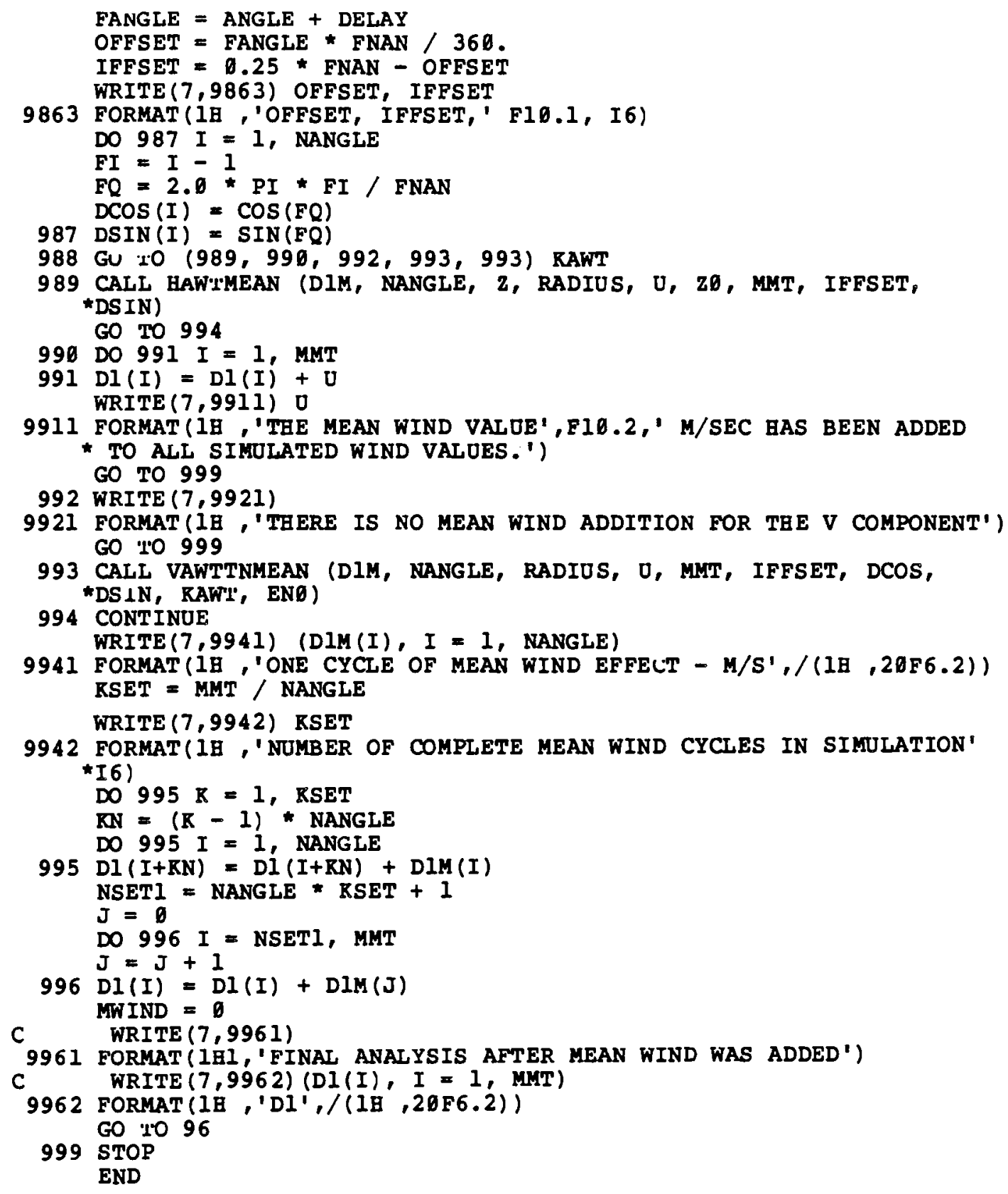




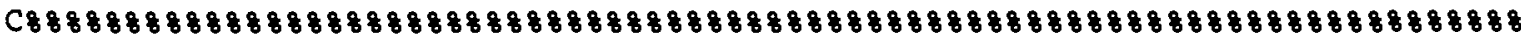

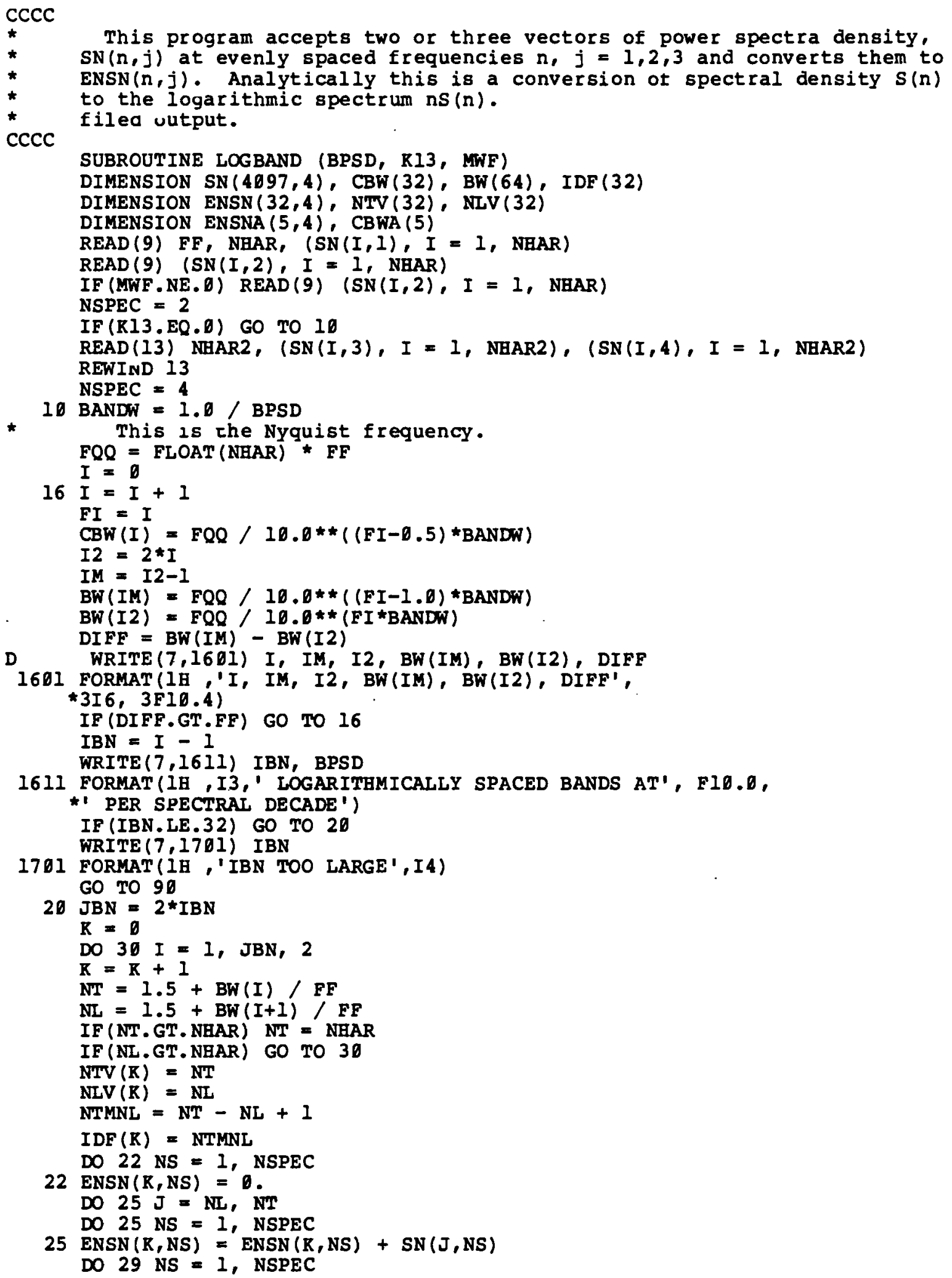




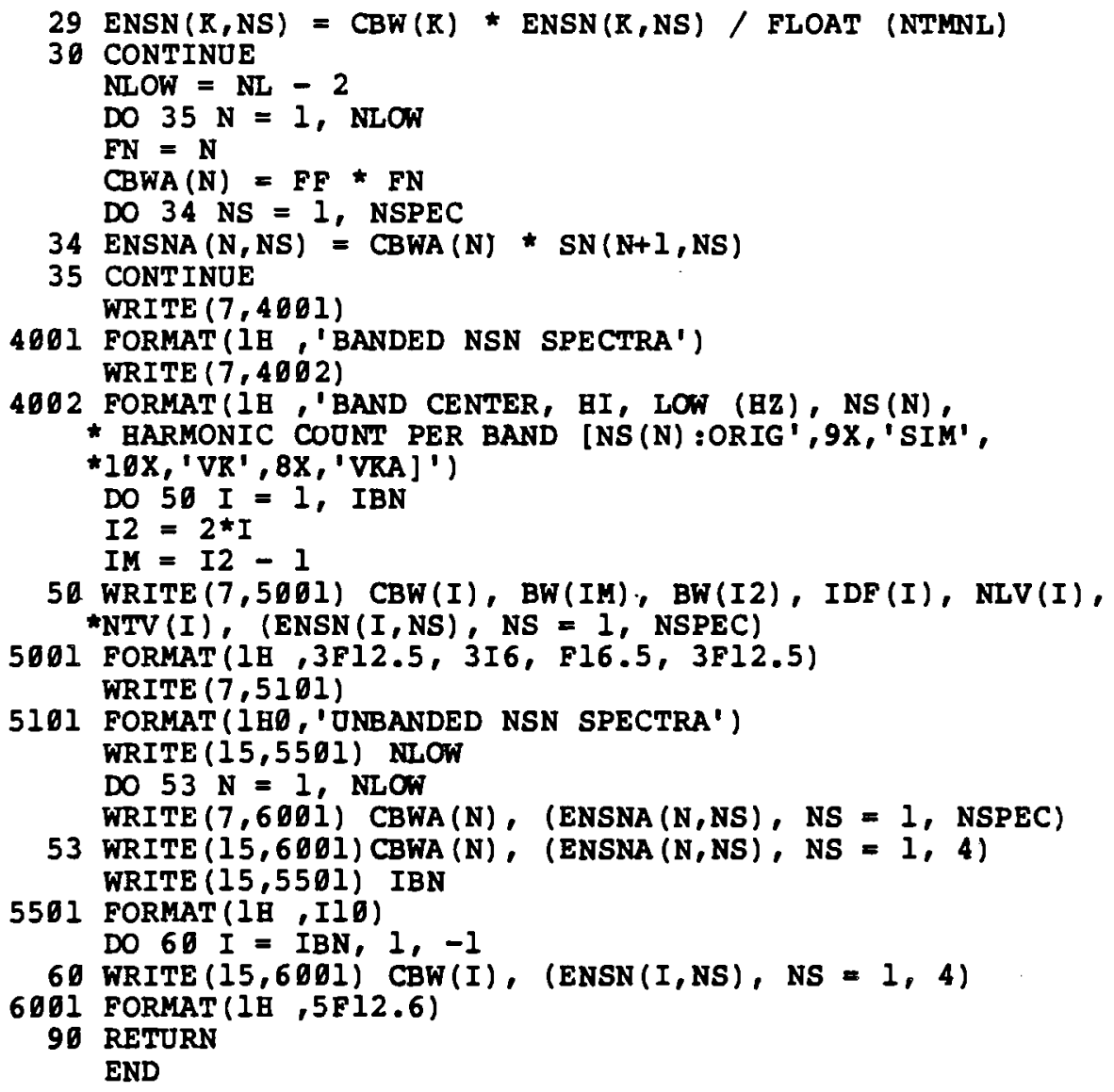




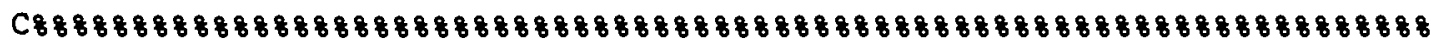

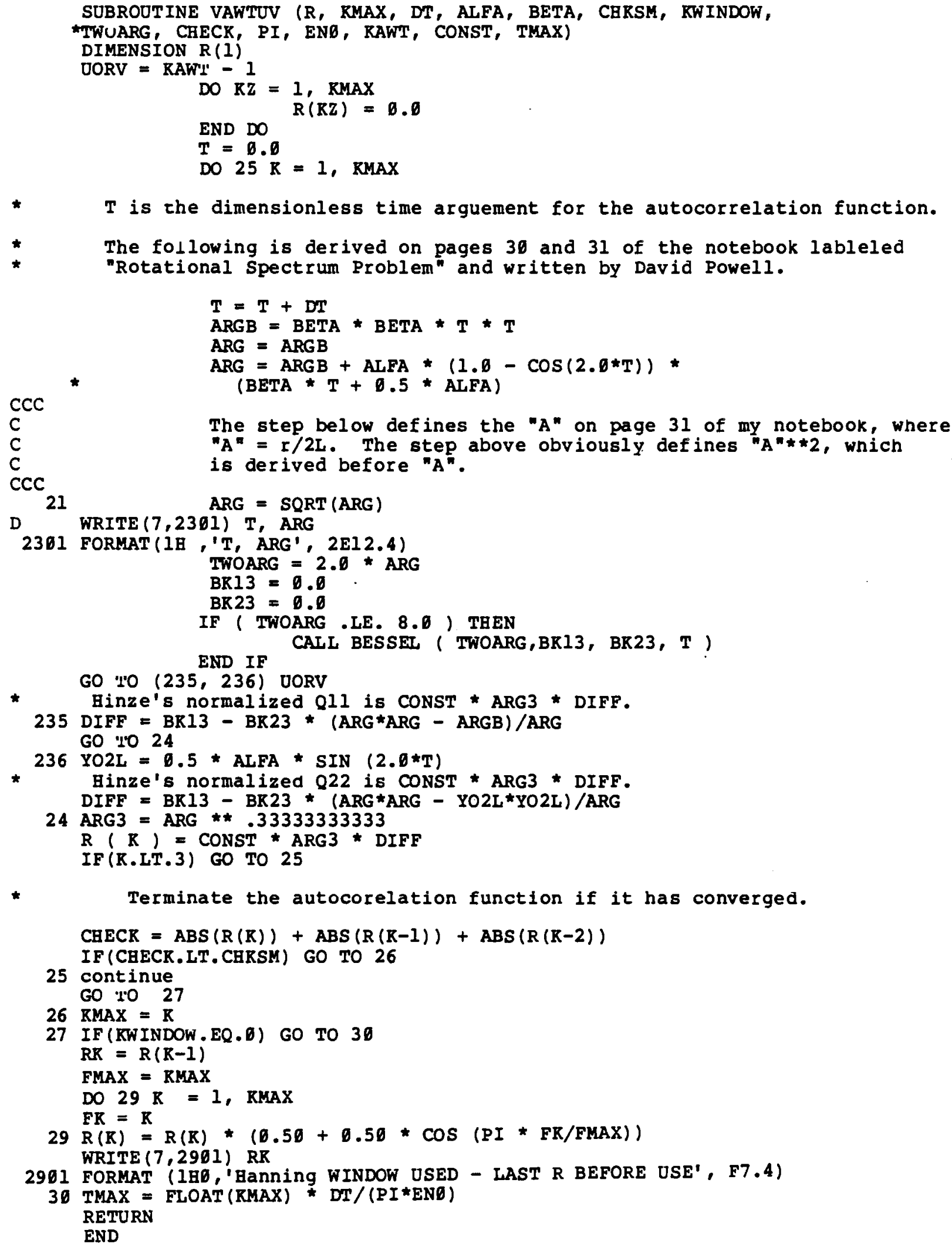




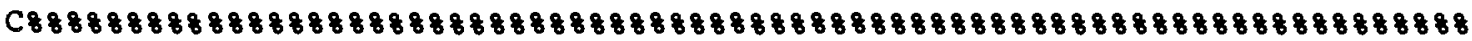

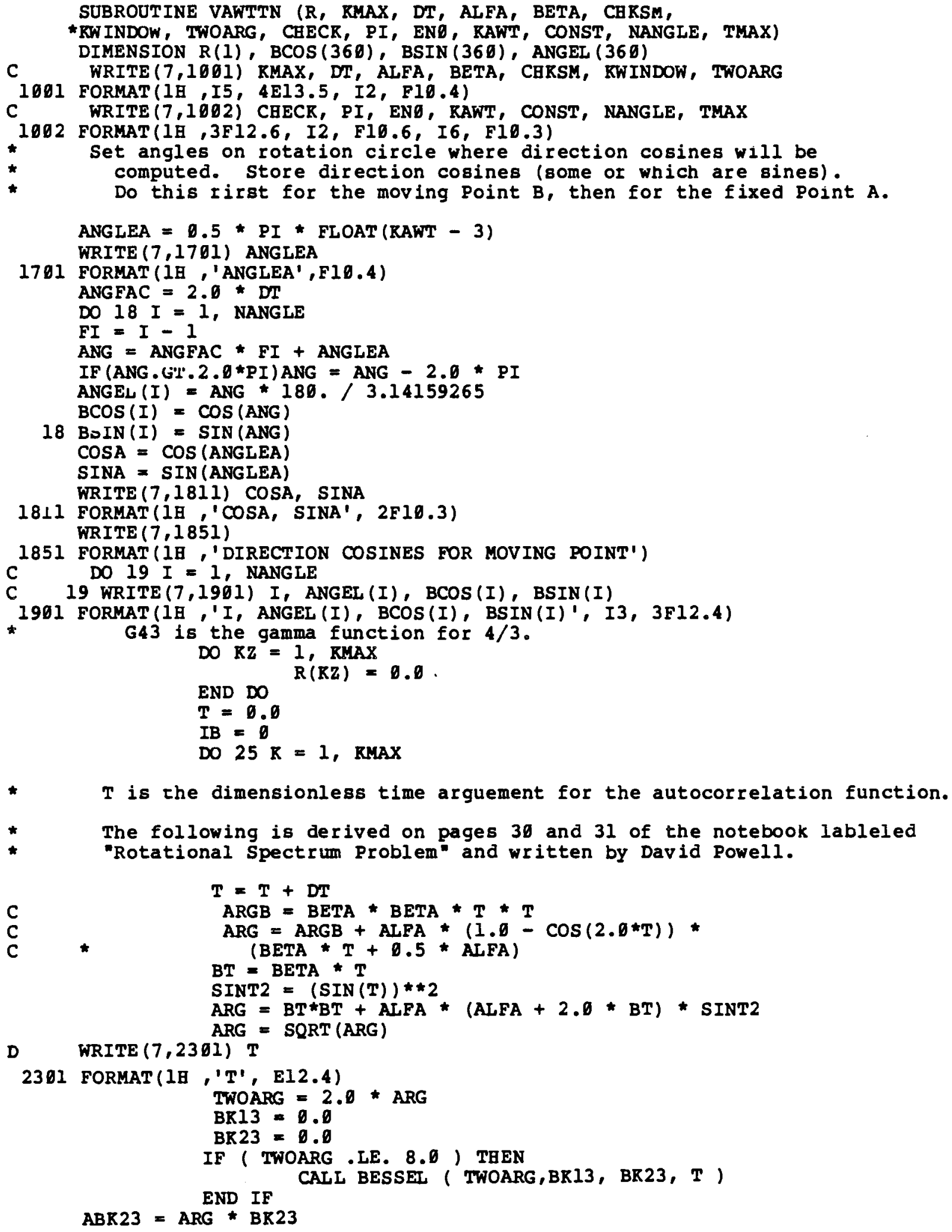




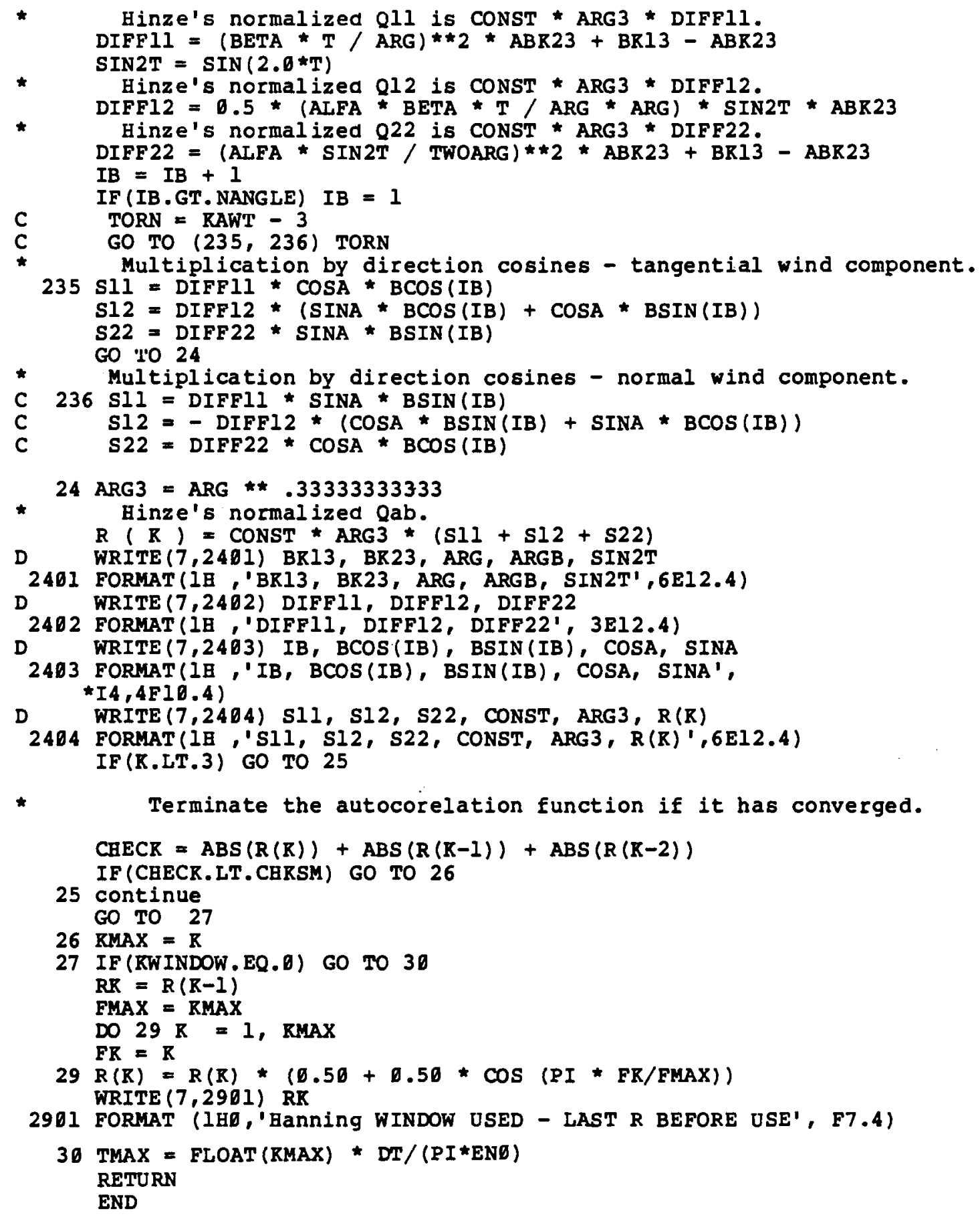


SUBROUTINE CUOLEY (A, NN)

$C$
$C$
$C$
$C$
$C$
$C$
$C$
$C$
$C$
$C$
$C$

PCF CKEATION DATE - 11 OCT 70, TIME 22.45.48

AU'HOR... JIM WINRELMAN, MODIFCATIONS FOR CDC 6600, MILT. SMITE

FAST FUURIER TRANSFORM FOR $N=2 \star \star L$

CALL THE SUBROUTINE FIRST WITH $N=-$ MAX (N) TO BE USED

A IS THE COMPLEX ARRAY OF OBSERVATIONS AND IS REPLACED

WITH A SCRAMBLED COMPLEX ARRAY OF ANSWERS

CALL THE SUBROUTINE WITH N= 0 TO ONSCRAMBLE THE ANSWER ARRAY TEE ARRAY TO BE UNSCRAMBLED MUST BE THE SAME SIZE AS TEE

LAST ARRAY TRANSFORMED
REFERENCE..COOLEY-TOREY, MATH OF COMP, APRIL 65, VOL 19 No 90

DIMENSION A(16384), W(8192)

COMPLEX $W, A, X$

COMPLEX CSQRT

IF (NN) $1,3,2$

$1 \mathrm{~N}=-\mathrm{NN}$

$W(1)=(1 . \theta, \theta . \theta)$

$X=(\theta . \theta, 1.0)$

$\mathrm{R}=\mathrm{I}$

$11 \mathrm{DO} 12 \mathrm{~J}=1, \mathrm{R}$

$M=J+R$

$12 W(M)=X \star W(J)$

$\mathrm{R}=\mathrm{R}+\mathrm{R}$

$X=C S Q R T(X)$

IF $((R+R)$.LT.N) GO TO 11

RETURN

$2 \mathrm{MM}=\mathrm{NN}$

$\mathrm{N}=\mathrm{NN}$

$L=1$

$23 \mathrm{M}=\mathrm{MM} / 2$

$I=1$

DO $21 \quad R=1, N$, MM

$M R=M+R-1$

DO $22 \mathrm{~J}=\mathrm{R}, \mathrm{MR}$

$J M=J+M$

$X=W(I) * A(J M)$

$A(J M)=A(J)-X$

$22 \quad A(J)=A(J)+X$

$21 \mathrm{I}=\mathrm{I}+1$

IF (M.LE.1) RETORN

$M M=M$

$\mathrm{L}=\mathrm{L}+1$

GO TO 23

3 DO $31 \mathrm{~J}=2, \mathrm{~N}-1$

MSR $=1$

$I=J-I$

$\mathrm{K}=\emptyset$

DO 33 II $=1, \mathrm{~L}$

$I M=I$. AND.MSR

IF (IM.GT.O) $R=R+1$

IF (II.EQ.L) GO TO 33

$\mathbf{R}=\operatorname{ISHFT}(\mathbb{R}, 1)$

33

MSR $=\operatorname{ISHFT}(M S K, 1)$

CONTINUE

$\mathbf{R}=\mathbf{R}+1$

IF (R.LE.J) GO TO 31

$X=A(J)$

$A(J)=A(R)$

$A(R)=X$

31 CONTINUE

RETURN

End 


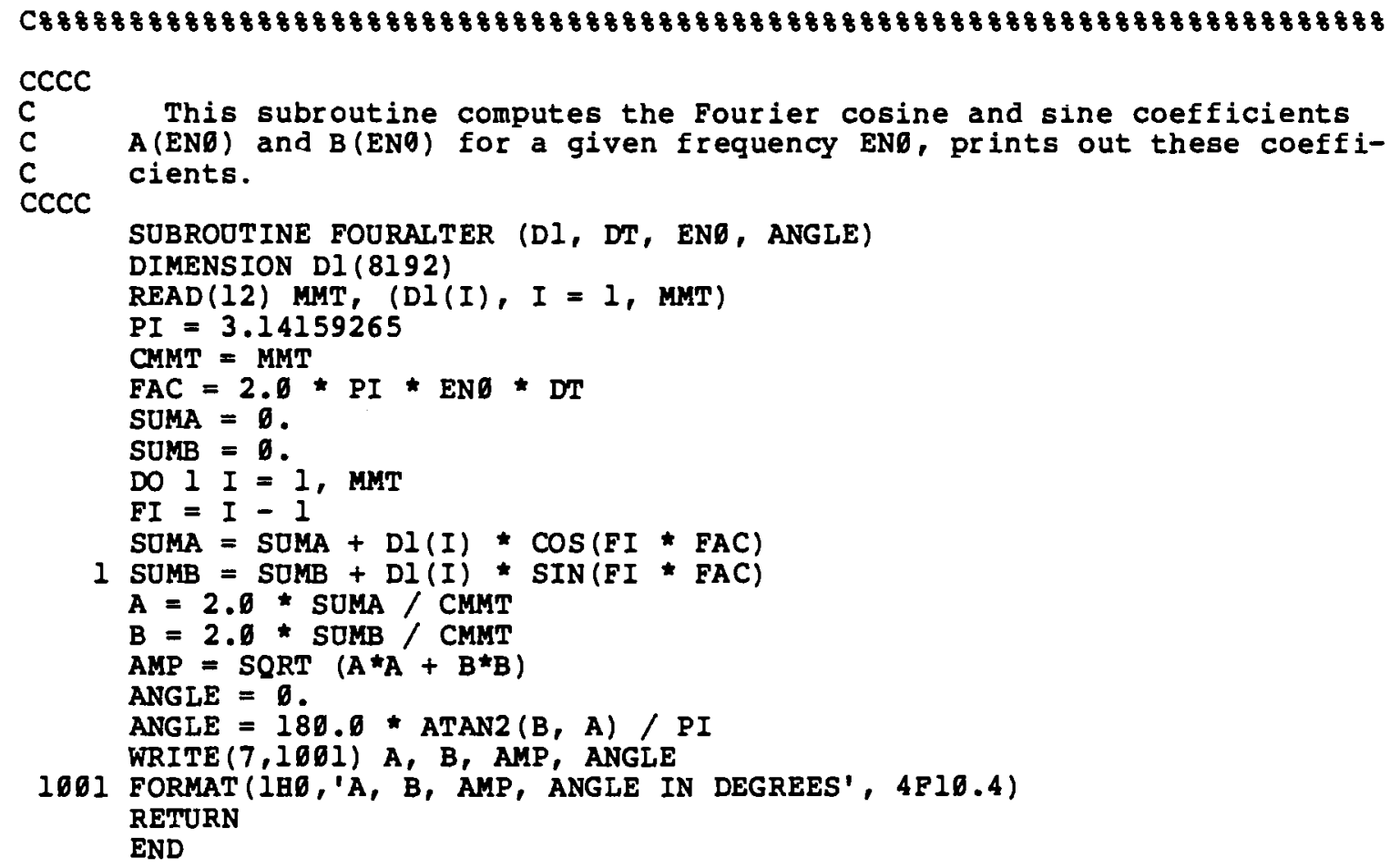




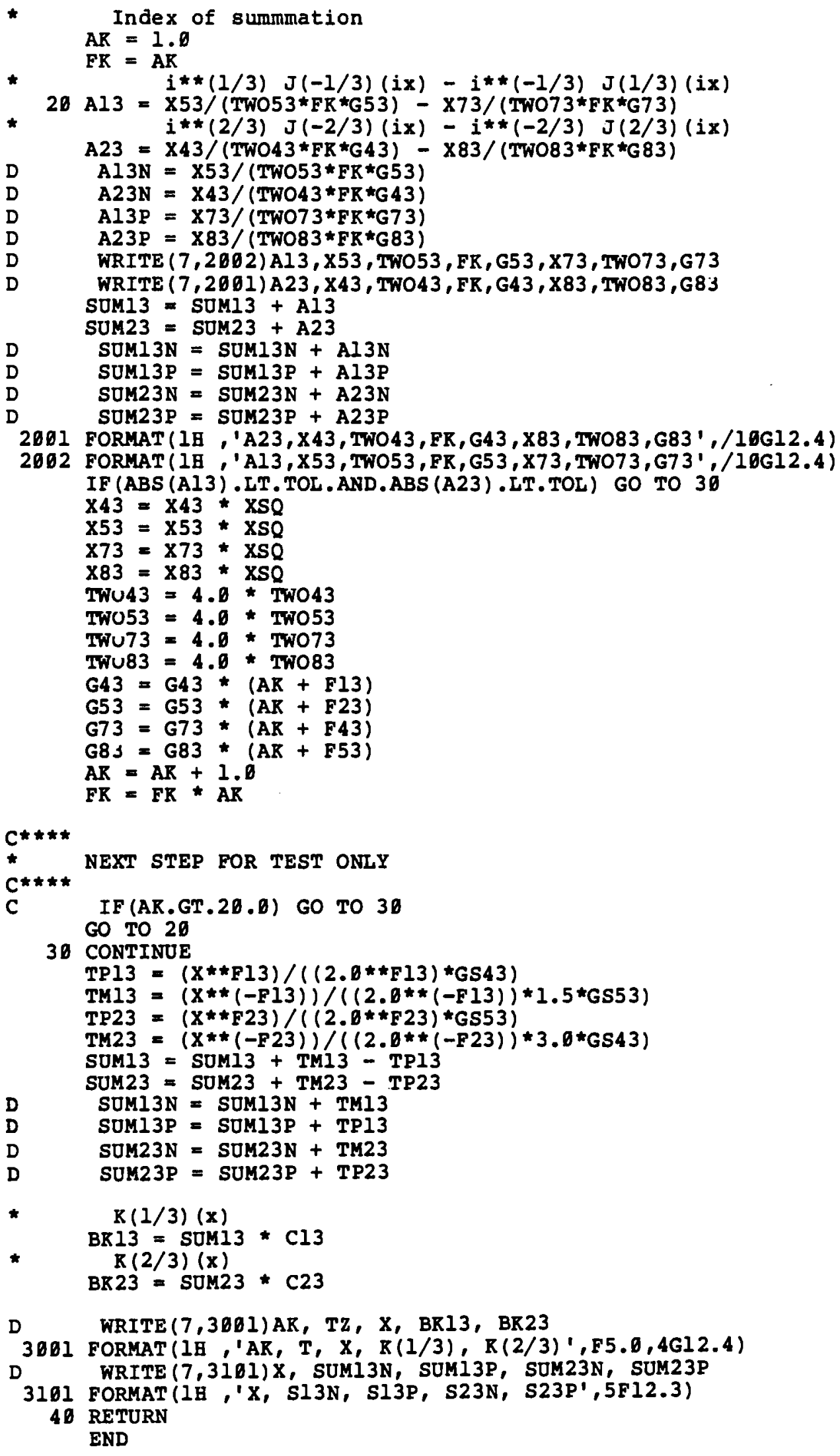


SOBRODTINE RODAPRINT(LU, KP)

COMMON MMT, MMTA, DT, DTA, DTND, DTAND, EN1, EN1ND, EN2, *EN2A, EN2ND, EN2AND, NANGLE, NANGLEA, RADIOS, ENQ, $z, 0$, *Z6, KSG, SIGU, SIGV, ELI, EL2, ILIAS, KNDOPT,

*KWINDUW, CHR, KMAX, NHAR, USTAR, ALFA, BETA, SIGU2,

* SIGV2, pVAR (7), PRMS (7), PVARVR(7)

IF (RP.NE.1) GO TO 40

WRITE (LO,1001) RADIUS

1601 FORMAT (1HQ, 'RADIUS OF ROTATION', F6.1,

*1 M')

WRITE (LU, 1051) ENE

1651 FORMAT ( 1 HQ, 'RATE OF ROTATION', FIl.4,' HZ')

WRITE (LO,1101) 2,20

1101 FORMAT (1HQ,' HOB BEIGHT', F14.1,' $M ', / 1 \mathrm{H}^{\prime}, '$ SURFACE

*RODGBNESS LENGTH', FI0.4,' $\mathrm{M}^{\prime}$ '

WRITE (LD,1151) U

1151 FORMAT (1H , 'MEAN WIND SPEED',F16.2,' M/S')

WRITE (LO,1201) SIGU, SIGV

1201 FORMAT ( 1 H, , 'TURBULENCE RMS VALOES', / $1 \mathrm{H}, 5 \mathrm{X}, ' \mathrm{U}$-COMPONENT',

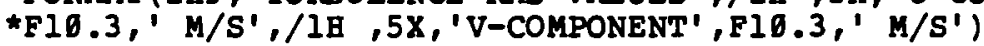
WRITE (LU,1301) SIGU2, SIGV2

1301 FORMAT ( $1 \mathrm{H} 9$, 'TORBDLENCE VARIANCES', $/ 1 \mathrm{~B}, 5 \mathrm{X},{ }^{\prime} \mathrm{U}$-COMPONENT', $\star$ Fl0.3,' $(M / S) \star \star 21, / 1 \mathrm{H}, 5 \mathrm{X}, \cdot \mathrm{V}$-COMPONENT', F10.3, $\star 1(M / S) * \star 2 !)$ WRITE (LU, 1401 ) USTAR

1401 FORMAT (1E0, 'FRICTION VELOCITY',F9.3,' M/S') WRITE (LU,1501) ELI, EL2

1561 FORMAT ( $1 \mathrm{H} 0, '$ 'TURBOLENCE INTEGRAL LENGTH SCALES',

*/1日 ,5X,' LONGITUDINAL ', F7.1,' $\mathrm{M}$ ',

*/1日 ,5X,'LATERAL ',F7.1,' M'; WRITE (LO, 1601) MMT

1601 FORMAT (1H0,' NUMBER DATA TO BE SIMULATED',I5) WRITE (LO,1761) DT

1701 FORMAT ( $1 \mathrm{H}$, 'DISCRETIZATION INTERVAL ',F13.4,' SEC') WRITE (LD, 1801) ILIAS

1801 FORMAT (1HQ, 'ALIAS FACTOR DEG $=360 . /$ FLOAT (NANGLE) WRITE (LD, 1901) DEG

1901 FORMAT(1H0,'ANGULAR DISCRETIZATION INTERVAL', F7.1, *1 DEGKEES') IF (KNDOPT. EQ. . $)$ WRITE (LD, 2001)

2001 FORMAT ( 1 Ho,'NANGLE WAS READ IN - DT WAS CALCULATED') IF (RNDOPT.NE. .) WRITE (LV, 2101)

2101 FORMAT ( $1 \mathrm{H} \theta$, 'DT WAS READ IN - NANGLE WAS CALCULATED') WRITE (LU, 2201) ALFA, BETA

2201 FORMAT ( $1 \mathrm{~B}$, 'ALFA, BETA', 2F12.4) WRITE (LU, 2301) RMAX, NHAR

2301 FORMAT (IHE, 'LIMIT ON MEMBERS OF AUTOCORRELATION FUNCTION', *I5,/1日 ,' NUMBER OF BARMONICS IN SPECTRA',I19,/1日, 'This is * also a comparison between number of harmonics in original * spectrum and reduced version.')

WRITE (LU, 246I) ENI

2461 FORMAT ( $1 \mathrm{H} 0$, ' EUNDAMENTAL FREQUENCY IS',F12.6,' HZ') WRITE (LU, 25BI) CER

2501 FORMAT(/1H,'MAX FINAL VALOE OF CORRELATION ACCEPTABLE WITHOUT * WINDUWING', F8.5) IF (LO.NE. 7) GO TO 50 WRITE (LU, 3001) 


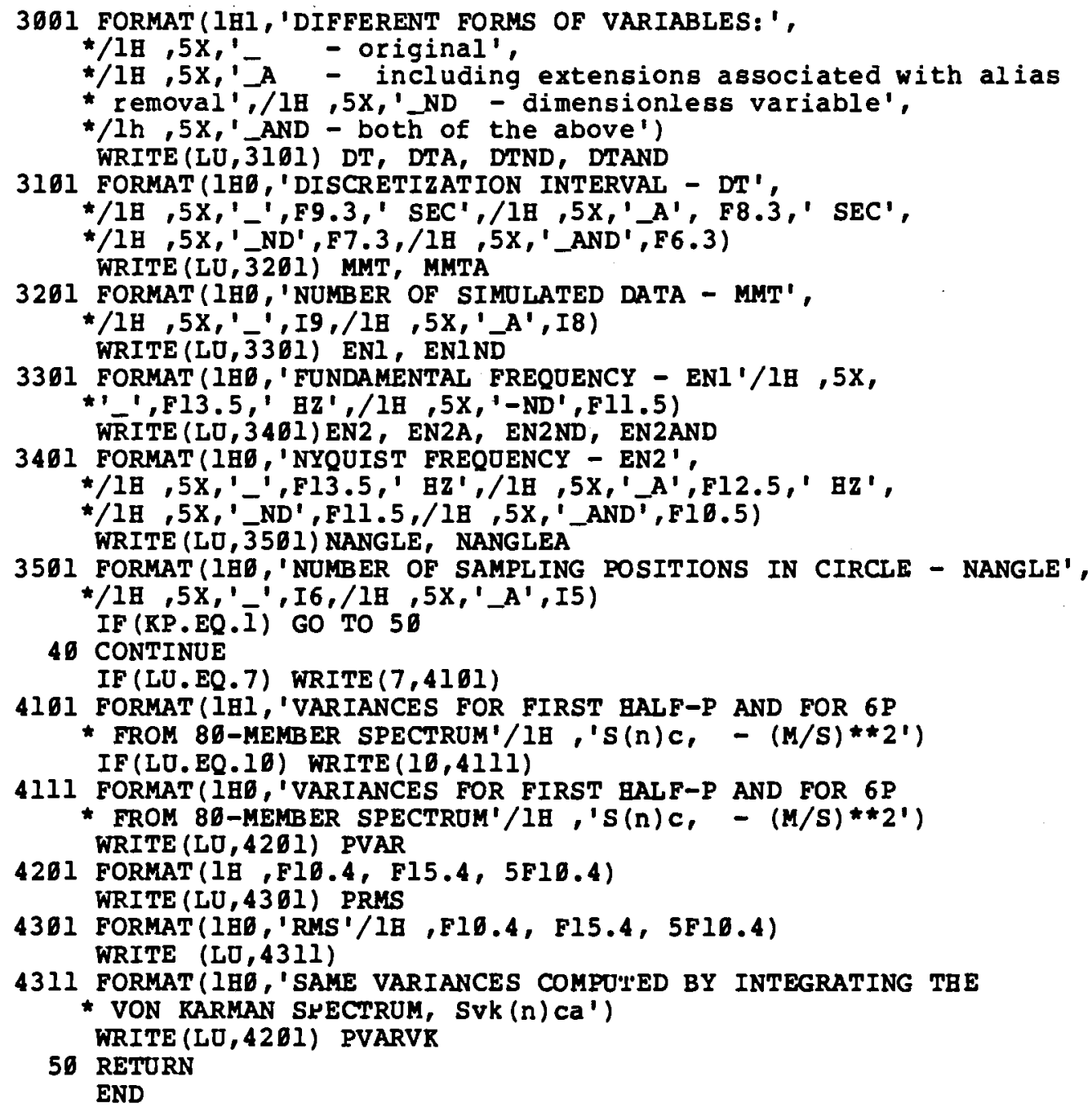




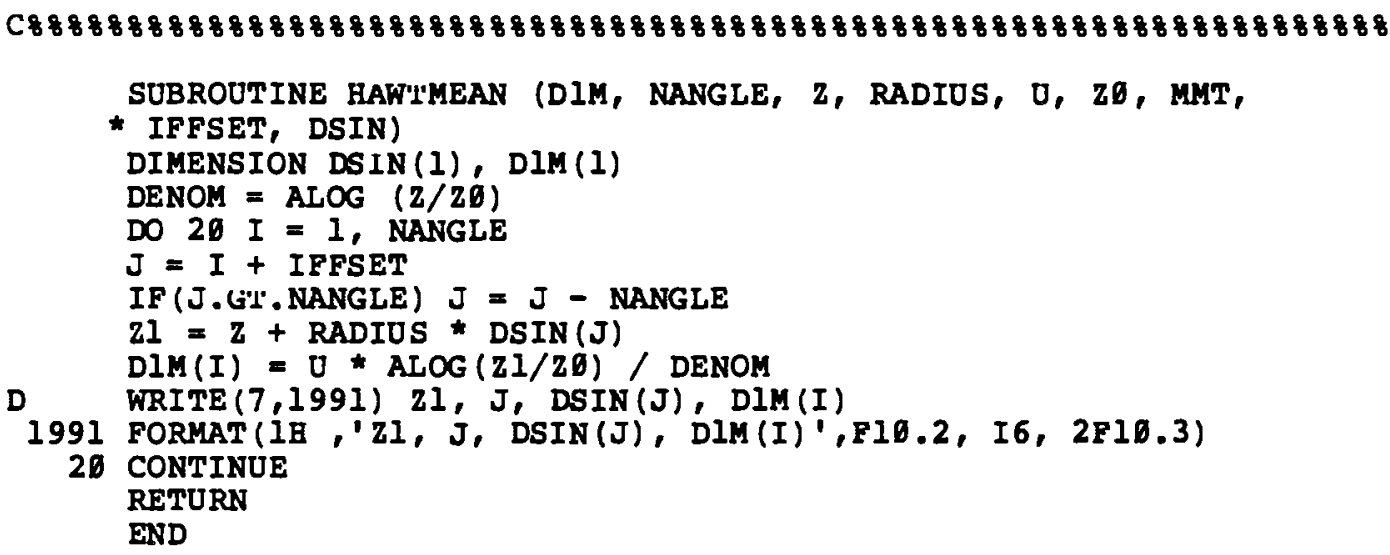




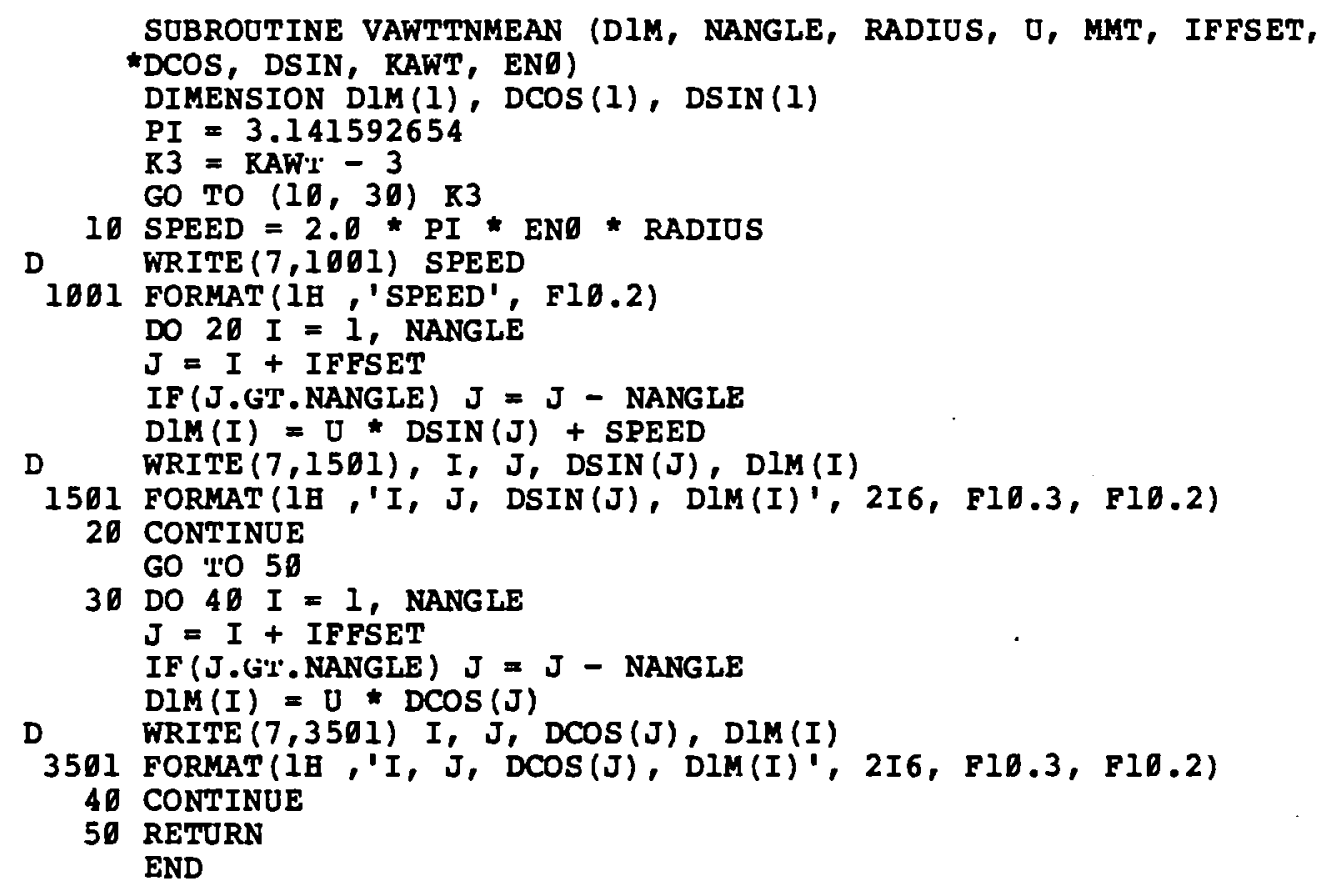





\section{A.2 GLOSSARY}

The following listing describes the commonly used variables in the program. Variables not listed are in one of three categories: 1) working or temporary variables defined and used within a small segment of the program, 2) generalized loop indices, or 3) modifications of basic variables, indicated by names ending with $A$, ND, or AND (see Section 3.3.1.1).

One helpful aspect of the glossary is that it gives the units of all variables. Of course, this depends on the units of such input variables as height and mean wind speed. The program assumes that lengths are in meters and times in seconds. Dimensionless variables are labeled 'dmls.'

\section{SCALARS}

\begin{tabular}{|c|c|c|c|}
\hline Symbol & Description & Unit & $\begin{array}{l}\text { Sub- } \\
\text { routine }\end{array}$ \\
\hline ALFA & $\begin{array}{l}\text { Blade radius/turbulence length scale } \\
\mathrm{L}_{y^{*}}\end{array}$ & dmls. & \\
\hline ALIAS & $\begin{array}{l}\text { Floating point ILIAS, alias reduction } \\
\text { factor. }\end{array}$ & dmls. & \\
\hline ANGLE & $\begin{array}{l}\text { Phase angle of } 1 P \text { harmonic in simulated } \\
\text { data. Zero value indicates a cosine wave. }\end{array}$ & deg & \\
\hline BETA & $\begin{array}{l}\text { Blade rotation rate/(mean wind speed } x \\
\text { turbulence length scale } L_{x} \text { ). }\end{array}$ & $\mathrm{dm} 1 \mathrm{~s}$. & \\
\hline BK13 & $\begin{array}{l}\text { Value of modified Bessel function of } 2 \text { nd } \\
\text { kind, } K(1 / 3) \text {. }\end{array}$ & dmls. & BESSEL \\
\hline BK23 & Same as above, but for $k(2 / 3)$. & $\mathrm{dmls}$. & BESSEL \\
\hline CHECK & Criterion for declaring acf convergent. & dmls. & \\
\hline CHK & $\begin{array}{l}\text { Read-in tolerance level defining conver- } \\
\text { gence of acf. }\end{array}$ & dmls. & \\
\hline CMMT & Floating point MMT. & $\mathrm{dmls}$. & \\
\hline
\end{tabular}




\begin{tabular}{|c|c|c|}
\hline Symbol & Description & Unit \\
\hline DSEED & $\begin{array}{l}\text { Parameter used in IMSL routine for gener- } \\
\text { ating uncorrelated random values evenly } \\
\text { spaced from zero to one. }\end{array}$ & dmis. \\
\hline DT & Discretization interval for simulated data. & $\sec$ \\
\hline EL1 & $\begin{array}{l}\text { Longitudinal integral length scale for } \\
u \text {-component turbulence, } L_{x} \text {. }\end{array}$ & $\mathrm{m}$ \\
\hline EL2 & $\begin{array}{l}\text { Lateral integral length scale for } \\
u \text {-component turbulence, } L_{y} \text {. }\end{array}$ & $\mathrm{m}$ \\
\hline EN & $\begin{array}{l}\text { Dimensional frequency argument for } \\
\text { von Karman spectrum. }\end{array}$ & $\mathrm{Hz}$ \\
\hline ENO & Blade rotation rate. & $\mathrm{Hz}$ \\
\hline EN1 & $\begin{array}{l}\text { Fundamental frequency of data: reciprocal } \\
\text { of total time span. }\end{array}$ & $\mathrm{Hz}$ \\
\hline EN2 & $\begin{array}{l}\text { Nyquist frequency of spectrum } S(n) r \text {, and } \\
\text { the spectrum of simulated data. }\end{array}$ & $\mathrm{Hz}$ \\
\hline ENVK & $\begin{array}{l}\text { Dimensionless frequency for von Karman } \\
\text { spectrum. }\end{array}$ & dmis. \\
\hline FAC & $\begin{array}{l}\text { Time factor converting Fourier squared } \\
\text { amplitudes to the one-sided spectral } \\
\text { density } S(n) \text {. }\end{array}$ & sec \\
\hline $\mathrm{FF}$ & $\begin{array}{l}\text { Fundamental frequency of spectral densities } \\
S(n)_{f}, S(n)_{r}, S v k(n)_{r} .\end{array}$ & $\mathrm{Hz}$ \\
\hline ILIAS & $\begin{array}{l}\text { Alias reduction factor. [If ILIAS }=4 \text {, } \\
1 / 4 \text { of the power spectrum } S(n)_{f} \text {, calcu- } \\
\text { lated from FFT of acf, is retained as } \\
\left.S(n)_{r} \cdot\right]\end{array}$ & dmis. \\
\hline JTCPL & $\begin{array}{l}\text { 1. Index of the last member of acf as it } \\
\text { is entered into the FFT process. }\end{array}$ & \\
\hline
\end{tabular}


JTCPL

(cont'd.)
2. Index of last member of $S(n)_{r}$ as it is entered into FFT process to compute impulse response function. Smaller value than above if ILIAS is greater than 1 .

3. Index of last value of $S(n)$ for simulated data. (Same value as in 2.)

4. Index of last value of random phase used to calculate simulated data. (Same value as in 2.)

$\mathrm{dmls}$.

K8

Option to write impulse response function to disk.

K9

Option to write $S(n)_{r}$ and spectrum of simulated data to disk. These spectra have half as many degrees of freedom as the simulated data have.

K11 Option to write 80 -member spectrum $S(n)_{C}$, $(0.1 \mathrm{P}, 0.2 \mathrm{P} \ldots 8 \mathrm{P})$ and corresponding altered von Karman spectrum to disk.

Option to write simulated data to file.

K13

Option to write von Karman spectra, original and altered, to file. These spectra have half as many degrees of freedom as the simulated data have.

K14 Option to write complex Fourier coefficients of transform of simulated data to file. K15 Option to calculate banded $n S(n)$ spectra for for simulated data; also does so for the von Karman spectra stored if $\mathrm{K} 13$ does not equal zero. 
KAWT

Simulation choice option:

1) HAWT u-component

2) VAWT u-component

3) VAWT $v$-component

4) VAWT tangential component

5) VAWT radial component.

KBR

Option for calculation method for simulated data:

0) Convolution integral of impulse response function with Gaussian white noise.

1) Fourier transform of amplitudes from spectral harmonics and random phase.

KEL Option for length scales EL1 and EL2:

0) Let program calculate them.

1) Read them in.

KMAX Maximum number of members allowed in acf. KNDOPT Option governing specification of discretization interval:

0) Specify angular value in degrees.

1) Specify time value in seconds.

KSERIAL Alphameric serial number for run, five characters.

KSG Option for SIGU and SIGV.

0) Let program calculate them, isotropically.

1) Read them in.

KWINDOW Option to multiply acf by Hamming window values.

0) Do not use window.

1) Use window. 
MMT

Number of simulated data. MMT must be $2^{\mathrm{N}}$, where iv is an integer.

NANGLE

Discretization interval in terms of number of angular divisions of rotational circle.

dmls.

NDG

Number of degrees of freedom in Gaussian white noise.

dmls.

NEF

Number of frequencies used in spectra $S(n)_{C}$ and corresponding von Karman spectra where frequency spacing interval is $0.1 \mathrm{P}$.

dmls.

NHAR

Number of harmonics (degrees of freedom)

in spectrum $S(n)_{r}$ and corresponding

von Karman spectra. $($ NHAR $=$ MMT/2.)

dmls.

NP

Arbitrary number of points to be used on one side of the two-sided impulse response function, not counting central value at zero argument.

dmls.

OMEGA

Blade rotation rate.

radians/sec

PI

3.141592654

dmls.

RADIUS

Radius of rotation, blade radius.

m

SIG2

SIGU2 or SIGV2, as is appropriate. If SIGU

and SIGV are calculated internally, they

are equal.

$(\mathrm{m} / \mathrm{s})^{2}$

SIGU

Rms of u-component turbulence.

$\mathrm{m} / \mathrm{s}$

SIGU2

Variance of $u$-component turbulence.

$(\mathrm{m} / \mathrm{s})^{2}$

SIGV

Rms of $v$-component turbulence.

$\mathrm{m} / \mathrm{s}$

SIGV2

Variance of $v$-component turbulence.

$(\mathrm{m} / \mathrm{s})^{2}$

$\mathrm{T}$

Dimensionless running time used in calculation of acf and in the cosine integration of the acf to obtain $S(n)_{c}$.

dmls. 


\begin{tabular}{|c|c|c|c|}
\hline Symbol & Description & Unit & $\begin{array}{l}\text { Sub- } \\
\text { routine }\end{array}$ \\
\hline THETA & Angle argument in phase angle vector. & radians & \\
\hline TMAX & Length of acf in seconds. & $\sec$ & \\
\hline TWOARG & Argument of calculated Bessel functions. & dmls. & \\
\hline$u$ & Mean wind speed at height $Z$. & $\mathrm{m} / \mathrm{s}$ & \\
\hline USTAR & Friction velocity. & $\mathrm{m} / \mathrm{s}$ & \\
\hline USTAR2 & Square of friction velocity. & $(m / s)^{2}$ & \\
\hline VAR & Variance from integrating $S(n)_{c^{\circ}}$ & $(m / s)^{2}$ & \\
\hline VSUM & $\begin{array}{l}\text { 1. Variance from integrating } S(n)_{r} \text {, } \\
\text { 2. Variance from integrating } S(n)_{r} \text { of } \\
\text { simulated data. }\end{array}$ & $\begin{array}{l}(\mathrm{m} / \mathrm{s})^{2} \\
(\mathrm{~m} / \mathrm{s})^{2}\end{array}$ & \\
\hline Z & Simulated wind turbine hub height. & $\mathrm{m}$ & \\
\hline 20 & $\begin{array}{l}\text { Surface roughness length. } \\
\qquad \text { ARRAYS }\end{array}$ & $\mathrm{m}$ & \\
\hline $\mathrm{D} 1(\mathrm{I})$ & Final simulated wind data. & $\mathrm{m} / \mathrm{s}$ & \\
\hline $\operatorname{D1M}(\mathrm{I})$ & One cycle of simulated mean wind effect. & $\mathrm{m} / \mathrm{s}$ & \\
\hline $\operatorname{ENL}(N)$ & $\begin{array}{l}80 \text { linearly spaced frequencies at interval } \\
\text { of } 0.1 P \text { for spectral density } \operatorname{SPECL}(N) \text {. }\end{array}$ & $\mathrm{Hz}$ & \\
\hline $\operatorname{ENL1}(N)$ & $\begin{array}{l}20 \text { linearly spaced frequencies at interval } \\
\text { of } 0.005 \mathrm{P} \text { for spectral density } \operatorname{SPECLI}(\mathrm{N}) \text {. }\end{array}$ & $\mathrm{Hz}$ & \\
\hline $\operatorname{ENP}(N)$ & $\begin{array}{l}\text { Same as } \operatorname{ENL}(N) \text { but numbered in } P \text { units } \\
\text { (harmonics), i.e., } 0.1,0.2, \ldots 8.0 \text {. }\end{array}$ & $P$ & \\
\hline $\mathrm{G} 1(\mathrm{I})$ & $\begin{array}{l}\text { Gaussian white noise vector of unit } \\
\text { variance. }\end{array}$ & dmls. & \\
\hline $\mathrm{HT} 1$ ( I ) & $\begin{array}{l}\text { Two sided impulse response function. } \\
\text { Mathematically, this is } h(t) \Delta t \text { where } h(t) \\
\text { is a true impulse response function. }\end{array}$ & $\mathrm{m} / \mathrm{s}$ & \\
\hline
\end{tabular}


$\operatorname{KAWTER}(C) \star 30 \quad$ Alphameric array indicating type of simulation.

$\operatorname{PRMS}(M) \quad$ Square root of $\operatorname{PVAR}(M)$.

$\mathrm{m} / \mathrm{s}$

$\operatorname{PVAR}(M) \quad$ Variance in each of the harmonic spikes of the rotational spectrum. PVAR(1) is variance of first $0.5 P$; PVAR(2) is variance of first spike, etc. This version is calculated by integrating $\operatorname{SPECL}(N)$. $(\mathrm{m} / \mathrm{s})^{2}$

PVARVK(M) Variances found by integrating over corresponding frequency ranges of von Karman spectrum. $(\mathrm{m} / \mathrm{s})^{2}$

PVAR2(M) Same as PVAR(M) but calculated by integrating $X \operatorname{IF} 1(N)$.

Autocorrelation function incorporating rotational feature. dm1s.

$R P(T S)$ Evenly spaced subset of values from $R(T)$ selected for printing convenience. $R P$ is not used analyticaliy. dmis.

$\operatorname{SMOM}(4)$ Mean, variance, skewness, kurtosis of simulated data.

$\operatorname{SPECL}(N) \quad$ Spectral density at 80 frequencies, $0.1 \mathrm{P}$, 0.2P...8.0, of simulated data. SPECL is calculated by direct cosine integration of $R(T)$.

SPECL1(N) Same as SPECL(N) but for the 20 frequencies $(0.005,0.01 \ldots .0 .1) P$.

VKSPEC(N) Von Karman spectrum for same frequencies as $\operatorname{SPECL}(N)$.

$X \operatorname{IF} 1(N)$ Spectral density $S(n)$ calculated by FFT of $R(T)$, where fundamental frequency is reciprocal of time length of data set. 
XTEND(K) Input complex vector for FFT.

$\operatorname{XVK}(\mathrm{N})$

Von Karman spectrum corresponding to XIF1.

$\left(m^{2} / s\right)$

$\operatorname{XVKA}(N)$

Altered von Karman spectrum corresponding to XIF1. 


\section{A.3 TEST CASE}

VAWT TANGENTIAL SIMULATION

SERIAL NUMBER 07461

RADIUS OF ROTATION $8.3 \mathrm{M}$

RATE OF ROTATION $1.0000 \mathrm{HZ}$

HUB HEIGHT $16.7 \mathrm{M}$

SURFACE KOUGHNESS LENGTH

MEAN WIND SPEED $10.00 \mathrm{M} / \mathrm{S}$

TURBULENCE KMS VALUES

$\begin{array}{ll}\text { U-COMPONENT } & 1.652 \mathrm{M} / \mathrm{S} \\ \mathrm{V} \text {-COMPONENT } & 1.652 \mathrm{M} / \mathrm{S}\end{array}$

TURBULENCE VARIANCES

$$
\begin{array}{lll}
\text { U-COMPONENT } & 2.729(\mathrm{M} / \mathrm{S}) \star \star 2 \\
\mathrm{~V}-\mathrm{COMPONENT} & 2.729(\mathrm{M} / \mathrm{S}) \star \star 2
\end{array}
$$

FRICTION VELOCITY $0.688 \mathrm{M} / \mathrm{S}$

TURBULENCE INTEGRAL LENGTH SCALES

$$
\begin{array}{ll}
\text { LONGITUDINAL } & 70.1 \mathrm{M} \\
\text { LATERAL } & 28.1 \mathrm{M}
\end{array}
$$

NUMBER DATA TO BE SIMULATED 1024

DISCKETIZATION INTERVAL

$0.017 \mathrm{SEC}$

ALIAS FACTOR

ANGULAR DISCKETIZATION INTERVAL 15.0 DEGREES

NANGLE WAS READ IN - DT WAS CALCULATED
ALFA, BETA
0.2958
0.0227

LIMIT ON MEMBERS OF AUTOCORRELATION FUNCTION 2048

NUMBER OF HARMONICS IN SPECTRA

$$
512
$$

This is also a comparison between number of harmonics in original spectrum and reduced version.

FUNDAMENTAL FREQUENCY IS $0.023438 \mathrm{~Hz}$

MAX FINAL VALUE OF CORRELATION ACCEPTABLE WITHOUT WINDOWING 
DIFFERENT FORMS UF VARIABLES:

- original

A - including extensions associated with allas removal

ND - dimensionless variable

AND - both of the above

DISCKETIZATION INTERVAL - DT

- $\quad 0.042$ SEC

-ND

AND 0.033

NUMBER OF SIMULATED DATA - MMT

$\begin{array}{rr}- & 1824 \\ - & 4096\end{array}$

FUNDAMENTAL FREQUENCY - ENI

- $0.02344 \mathrm{HZ}$

NYOUIST FREOUENCY - EN2

$\begin{array}{r}\text { A } \\ \text { A } \\ \hline\end{array}$

ND $\quad 3.81972$

1
1
0

NUMBER OF SAMPLING POSITIONS IN CIRCLE - NANGLE

A $\quad 24$

ANGLEA $\vec{A} \quad 1.5708$

COSA, SINA 1.0000

DIRECTION COSINES FOR MOVING POINT

Hanning WINDOW USED - LAST R BEFORE USE- 0.0004

\begin{tabular}{|c|c|c|c|c|c|c|c|c|c|c|c|c|c|c|}
\hline $\begin{array}{r}\text { AU'OOCOR } \\
0.9307 \\
0.3079 \\
-0.1271 \\
-0.2300 \\
-0.1908 \\
0.0801 \\
0.5785 \\
0.4363 \\
-0.0019 \\
-0.1527 \\
-0.1567 \\
-0.0508 \\
0.2746 \\
0.4162 \\
0.0997\end{array}$ & $\begin{array}{r}\text { RELATION } \\
0.8880 \\
0.2679 \\
-0.1422 \\
-0.2309 \\
-0.1824 \\
0.1101 \\
0.6017 \\
0.4028 \\
-0.0209 \\
-0.1553 \\
-0.1545 \\
-0.0359 \\
0.2991 \\
0.4027 \\
0.0798\end{array}$ & $\begin{array}{r}\text { FUNCTION } \\
0.8483 \\
0.2290 \\
-0.1556 \\
-0.2313 \\
-0.1728 \\
0.1413 \\
0.6205 \\
0.3689 \\
-0.0384 \\
-0.1575 \\
-0.1519 \\
-0.0198 \\
0.3228 \\
0.3868 \\
0.0610\end{array}$ & $\begin{array}{r}906 \\
0.8091 \\
0.1914 \\
-0.1676 \\
-0.2313 \\
-0.1620 \\
0.1738 \\
0.6343 \\
0.3350 \\
-0.0545 \\
-0.1592 \\
-0.1488 \\
-0.0025 \\
0.3451 \\
0.3688 \\
0.0432\end{array}$ & $\begin{array}{r}\text { steps } \\
0.7695 \\
0.1553 \\
-0.1782 \\
-0.2309 \\
-0.1500 \\
0.2074 \\
0.6427 \\
0.3014 \\
-0.0690 \\
-0.1606 \\
-0.1451 \\
0.0160 \\
0.3659 \\
0.3490 \\
0.0266\end{array}$ & $\begin{array}{r}9.44 \\
0.7293 \\
0.1207 \\
-0.1875 \\
-0.2301 \\
-0.1366 \\
0.2418 \\
0.6457 \\
0.2682 \\
-0.0822 \\
-0.1616 \\
-0.1408 \\
0.0356 \\
0.3847 \\
0.3278 \\
0.0112\end{array}$ & $\begin{array}{r}\text { seconds } \\
0.6883 \\
0.0878 \\
-0.1956 \\
-0.2289 \\
-0.1218 \\
0.2770 \\
0.6433 \\
0.2358 \\
-0.0940 \\
-0.1622 \\
-0.1359 \\
0.0563 \\
0.4013 \\
0.3055 \\
-0.0031\end{array}$ & $\begin{array}{r}0.6467 \\
0.0566 \\
-0.2027 \\
-0.2272 \\
-0.1055 \\
0.3127 \\
0.6356 \\
0.2042 \\
-0.1046 \\
-0.1627 \\
-0.1302 \\
0.0780 \\
0.4153 \\
0.2824 \\
-0.0162\end{array}$ & $\begin{array}{r}0.6044 \\
0.0272 \\
-0.0087 \\
-0.2250 \\
-0.0878 \\
0.3487 \\
0.6228 \\
0.1737 \\
-0.1139 \\
-0.1628 \\
-0.1237 \\
0.1097 \\
0.4264 \\
0.2588 \\
-0.0282\end{array}$ & $\begin{array}{r}0.5617 \\
-0.0004 \\
-0.2138 \\
-0.2223 \\
-0.0685 \\
0.3848 \\
0.6054 \\
0.1444 \\
-0.1222 \\
-0.1627 \\
-0.1163 \\
0.1243 \\
0.4345 \\
0.2350 \\
-0.0390\end{array}$ & $\begin{array}{r}0.5188 \\
-0.0261 \\
-0.2181 \\
-0.2190 \\
-0.0416 \\
0.4205 \\
0.5838 \\
0.1164 \\
-0.1294 \\
-0.1624 \\
-0.1080 \\
0.1486 \\
0.4395 \\
0.2113 \\
-0.0488\end{array}$ & $\begin{array}{r}0.4759 \\
-0.0499 \\
-0.2217 \\
-0.2149 \\
-0.0251 \\
0.4555 \\
0.5587 \\
0.0897 \\
-0.1356 \\
-0.1618 \\
-0.0988 \\
0.1734 \\
0.4411 \\
0.1877 \\
-0.0576\end{array}$ & $\begin{array}{r}0.4331 \\
-0.0719 \\
-0.2246 \\
-0.2102 \\
-0.0011 \\
0.4894 \\
0.5309 \\
0.0646 \\
-0.1410 \\
-0.1610 \\
-0.0884 \\
0.1987 \\
0.4396 \\
0.1647 \\
-0.0654\end{array}$ & $\begin{array}{r}0.3907 \\
-0.0921 \\
-0.2269 \\
-0.2047 \\
0.0245 \\
0.5216 \\
0.5008 \\
0.0409 \\
-0.1456 \\
-0.1599 \\
-0.0170 \\
0.0241 \\
0.4348 \\
0.1422 \\
-0.0122\end{array}$ & $\begin{array}{r}0.3489 \\
-0.1104 \\
-0.2287 \\
-0.1982 \\
0.0516 \\
0.5516 \\
0.4692 \\
0.0187 \\
-0.1494 \\
-0.1584 \\
-0.0645 \\
0.2495 \\
0.4270 \\
0.1205 \\
-0.0782\end{array}$ \\
\hline
\end{tabular}




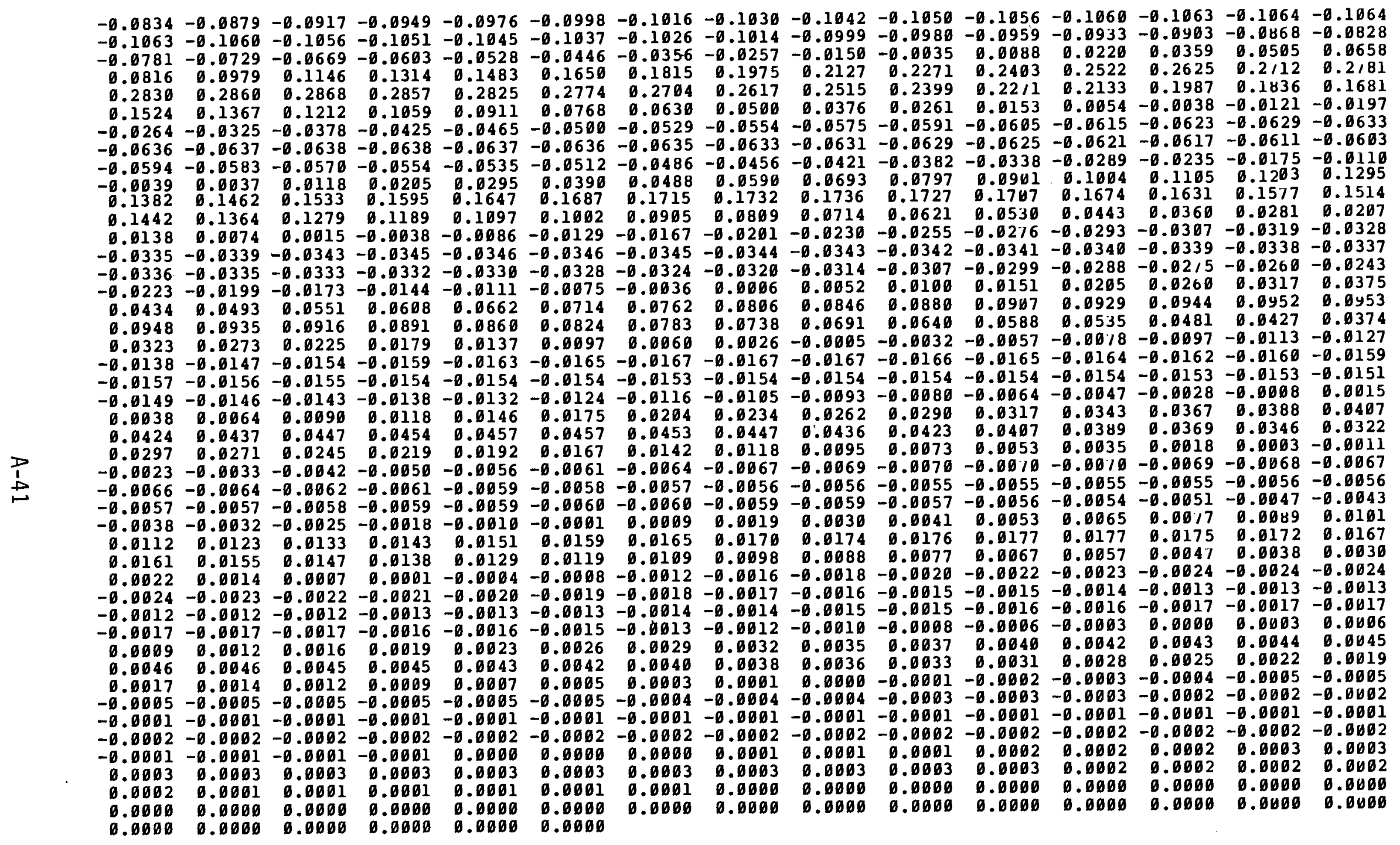

VARIANCE YROM INTEGRATION OF ROTATIONAL S(M) COMPUTED BY FFT OF ACF $2.536335(\mathrm{M} / \mathrm{S})$ **2 


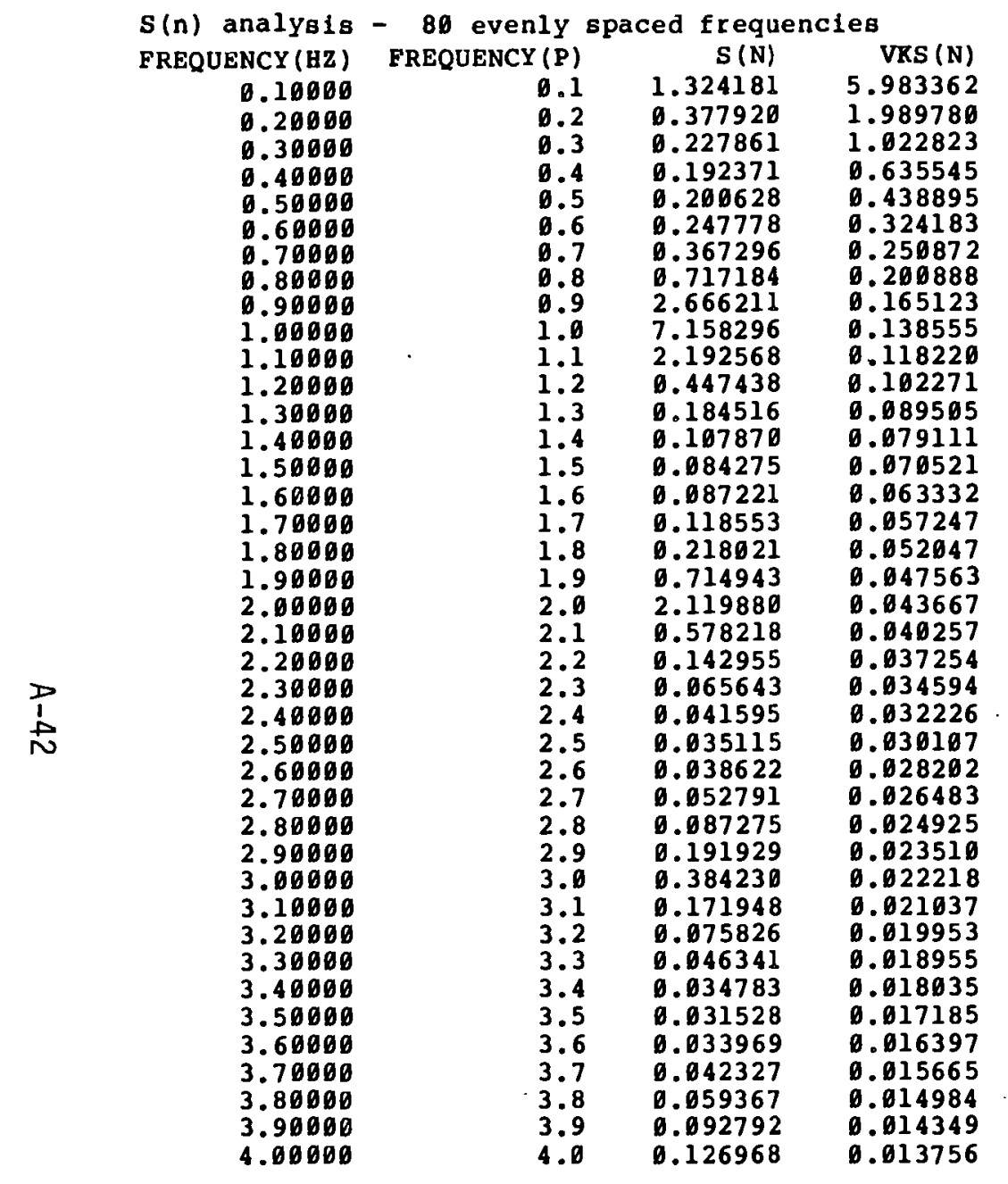

SPECTRAL DENSITY FOR $2 \theta$ DIVISIONS OF LOWEST FREQUENCY BAND FREQUENCIES
0.005000
0.055000
0.010000
$S(N)$
3.88
2.73
3.85
2.56
0.015000
0.020000
0.025000
05060
3.71
$54.85^{3.62} 2.85$
SUMS UF $S(N)$ FOR THE TWO SERIES 22.92

\begin{tabular}{|c|c|}
\hline $\begin{array}{r}\text { FREQUENCY(HZ) } \\
4.10000 \\
4.20000 \\
4.30000 \\
4.40000 \\
4.50000 \\
4.60000 \\
4.70000 \\
4.80000 \\
4.90000 \\
5.00000 \\
5.10000 \\
5.20000 \\
5.30000 \\
5.40000 \\
5.50000 \\
5.60000 \\
5.70000 \\
5.80000 \\
5.90000 \\
6.00000 \\
6.10000 \\
6.20000 \\
6.30000 \\
6.40000 \\
6.50000 \\
6.60000 \\
6.70000 \\
6.80000 \\
6.90000 \\
7.00000 \\
7.10000 \\
7.20000 \\
7.30000 \\
7.40000 \\
7.50000 \\
7.69000 \\
7.79000 \\
7.80000 \\
7.90000 \\
8.00000\end{array}$ & $\begin{array}{r}\text { FREQUENCY } \\
4 \\
4\end{array}$ \\
\hline
\end{tabular}

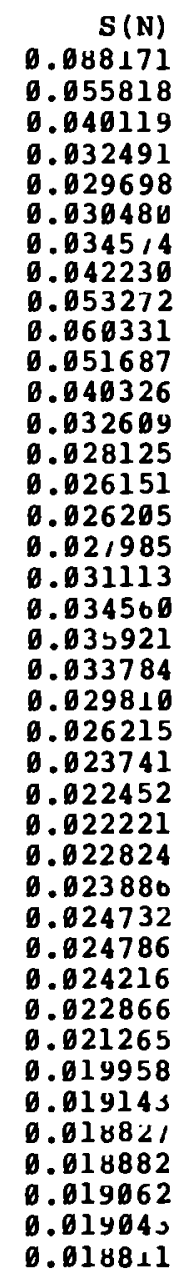

VKS (N)

0.013201

0.012682

0. 011736

0.011304

0.011304

0.016898

0.010152

0.009809

0.069484

0.069484
0.009176

0.008884

0.008606

0.008342

0.008091

0.007852

0.007623

00746

0.007406

0.007198
0.006999

0.006999

0.006809
0.006621

0.006452

0.006285

0.006125

0.005971

0.005823

0.05823

0.005681

0.005544

0.005413
0.005287

0.005163

0.005047

b. 004934

b. 004825

0.004720

0.004610

0.004520

0.004520

0.004425
0.004333
0.030000
0.080000

3.50
0.035000
0.085000

3.37
0.040000
0.045000

0.095000

3.07
0.050000
0.100000

2.90 


\begin{tabular}{|c|c|c|c|c|c|c|c|c|c|}
\hline $\begin{array}{l}0.33821 \\
0.26865 \\
0.21339 \\
0.16950 \\
0.13464 \\
0.10695\end{array}$ & $\begin{array}{l}0.37947 \\
0.30143 \\
0.23943 \\
0.19019 \\
0.15107 \\
0.12000\end{array}$ & $\begin{array}{l}0.30143 \\
0.23943 \\
0.19019 \\
0.15107 \\
0.12000 \\
0.09532\end{array}$ & $\begin{array}{l}4 \\
4 \\
3 \\
3 \\
2 \\
2\end{array}$ & $\begin{array}{r}14 \\
11 \\
9 \\
7 \\
6 \\
5\end{array}$ & $\begin{array}{r}17 \\
14 \\
11 \\
9 \\
7 \\
6\end{array}$ & $\begin{array}{l}0.07044 \\
0.06927 \\
0.07571 \\
0.09019 \\
0.11050 \\
0.13126\end{array}$ & $\begin{array}{l}0.07044 \\
0.06921 \\
0.07571 \\
0.09019 \\
0.11050 \\
0.13126\end{array}$ & $\begin{array}{l}0.21048 \\
0.24035 \\
0.21531 \\
0.31840 \\
0.35177 \\
0.36823\end{array}$ & $\begin{array}{l}0.25501 \\
0.29679 \\
0.33235 \\
0.38295 \\
0.42114 \\
0.43821\end{array}$ \\
\hline
\end{tabular}

VARIANCE OF $S(N)$ ON THIS PAGE, $S(N) C \quad 2.4766(M / S) \star \star 2$

LENGTH SLALE FROM INTEGRATION OF ACF IS $3.6 \mathrm{M}$

VARIANCES FOR FIRST HALF-P AND FOR 6P FROM 80-MEMBER SPECTRUM

$\begin{array}{rllllll}S(n) C_{,}-(M / S) \star * 2 & -(M 41 & 0.4122 & 0.1115 & 0.0602 & 0.0400 & 0.0292\end{array}$

RMS
0.6117
1.1905
0.6420
0.3340
0.2453
0.1999
0.1708

SAME VARIANCES COMPUTED BY INTEGRATING THE VON RARMAN SPECTRUM, Svk(n) ca

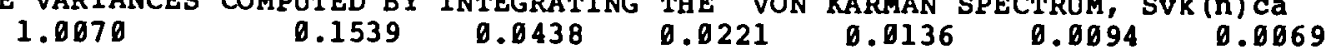

VARIANCES FOR FIRST HALF-P AND FOR 6P FROM SPECTRUM OF SIMULATED DATA, $S(n) r$

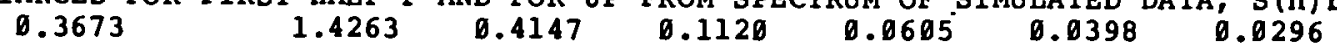

SPECTRAL ESTIMATES FROM SIMULATED DATA

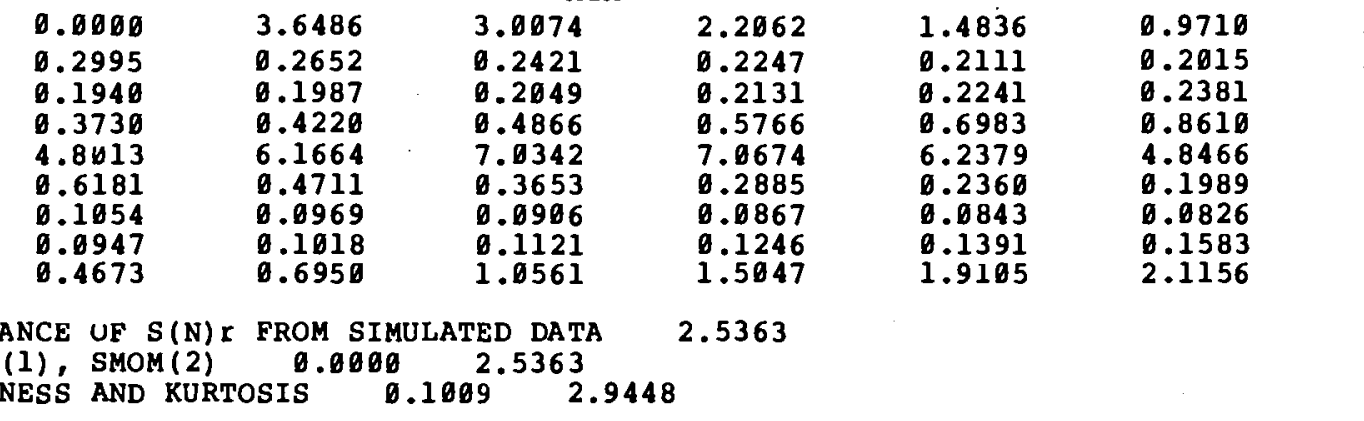

0.6704
0.1958
0.2547
1.1042
3.3504
0.1697
0.0821
0.1871
2.0272

0.5190

ఏ. 1925

0.4159

0.3491

0.2747
1.5259

0.1909

0.3003

2. 2617

0.1913

2.1234

1.3130

0.1283

0.1460

.

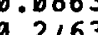

0.3330

3.3886

0.8595

0.1154

0.0900

0.3450

0.22680 .2763

VARIANCE UF S(N) T RROM SIMULATED DATA

SMOM (1), SMOM(2) 0.0000
SKEWNESS AND KURTOSIS 2.5363
0.1009

HALF-RANDOMIZING SIMULATION - PHASE RANDOMIZED

21 LOGARITHMICALLY SPACED BANDS AT 10 . PER SPECTRAL DECADE BANDED NSN SPECTRA

BAND CENTER, HI, LOW (HZ), NS(N), HARMONIC COUNT PER BAND [NS(N):ORIG

\begin{tabular}{|c|c|c|c|c|c|c|c|c|}
\hline $\begin{array}{l}\text { CENTER, } \\
0.69501 \\
8.49535 \\
6.74810 \\
5.36020 \\
4.25776 \\
3.38296 \\
2.68641 \\
2.13394 \\
1.69594\end{array}$ & $\begin{array}{c}\text { HI, LOW }(\mathrm{HZ}), \\
12.90909 \\
9.53194 \\
7.57149 \\
6.91425 \\
4.77729 \\
3.79473 \\
3.91426 \\
2.39431 \\
1.99187\end{array}$ & $\begin{array}{r}\text { NS (N) } \\
9.53194 \\
7.57149 \\
6.01425 \\
4.77729 \\
3.79473 \\
3.01426 \\
2.39431 \\
1.90187 \\
1.51071\end{array}$ & $\begin{array}{lc}\text { HARMONIC } \\
4 & 105 \\
9 & 85 \\
5 & 67 \\
9 & 54 \\
3 & 43 \\
6 & 34 \\
1 & 28 \\
7 & 22 \\
1 & 18\end{array}$ & $\begin{array}{l}\text { COUNT } \\
498 \\
324 \\
258 \\
205 \\
163 \\
139 \\
103 \\
82 \\
65\end{array}$ & $\begin{array}{l}\text { PER } \\
512 \\
468 \\
324 \\
258 \\
265 \\
163 \\
139 \\
163 \\
82\end{array}$ & ? & $\begin{array}{r}\text { [NS (N) : ORIG } \\
0.12547 \\
0.14169 \\
0.16401 \\
0.20215 \\
9.24871 \\
0.26992 \\
9.31014 \\
1.43917 \\
0.32362\end{array}$ & $\begin{array}{l}\text { SIM } \\
0.12547 \\
0.14169 \\
0.16401 \\
0.20215 \\
0.24871 \\
0.26092 \\
0.31014 \\
1.43917 \\
0.32362\end{array}$ \\
\hline
\end{tabular}

$V K$
0.02343
0.02725
0.03172
0.03689
0.04297
0.04990
0.05811
0.06778
0.07903

VKA]
0.02840
0.03310
0.03852
0.04481
0.05220
0.06061
0.07058
0.08233
0.09598 


\begin{tabular}{|c|c|c|c|c|c|c|c|c|c|}
\hline $\begin{array}{l}1.34642 \\
1.06950 \\
0.84953 \\
0.67481 \\
0.53602 \\
0.42578\end{array}$ & $\begin{array}{l}1.51071 \\
1.20000 \\
0.95319 \\
0.75715 \\
0.60142 \\
0.47773\end{array}$ & $\begin{array}{l}1.20000 \\
0.95319 \\
0.75715 \\
0.60142 \\
0.47773 \\
0.37947\end{array}$ & $\begin{array}{r}14 \\
11 \\
16 \\
7 \\
7 \\
5\end{array}$ & $\begin{array}{l}52 \\
42 \\
33 \\
27 \\
21 \\
17\end{array}$ & $\begin{array}{l}65 \\
52 \\
42 \\
33 \\
27 \\
21\end{array}$ & $\begin{array}{l}0.24843 \\
3.89765 \\
1.85797 \\
0.23564 \\
0.11699 \\
0.08213\end{array}$ & $\begin{array}{l}0.24843 \\
3.89765 \\
1.85197 \\
0.23564 \\
0.11699 \\
0.08213\end{array}$ & $\begin{array}{l}0.09177 \\
0.16492 \\
0.12177 \\
0.13981 \\
0.16191 \\
0.18968\end{array}$ & $\begin{array}{l}0.11146 \\
0.12742 \\
0.14785 \\
0.16971 \\
0.19646 \\
0.22928\end{array}$ \\
\hline $\begin{array}{r}\text { UNBANDED NSN } \\
0.023438 \\
0.0468 \% \\
0.070313\end{array}$ & $\begin{array}{l}\text { SPECTRA } \\
0.085513 \\
0.140972 \\
0.155125\end{array}$ & $\begin{array}{l}0.085513 \\
0.146972 \\
0.155125\end{array}$ & $\begin{array}{l}0.2 \\
0.2 \\
0.2\end{array}$ & $\begin{array}{l}659 \\
544 \\
881\end{array}$ & $\begin{array}{l}0.394380 \\
0.470174 \\
0.463950\end{array}$ & & & & \\
\hline
\end{tabular}

ANALYSIS OF SIMULATED DATA INCLUDING MEAN WIND EFFECT

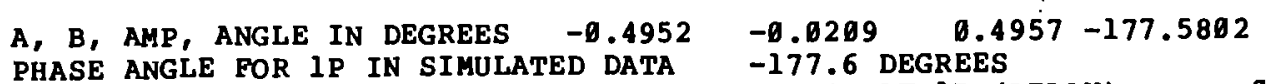

OFFSET ANGLE BETWEEN MEAN WIND AND TURBULENCE AT IP (DELAY)

OFFSET, IFFSET, $\quad-11.8 \quad 17$

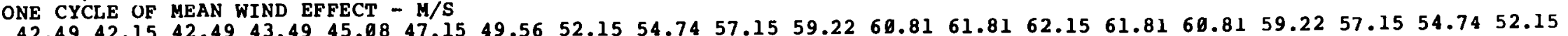
42.4942 .1542 .4943 .49

49.5647 .1545 .0843 .4945 .0847 .1549 .5652 .1554 .7457

NUMBER OF COMPLETE MEAN WIND CYCLES IN SIMULATION 42

\begin{tabular}{c}
$P$ VARIANCES FOR FIRST HALF-P \\
$\rightarrow \quad 0.4467$ \\
\hline
\end{tabular}

SPECTRAL ESTIMATES FROM SIMULATED DATA

\begin{tabular}{|c|c|c|c|c|c|c|c|c|c|}
\hline $\begin{array}{r}4.3466 \\
0.2127 \\
0.2966 \\
1.5659 \\
21.3448 \\
2.8875 \\
0.9222 \\
9.6222 \\
9.1899\end{array}$ & $\begin{array}{r}3.5060 \\
0.3647 \\
9.2778 \\
0.3952 \\
29.1784 \\
1.6797 \\
9.9675 \\
9.1448 \\
1.3990\end{array}$ & $\begin{array}{r}2.8048 \\
6.2804 \\
9.0912 \\
2.7477 \\
452.5435 \\
0.8501 \\
1.1110 \\
9.1499 \\
1.9194\end{array}$ & $\begin{array}{r}1.9575 \\
9.1323 \\
0.2135 \\
2.4338 \\
1678.2128 \\
3.5953 \\
9.9894 \\
9.3218 \\
2.1765\end{array}$ & $\begin{array}{r}1.3102 \\
9.4593 \\
6.9288 \\
4.3573 \\
52.2266 \\
9.6085 \\
9.8554 \\
9.5396 \\
2.2794\end{array}$ & $\begin{array}{r}9.7749 \\
9.3747 \\
1.9551 \\
9.5928 \\
12.4226 \\
2.5141 \\
9.6363 \\
9.7972 \\
3.4165\end{array}$ & $\begin{array}{r}9.5326 \\
9.0345 \\
1.1599 \\
4.0769 \\
29.8991 \\
9.5196 \\
9.89 \% 1 \\
9.2993 \\
1.8661\end{array}$ & $\begin{array}{r}9.4728 \\
9.4965 \\
9.1764 \\
19.7664 \\
18.6926 \\
1.3119 \\
0.8586 \\
9.6795 \\
2.8216\end{array}$ & $\begin{array}{r}9.4466 \\
9.0319 \\
0.4858 \\
3.6592 \\
11.6762 \\
0.8335 \\
9.8123 \\
0.3239 \\
9.6552\end{array}$ & $\begin{array}{r}0.2192 \\
0.0129 \\
0.3841 \\
26.3678 \\
9.3697 \\
1.2896 \\
0.7592 \\
1.0874 \\
1.2249\end{array}$ \\
\hline
\end{tabular}

VARIANCE OF $S(N)$ I FROM SIMULATED DATA 57.5320

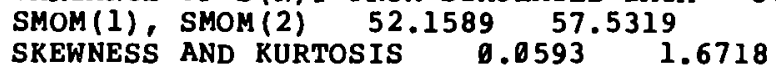


HALF-RANDOMIZING SIMULATION - PHASE RANDOMIZED

21 LOGARITHMICALLY SPACED BANDS AT 10 . PER SPECTRAL DECADE BANDED NSN SPECTRA

BAND CENTER, HARMONIC COUNT PER BAND [NS (N) : ORIG

10.695, HI, LOW (HZ), NS(N), HARMONIC COUNT PER BAND [NS (N):ORIG

9.53194

$9.53194 \quad 105 \quad 408 \quad 512$

0.12547
0.14169

6.74810

.57149

7.57149

85
67

324

0.16401

4.77729

54205

5.36020

6.01425

3.79473

$43 \quad 163$

$3.38206 \quad 3.79473$

$2.68647 \quad 3.01426$

3.01426

3.01426

2.39431

2.13394

2.39431

1.90187

1.34642

1.90187

1.51071

1.51671

0.84953

1.20000

0.95319

0.6793

0.95319

0.75715

0.53602

.75715

0.60142

$34 \quad 130 \quad 265$

0.47773

0.47773

0.30143

33821

.

0.30143

0.26865

. 30143

0.16950

0.23943

0.19019

0.15107

0.13464

0.15107

0.12000

0.10695

0.12000

0.09532

UNBANDED NSN SPECTRA

$\begin{array}{lllll}0.023438 & 0.085513 & 0.082172 & 0.367659 & 0.394380 \\ 0.046872 & 0.140972 & 0.131477 & 0.411544 & 0.470174 \\ 0.070313 & 0.155125 & 0.137637 & 0.395881 & 0.463950\end{array}$

0.20215

0.24871

0.26092

0.31014

0.32362

0.24843

3.89765

1.85797

0.23564

0.11699

0.08213

0.07044

0.06927

0.07571

0.09019

0.11050

0.13126

SIM

0.20253

0.22827

0.21740

0.23936

0.32947

0.29481

0.50631

2.15444

1.06075

1.73564

222.62056

8.96405

.66668

0.30116

.08463

0.06650

0.06249

0.08204

0.08796

0.11145

$V K$
0.02343

VKA]

0.02846

0.03172

0.03689

0.042970 .05220

$0.04990 \quad 0.06061$

0.058110 .07058

0.067780 .08233

$0.07903 \quad 0.09598$

$0.09177 \quad 0.11146$

$0.10492 \quad 0.12142$

$0.12177 \quad 0.14785$

$0.13481 \quad 0.16471$

0.16191

b. 22928

0.21048

0.29074

0.29679

$.31840 \quad 0.38295$

0.42114

$0.36823 \quad 0.4582$ I

0.04687

0.155125

.137637

0.395881

0.463950 
APPENDIX B

COMPARISON OF VON KARMAN SPECTRA WITH

CORRESPONDING ROTATIONAL SPECTRA WHEN ROTATIONAL

RATE AND ROTATION RADIUS OF THE LATTER APPROACH ZERO 
APPENDIX B

COMPARISON OF VON KARMAN SPECTRA WITH CORRESPONDING ROTATIONAL SPECTRA WHEN ROTATIONAL RATE AND ROTATION RADIUS OF THE LATTER APPROACH ZERO

Because the autocorrelation functions of the rotational data reduce to von Karman autocorrelation functions when the rotational rate approaches zero, the rotational spectra that are the transforms of these acf's should approach the corresponding von Karman spectra. Specifically, this should hold for the u- and v-components. Powell et al. (1985) showed that this was not exactly the case for the HAWT u-component model. There, the acf transformed into a different spectrum that could be "derived" from the von Karman u-spectrum by transposing the number 1.339 in the denominator.

For this report, a more thorough investigation of the program was conducted. In particular, since the program calculates the acf's as functions of dimensionless parameters, a new reduced version of the program was written that calculated the HAWT u-component acf using von Karman's original dimensional parameters. The results of this analysis were the same as the previous results. In other words, no mistake was made in the transformation between dimensional and dimensionless parameterizations.

The spectral transforms of the acf's in dimensionless parameters for VAWT $u$ modeling and VAWT $v$ modeling for rotation rates and radi $i$ that approach zero were compared with the von Karman $u$ - and v-spectra. In all cases, it was found that the rotational spectra with rotational features approaching zero also approached the von Karman spectra that can be derived from the original simply by replacing the frequency variable $F$ where it equals $n L / U$ with $F / 1.339$. This is the same as replacing $L$ by $L / 1.339$. Note that 1.339 is a conspicuous number in the original von Karman spectra. These spectra are as follows:

von Karman u-spectrum:

$$
\left[n S u(n) / \sigma^{2}\right]=4 F /\left[1+1.339(2 \pi) F^{2}\right] 0.83333
$$


von Karman variant u-spectrum:

$$
\left[n S u(n) / \sigma^{2}\right]=4 F /\left\{1.339\left[1+(2 \pi F)^{2}\right]^{0.83333}\right\}
$$

von Karman v-spectrum:

$$
\left[n S v(n) / \sigma^{2}\right]=2 F\left[1+(8 / 3)(1.339(2 \pi) F)^{2}\right] /\left[1+(1.339(2 \pi) F)^{2}\right] 1.83333
$$

von Karman variant $v$ spectrum:

$$
\left[n S v(n) / \sigma^{2}\right]=2 F\left[1+(8 / 3)(2 \pi F)^{2}\right] /\left\{1.339\left[1+(2 \pi F)^{2}\right]^{1.83333}\right\} \text {. }
$$

These comparisons are shown in Figure B.1. From Figure B.2, we see that the starting tangential component is like the $v$-component while the starting radial component is like the u-component. When the rotation rate is reduced to approach zero for the tangential and radial component simulations, they approach $v$ - and u-components, respectively, as shown in Figure B.2. We were unable to envisage any kind of programming mistake that could have consistently produced this kind of error. Therefore, we believe the program is correct. 
a

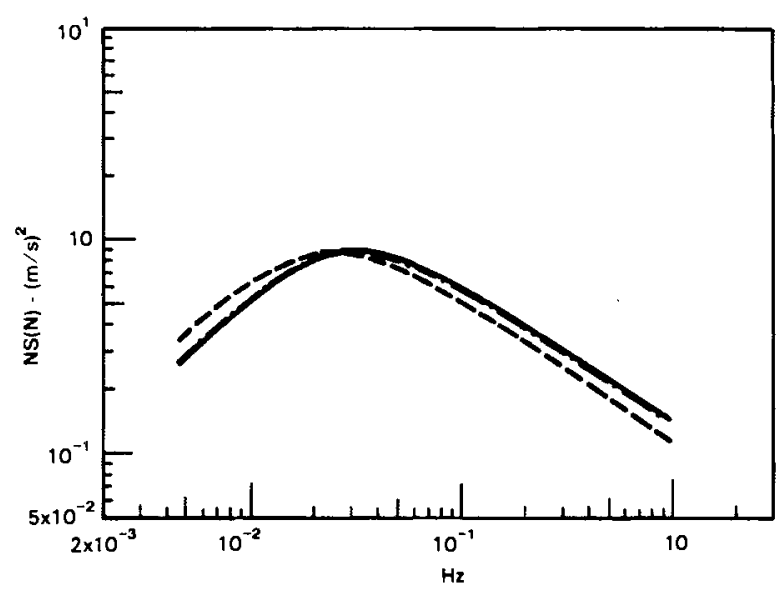

b

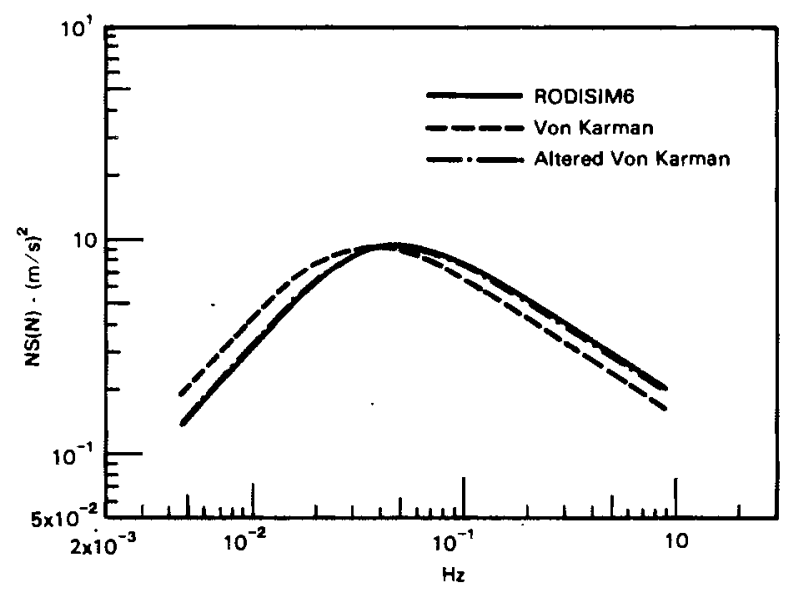

FIGURES B.1. Rotational Spectra with Rotational Rate and Radi i Approaching Zero, Compared to von Karman Spectra and von Karman Variant Spectra.

a. VAWT u-spectrum; b. VAWT v-spectrum. 
a

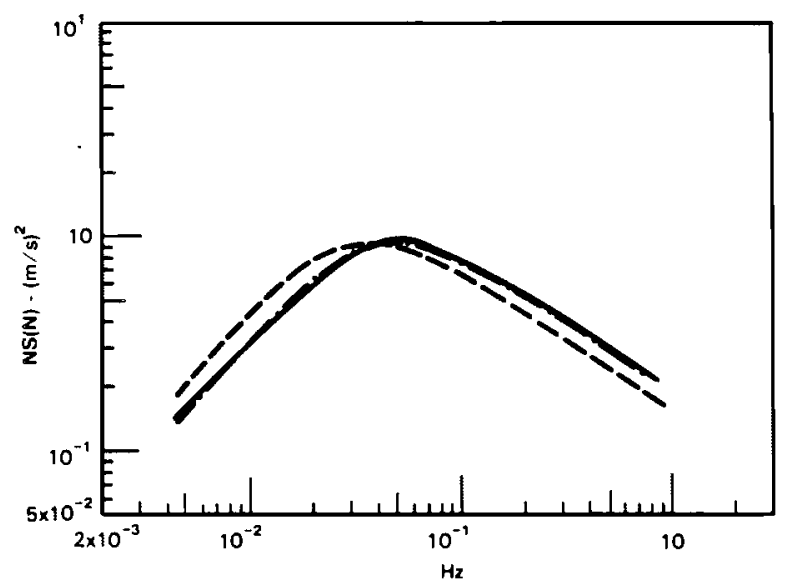

b

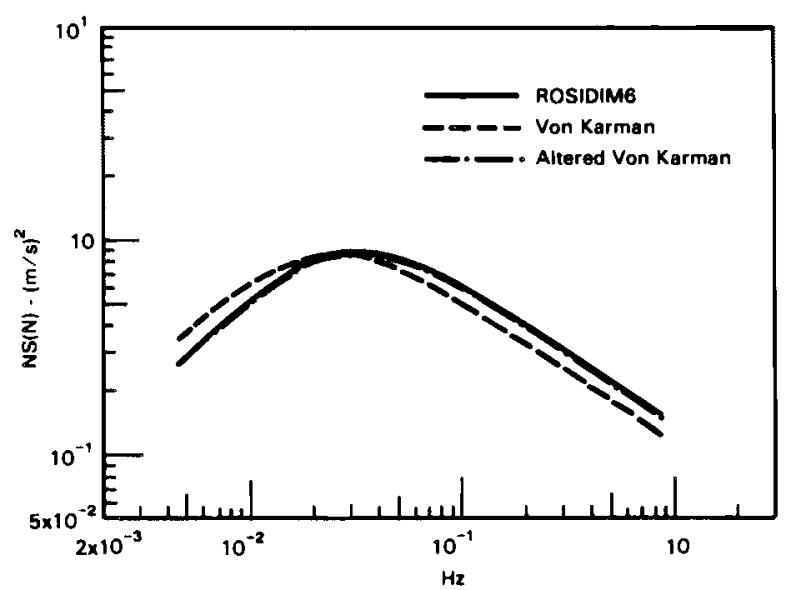

FIGURE B.2. Rotational Spectra with Rotational Rate and Radii Approaching Zero, Compared to von Karman Spectra and von Karman Variant Spectra. a. VAWT tangential spectrum; b. VAWT radial spectrum. 
APPENDIX C

SOME BASIC TURBULENCE DEFINITIONS

AND LENGTH SCALE CONSIDERATIONS 


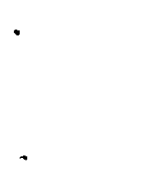

. 


\section{C.1 BASIC TURBULENCE DEFINITIONS}

Consider a time series $U(t)$. Subtracting out the mean value yields a new time series, $u(t)$, with a mean of zero. The autocorrelation function is defined by

$$
\rho_{u}(\tau)=\langle u(t) u(t+\tau\rangle /(\text { Variance of } u) \text {, }
$$

where $<>$ indicates a time average. (The $\tau$ is not the dimensionless variable of Equation (7).) In particular,

$$
\rho_{u}(0)=1
$$

and for a stationary process

$$
\begin{aligned}
& \rho_{u}(\tau) \rightarrow 0 \text {, as } \\
& \tau \rightarrow \infty .
\end{aligned}
$$

By assuming Equation (C.3), we can define the integral time scale

$$
L_{u} t=\lim _{T \rightarrow \infty} \int_{0}^{T} \rho_{u}(\tau) d(\tau)
$$

We may conceive of correlation in space as well as in time. Thus, letting $x$ and $y$ be the alongwind and crosswind directions, respectively,

$$
\rho_{u}(x)=\left[u\left(x_{0}+x\right) u\left(x_{0}\right)\right] / \text { Variance }(u),
$$


where the brackets indicate spatial averaging over $x_{0}$, is the spatial correlation of $u$ in the alongwind direction. Assuming that

$$
\begin{aligned}
\rho_{u}(x) & \rightarrow 0, \text { as } \\
x & \rightarrow \infty,
\end{aligned}
$$

we can define an integral length scale in the $x$ direction. This is

$$
L_{u} x=\lim _{x \rightarrow \infty} \int_{0}^{x} \rho_{u}(x) d x
$$

Similarly, the spatial correlation of $u$ in the crosswind direction is given by

$$
\rho_{u}(y)=\left[u\left(y_{0}+y\right) u\left(y_{0}\right)\right] / \operatorname{Variance}(u),
$$

and an integral scale for $u$ may be defined in the crosswind direction:

$$
L_{u} y=\lim _{y \rightarrow \infty} \int_{0}^{y} \rho_{u}(y) d y \quad .
$$

Turbulence loses its correlation in a shorter length in the crosswind direction than in the alongwind direction. Therefore, $L_{u} y$ is less than $L_{u} x$.

One would assume that evaluation of $\rho_{u}(x)$ or $\rho_{u}(y)$ would require simultaneous recording of wind from a line of many anemometers in $x$ or $y$ directions, respectively. This is true for $\rho_{u}(y)$ but not for $\rho_{u}(x)$. By assuming Taylor's hypothesis, we can write

$$
\rho_{u}(x)=\rho_{u}(t) \text { when } x=U \tau \text {. }
$$

From that

$$
L_{u} x=U L_{u} t
$$


Therefore, $L_{u} x$ may be evaluated from analyzing time series data from one anemometer, which is not true of $L_{u} y$.

In a similar manner, length scales for the lateral component of turbulence, the $v$-component, can be defined. These would be $L_{v} x$ and $L_{v} y$. 


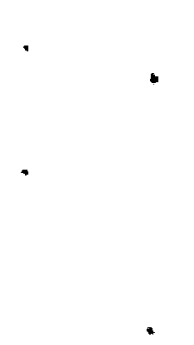


APPENDIX D

SAMPLES OF OUTPUT

$\mathbf{t}$ 
APPENDIX D

\section{SAMPLES OF OUTPUT}

The types of output we illustrate here are rotational spectra and simulated time series data. These results were generated using the following set of input parameters. The machine parameters are known to be appropriate for the VAWT but not for the HAWT. However the same input data were used for both, for the purpose of comparing model output. The parameters are:

$\begin{array}{lc}\text { Radius of Rotation } & 8.3 \mathrm{~m} \\ \text { Rate of Rotation } & 1.0000 \mathrm{~Hz} \\ \text { Hub Height } & 16.7 \mathrm{~m} \\ \text { Mean Wind Speed } & 10.00 \mathrm{~m} / \mathrm{s} \\ \text { Turbulence RMS Values } & \\ \quad \text { u-Component } & 1.652 \mathrm{~m} / \mathrm{s} \\ \quad \text { v-Component } & 1.652 \mathrm{~m} / \mathrm{s} \\ \text { Turbulence Variances } & \\ \quad \text { u-Component } & 2.729(\mathrm{~m} / \mathrm{s})^{2} \\ \quad \text { v-Component } & 2.729(\mathrm{~m} / \mathrm{s})^{2} \\ \text { Friction Velocity } & 0.688 \mathrm{~m} / \mathrm{s} \\ \text { Turbulence Integral Length Scales } & \\ \quad \text { Longitudinal } & 70.1 \mathrm{~m} \\ \quad \text { Lateral } & 28.1 \mathrm{~m} \\ \text { Number of Data to be Simulated } & 1024 \\ \text { Discretization Interval } & 0.0417 \mathrm{sec} \\ \text { Alias Factor } & 4 \\ \text { Angular Discretization Interval } & 15.0 \mathrm{degrees}\end{array}$

Figure D.1 compares the turbulence spectra of the simulated HAWT $u$-component and the simulated VAWT u-component. Both spectral density $S(n)$ and the logarithmic spectrum $n S(n)$ are shown. It should be emphasized that the mean wind effect has been omitted in each case. If it had been included, the 1P spike would have been higher in both spectra, considerably higher for the 
a

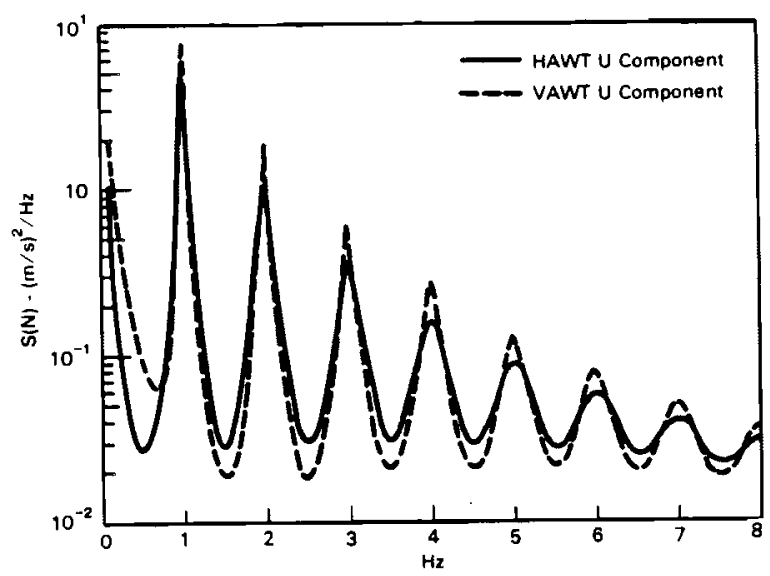

b

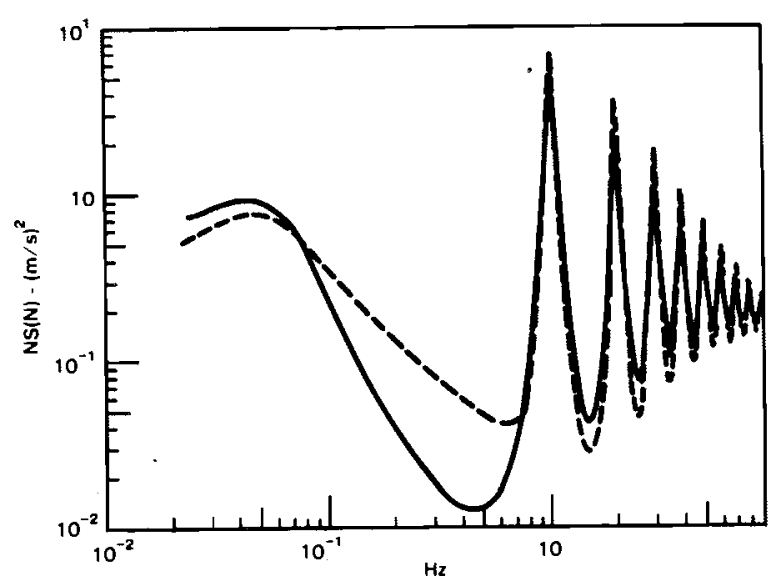

FIGURE D.1. Rotational HAWT $u$ - and VAWT u-Spectra.

a. $S(n) ; b \cdot n S(n)$

VAWT u-spectrum. Clearly, however, the effect of turbulence alone in the u-component on the rotationally sampled spectrum of wind is more severe for the VAWT than for the HAWT, i.e., more severe on the horizontal circle than on the vertical circle.

Similar plots for the four VAWT simulations ( $u, v$, tangential and radial) are shown in Figure D.2. Interesting features of this figure are:

1. At low $P$, the VAWT radial simulation has the strongest peaks.

2. At higher $P$, only the two $u$ simulations maintain a distinct harmonic spike structure (see Figure D.1). 
a

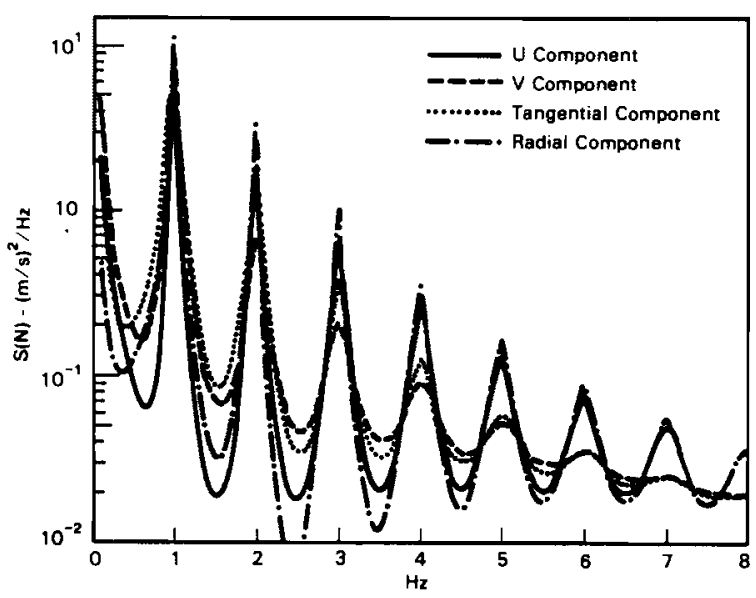

b

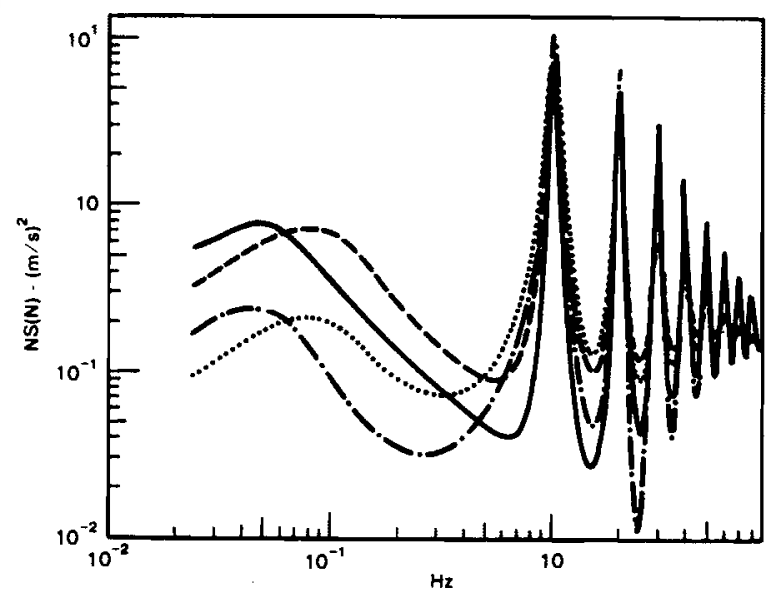

FIGURE D.2. Rotational Spectra $S(n)$ and $n S(n)$ for the Four VAWT Simulations

a. $S(n) ; b . n S(n)$

In both Figure $D .1$ and Figure $D .2$, the $S(n)$ spectra are the 80 -frequency spectra $S(n)_{c}$. The $n S(n)$ spectra are made by banding the $S(n)_{r}$ spectral estimates in eight evenly spaced bands.

The turbulence variances for the five runs are given in Table D.1. The spectra $S(n)_{r}$ and $S(n)_{c}$ are defined in Section 3.3.1.2.

The theoretical Eulerian turbulence variance for all cases is 2.73 $(\mathrm{m} / \mathrm{s})^{2}$. The variances above are less because the total length of the simulated time series is only 43 seconds, rather than the 10 or 15 minutes that is required to attain the theoretical variance from field data. 
TABLE D.1. Variances of the Five Simulations, in $(\mathrm{m} / \mathrm{s})^{2}$

$\frac{\text { Integration of }}{S(n)_{r} \quad \frac{S(n)_{c}+S(n)_{c 1}}{2}}$

$\begin{array}{lll}\text { HAWT } \mathrm{u} & 2.17 & 2.41 \\ \text { VAWT } \mathrm{u} & 2.26 & 2.54 \\ \text { VAWT } \mathrm{v} & 2.41 & 2.35 \\ \text { VAWT } \mathrm{t} & 2.53 & 2.48 \\ \text { VAWT } \mathrm{r} & 2.45 & 2.72\end{array}$

Simulated data for VAWT U-component and VAWT radial component turbulence are shown in Figure D.3. The simulated wind speed time series are derived from these spectra. The graphs illustrate turbulence only. The changing mean wind effect is not included because it would mask the turbulence. The difference in the character of these stationary data over a short period is evident.

The variances in the first five harmonics for each type of simulation are shown in Figure D.4. One graph, D.4.a, compares the spike variances for the HAWT $u$ and VAWT $u$ simulations; the other, D.4.b, compares the spike variances for all four VAWT simulations. The energy in the first spike of the VAWT $u$ simulation is greater than that in the first spike of the HAWT u simulation. However, the greatest differences are between the VAWT tangential and radial simulations on one hand, and the three other simulations on the other. 
a
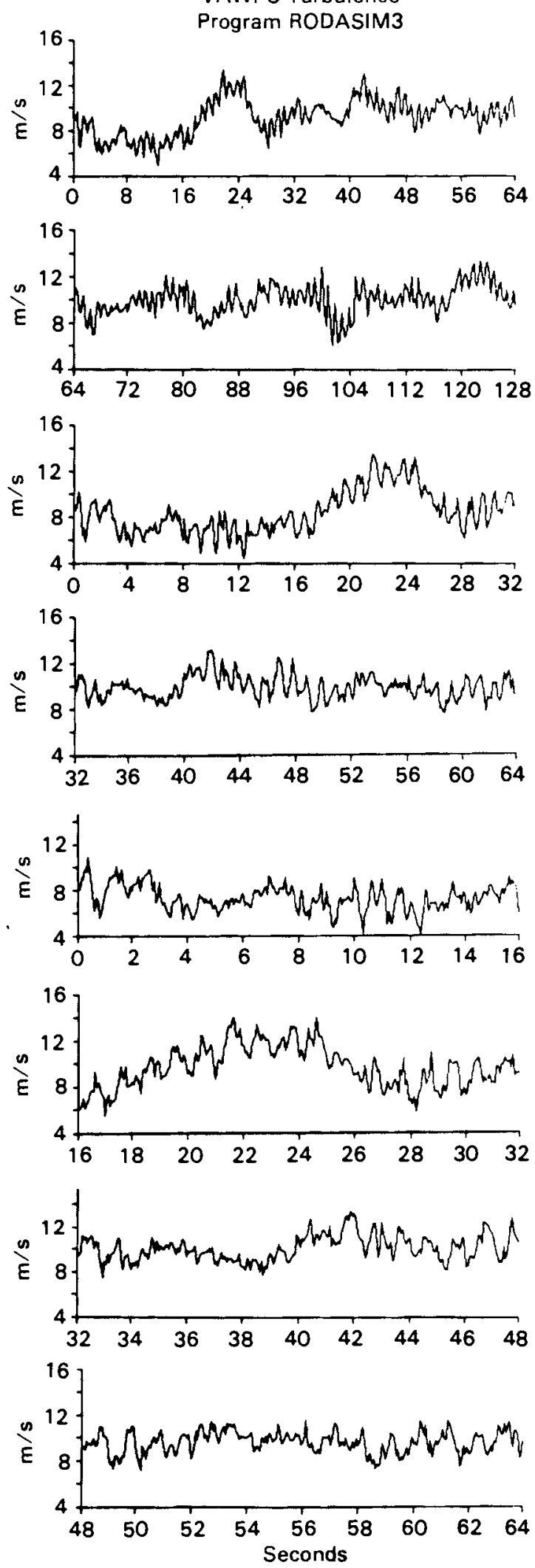

VAWI Radial Turbulence Program RODASIM3
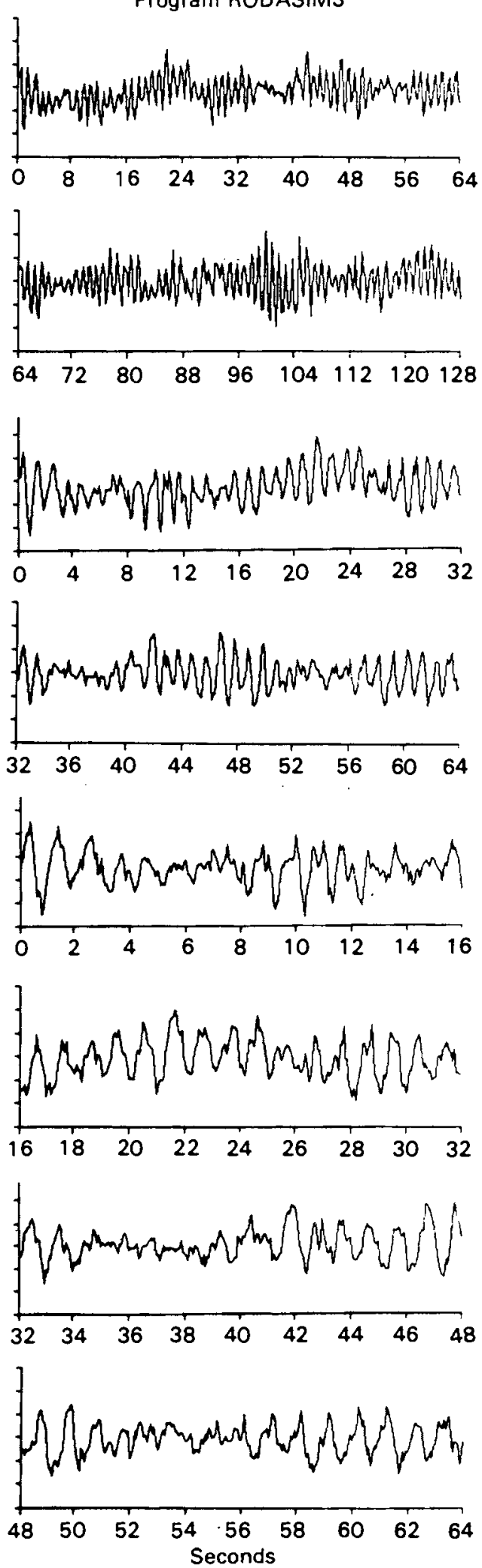

FIGURE D.3. Simulated Turbulence Data. b. VAWT radial component

a. VAWT u-Components; 
a

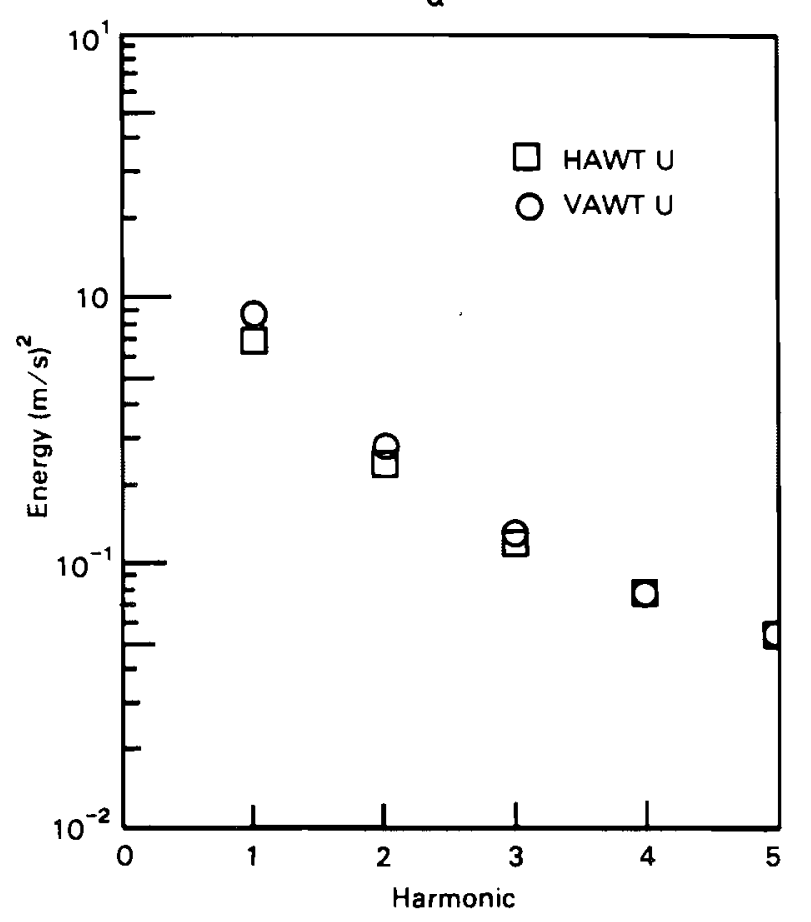

b

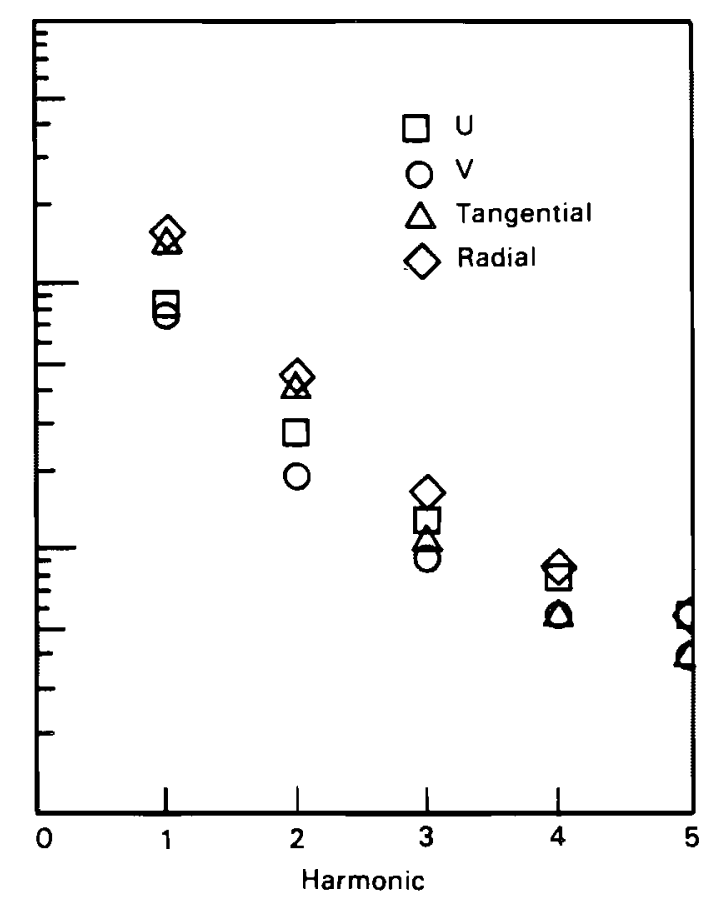

FIGURE D.4. Turbulence Variances for the First Five Harmonics $a$. HAWT and VAWT turbulence, u-components; b. VAWT turbulence, $u-, v-$, tangential and radial components 


\section{DISTRIBUTION}

No. of

Copies

OFFSITE

Carl Aspliden

Battelle Memorial Institute

Washington Office

2030 M Street NW

Washington, DC 20036

J. Cadogan

Department of Energy

Wind Energy Technology Division

1000 Independence Avenue

Forrestal Building, Room $5 \mathrm{H} 048$

Washington, DC 20585

D. F. Ancona

Department of Energy

Wind Energy Technology Division

1000 Independence Avenue

Forrestal Building, Room $5 \mathrm{H048}$

Washington, DC 20585

G. P. Tennyson

Department of Energy

Albuquerque Operations Office

P.0. Box 5400

Albuquerque, NM 87110

30 DOE Technical Information Center

W. A. Vachon

P.0. Box 149

Manchester, MA 01944

R. L. George

TERRA Sciences, Inc.

7555 W. 10th Avenue

Lakewood, CO 80214

R. B. Schlueter

Department of Electrical

Engineering

Michigan State University

East Lansing, MI 48824
No. of

Copies

David Spera

NASA/Lewis Research Center 21000 Brookpark Road

Cleveland, $\mathrm{OH} 44135$

Peter M. Moretti

Oklahoma State University

Mechanical and Aerospace

Engineering

Engineering North 218

Stillwater, OK 74074

P. Klimas

Sandia Laboratories

Division 5443, P.0. Box 5800

Albuquerque, NM 87115

Robert Thresher

Solar Energy Research Institute

1617 Cole Boulevard

Golden, C0 80401

Sherman M. Chan

Systems Control, Inc.

1801 Page Mill Road

P.0. Box 10025

Palo Alto, CA 94303

R. H. Kirchhoff

Department of Mechanical

Engineering

University of Massachusetts

Amherst, MA 01003

ONSITE

DOE Richland Operations Office

D. R. Segna

J. J. Sutey 
34 Pacific Northwest Laboratory
J. C. Barnard
J. W. Buck
J. R. Connell
D. W. Dragnich
C. E. Elderkin
D. L. Elliott
L. K. Grove
J. M. Hales
P. C. Hays
M. E. Hinchee
B. D. Holst
A. H. Miller
V. R. Morris
D. C. Powell (5)
J. A. Stottlemyre
T. K. Thompson
L. L. Wendell
R. E. Wildung
Technical Information Files (5)
Publishing Coordination (2)
WCPE Program Office (5) 